\title{
How ecological processes shape the outcomes of stock enhancement and harvest regulations in recreational fisheries
}

Fiona D. Johnston, Micheal S. Allen, Ben Beardmore (1) https://orcid.org/0000-0002-0276-427X, Carsten Riepe, Thilo Pagel, Daniel Hühn, Robert Arlinghaus (i) https://orcid.org/0000-0003-2861-527X

DOI

10.1002/eap.1793

Original publication date

24 August 2018

Document version

Accepted version

Published in

Ecological Applications

Citation (Vancouver)

Johnston FD, Allen MS, Beardmore B, Riepe C, Pagel T, Hühn D, et al. How ecological processes shape the outcomes of stock enhancement and harvest regulations in recreational fisheries. Ecol Appl. 2018;28(8):2033-54. 


\section{Running Head: Ecology, stocking and length limits}

2 How ecological processes shape the outcomes of stock enhancement and harvest regulations in recreational fisheries

4 Fiona D. Johnston ${ }^{1,5^{*}}$, Micheal S. Allen ${ }^{3}$, Ben Beardmore ${ }^{4}$, Carsten Riepe ${ }^{1}$, Thilo Pagel ${ }^{1}$, Daniel Hühn $^{1}$, and Robert Arlinghaus ${ }^{1,2}$

$6{ }^{1}$ Department of Biology and Ecology of Fishes, Leibniz-Institute of Freshwater Ecology and

7 Inland Fisheries, Müggelseedamm 310, 12587 Berlin, Germany

$8 \quad 2$ Division of Integrative Fisheries Management, Faculty of Life Sciences, Humboldt-Universität

9 zu Berlin, Philippstrasse 13, Haus 7, 10115 Berlin, Germany

$10 \quad{ }^{3}$ Program for Fisheries and Aquatic Sciences, School of Forest Resources and Conservation, The 11 University of Florida, 7922 NW 71st St. Gainesville, Florida 32653-3071, USA.

$12{ }^{4}$ Wisconsin Department of Natural Resources, Madison, WI 53703, USA.

$13{ }^{5}$ Department of Biological Sciences, University of Calgary, 2500 University Dr. N.W., Calgary, 14 Alberta, T2N 1N4, Canada.

15 *Corresponding author: fiona.johnston@ucalgary.ca

16 


\section{ABSTRACT}

Fish stocking and harvest regulations are frequently used to maintain or enhance freshwater recreational fisheries and contribute to fish conservation. However, their relative effectiveness has rarely been systematically evaluated using quantitative models that account for key size- and density-dependent ecological processes, and adaptive responses of anglers. We present a new integrated model of freshwater recreational fisheries where the population dynamics of two model species affect the effort dynamics of recreational anglers. With this model we examined how stocking various fish densities and sizes (fry, fingerlings, and adults) performed relative to minimum-length limits using a variety of biological, social and economic performance measures, while evaluating trade-offs. Four key findings are highlighted. First, stocking often augmented the exploited fish population, but size- and density-dependent bottlenecks limited the number of fry and fingerlings surviving to a catchable size in self-sustaining populations. The greatest enhancement of the catchable fish population occurred when large fish that escaped early bottlenecks were stocked, but this came at the cost of wild-stock replacement, thereby demonstrating a fundamental trade-off between fisheries benefits and conservation. Second, the relative performance of stocking naturally reproducing populations was largely independent of habitat quality and was generally low. Third, stocking was only economically advisable when natural reproduction was impaired or absent, stocking rates were low, and enough anglers benefitted from stocking to offset the associated costs. Fourth, in self-sustaining fish populations, minimum-length limits generally outperformed stocking when judged against a range of biological, social and economic objectives. By contrast, stocking in culture-based fisheries often generated substantial benefits. Collectively, our study demonstrates that size- and densitydependent processes, and broadly the degree of natural recruitment, drive the biological, social 
40 and economic outcomes of popular management actions in recreational fisheries. To evaluate

41 these outcomes and the resulting trade-offs, integrated fisheries-management models that

42 explicitly consider the feedbacks among ecological and social processes are needed.

43 KEYWORDS density-dependence, size-dependent mortality, harvest regulations, fish stock

44 enhancement, human dimensions, recreational fishing, northern pike (Esox lucius), common carp

45 (Cyprinus carpio).

46 


\section{INTRODUCTION}

48 Many inland fish populations are under threat due to anthropogenic impacts on habitat quality

49 and quantity, climate change, the stocking and spread of non-native fishes and genotypes and

50 resulting changes in genetic diversity, and overharvest (Dudgeon et al. 2006, Laikre et al. 2010,

51 Cooke et al. 2016). Recreational fishers are the dominant users of inland fish stocks in

52 industrialized countries (Arlinghaus et al. 2002, FAO 2012), and their activities and expenditures

53 are fundamentally important drivers for fish conservation and fisheries-management activities

54 (Arlinghaus 2006, Tufts et al. 2015). Collectively, recreational fishers can exert substantial

55 harvesting pressures on fish populations (Post et al. 2002, Cooke and Cowx 2006, Lewin et al.

56 2006). Managers tend to respond to impacts on recreational fisheries using three general

57 strategies (Arlinghaus et al. 2016): i) implementing input and output regulations that control

58 fishing effort (input) or regulate which sizes and how many fish are harvested (output), ii)

59 improving and restoring habitat, or iii) engaging in stocking-based enhancements. Among these,

60 harvest regulations and stocking are the most widespread due to tradition and ease of

61 implementation (van Poorten et al. 2011, Arlinghaus et al. 2016, Sass et al. 2017).

62 To manage fish stocking sustainably, it is important to understand when to engage in a specific

63 action and when to use alternatives (Lorenzen 2014, Arlinghaus et al. 2016, Arlinghaus et al.

64 2017). Although stocking can help fish stocks recover and enhance fisheries use and catch

65 (Lorenzen et al. 2012, Amoroso et al. 2017), the practice can also contribute to the decline of

66 wild fish populations by elevating competition or predation, fostering disease outbreaks,

67 promoting mixing of wild populations with domesticated, hatchery-reared fishes (Laikre et al.

68 2010, van Poorten et al. 2011, Lorenzen et al. 2012), and potentially increasing fishing pressure

69 on wild stocks (Baer et al. 2007). The ability of stocking to maintain or boost fisheries catches 
70 beyond levels achievable by wild populations may correlate with a decline in environmental

71 quality that constrains natural recruitment, thereby freeing "niches" for hatchery fish (Rogers et

72 al. 2010, Ziegler et al. 2017). However, stocking hatchery fish may further burden an already

73 dwindling wild stock (Laikre et al. 2010, van Poorten et al. 2011, Cochran-Biederman et al.

74 2015), creating a fundamental trade-off between wild fish conservation and maintaining or

75 enhancing fisheries through (successful) stocking (Lorenzen 2005, Camp et al. 2017, Amoroso et

76 al. 2017). In light of key feedbacks among the ecological and social components of a fishery

77 (Camp et al. 2014, Lorenzen 2014, Arlinghaus et al. 2016), navigating this trade-off demands

78 careful analysis of how the outcomes from stocking vary with ecological conditions (e.g.,

79 whether a stock is self-sustaining or not) and properties of the management intervention (e.g.,

80 size and density of stocked fishes, fitness of hatchery fish in the wild). Such an analysis using an

81 integrated social-ecological model of recreational fisheries that incorporates a mechanistic model

82 of angler behavior and a realistic ecological representation of a stock-enhanced fishery regulated

83 by multiple size- and density-dependent ecological processes has so far not been completed.

84 An alternative management response common in freshwater recreational-fisheries management

85 is the implementation of harvest regulations (Arlinghaus et al. 2016). Harvest regulations are

86 used to limit fishing mortality, manage size structure, and distribute harvest more equally among

87 anglers (Radomski et al. 2001). However, constraints on an individual's ability to harvest fish

88 can have high social costs for angler groups most affected by the regulations (Beard et al. 2003,

89 Johnston et al. 2011, Haglund et al. 2016). Thus, implementing restrictive harvest controls is

90 rarely preferred by anglers over stocking or the control of perceived or real competitors (e.g.,

91 commercial fishers, fish-eating birds, Arlinghaus and Mehner 2003a, Dorow and Arlinghaus

92 2012). An analysis of fish-angler interactions that integrates ecological and social dimensions 
93 and considers dynamic angler responses is needed to outline the ecological and socio-economic

94 conditions that favor one management approach (e.g. harvest restrictions) over another (e.g.,

95 stocking) (Arlinghaus et al. 2017).

96 A range of fish stocking models incorporating key ecological mechanisms, such as density- and

97 size-dependent mortality, are available to examine the ecological conditions constraining the

98 additive potentials of fish stocking (e.g., Lorenzen 2005, Rogers et al. 2010, Askey et al. 2013,

99 Camp et al. 2014). However, few of these models have explicitly considered multi-attribute

100 decision making by anglers. Both strategic and tactical recreational-fisheries models should

101 consider anglers' preferences and behavioral responses to policy interventions (Johnston et al.

102 2010), because they can strongly influence social (e.g., effort directed at a given site) and

103 ecological (e.g., fish abundance or catch rate) outcomes (Arlinghaus et al. 2017). Mechanistic

104 choice models based on economic random utility theory can be used to extrapolate complex,

105 human behavioral responses (Fenichel et al. 2013a), but no stocking model using a rigorous

106 choice-based representation of angler behavior exists. Considering both the ecological and social

107 dimensions of fisheries will likely affect management trade-offs, and the costs and benefits of

108 particular management actions. Moreover, judging the performance of any management action

109 will depend on the performance measure used, and ultimately on the underlying normative

110 framework and objectives (e.g., conservation, fisheries quality, economic benefits) upon which

111 the measures are based (Fenichel et al. 2013b, Camp et al. 2017).

112 Management actions such as harvest regulations and stocking will likely not be equally effective

113 at achieving various objectives, because they differentially affect fish populations and anglers.

114 The outcomes of stocking will be governed by a range of ecological processes that determine

115 how hatchery reared fish interact with their wild conspecifics (Lorenzen 2014). Most fish 
116 populations are regulated by density-dependent compensatory mortality in the early juvenile

117 stage (Lorenzen 2005). Another key regulatory process is size-dependent mortality coupled with

118 density-dependent growth in later life stages (Lorenzen 2005). Size- and density-dependent

119 ecological processes are relevant for the success of minimum-length limits because they will 120 determine if fishing mortality is being affected (FAO 2012). These processes are also important

121 for determining stocking success, because they influence whether or not stocked fish can

122 circumvent factors limiting the wild population (Lorenzen 2005, Rogers et al. 2010, Camp et al.

123 2014). In addition, limited recruitment or productivity due to poor habitat quality, compensatory

124 changes in growth or survival of fish populations, and a lack of local adaptation of stocked fishes

125 to the wild can limit the ability of hatchery-reared fish to survive and reproduce (Cowx 1994,

126 Lorenzen et al. 2012, Cochran-Biederman et al. 2015). The situation is somewhat different in

127 non-naturally reproducing populations where stocked fish will not face intraspecific competition

128 with wild conspecifics.

129 We hypothesize that stocking should generate large social and economic benefits when natural

130 reproduction is lacking, while harvest regulations shall socio-economically outperform most

131 stocking events in self-sustaining stocks. We also hypothesize that stocking will be most

132 effective when large, recruited fishes are stocked that are no longer affected by compensatory

133 juvenile mortality (Lorenzen 2005), but that such stocking in naturally-reproducing populations

134 will create a fundamental trade-off between conservation and fisheries benefits (Amoroso et al.

135 2017, Camp et al. 2017). We test these hypotheses using a fully integrated model of fish-angler

136 interactions with explicit angler behavioral feedback grounded in economic utility theory. We

137 use this model to systematically explore how the contrasting ecology of two freshwater fishes,

138 naturally-reproducing and non-reproducing, shape the ecological, conservation and 
139 socioeconomic outcomes of both stocking and a commonly applied harvest regulation, the

140 minimum-length limit (MLL). In the model, angler behavior is described mechanistically as a

141 function of multiple attributes of the fishing experience using results from an empirically

142 grounded stated preference model of anglers (Arlinghaus et al. 2014). The ecological sub-model

143 is calibrated to represent two prototypical freshwater fish populations, naturally-reproducing

144 northern pike (Esox lucius) that recruits to the fishery and common carp (Cyprinus carpio) that

145 does not naturally recruit to the fishery (referred to as non-reproducing). Pike was chosen

146 because it is a popular target species among anglers that is commonly stocked in both North

147 America (Paukert et al. 2001, Margenau et al. 2008) and Europe (Wedekind et al. 2001,

148 Arlinghaus and Mehner 2004, Hühn et al. 2014). Both stock enhancement (stocking into wild

149 populations) and culture-based stocking (into systems in which natural reproduction is absent)

150 can occur (Lorenzen et al. 2012). Despite carp being considered a pest in North America,

151 Australia and some parts of Europe (e.g. Spain), carp was chosen because of its importance as a

152 culture-based, harvest-oriented inland fishery in central Europe (Wedekind et al. 2001,

153 Arlinghaus and Mehner 2003b, Vilizzi et al. 2015). In central Europe, carp populations depend

154 almost entirely on stocking, because, while they regularly spawn, they rarely recruit to the

155 population successfully in the wild (Kottelat and Freyhof 2007). Hypotheses for why this occurs

156 include; unsuitable temperatures and flow for spawning, and competition or predation from

157 native cyprinids that usually spawn substantially earlier than carp (Kottelat and Freyhof 2007,

158 Bajer and Sorensen 2010). In the model we also considered recruitment-limited pike populations,

159 such as might occur in response to the loss of vegetated habitat (Casselman and Lewis 1996),

160 thereby studying the full range of possibilities as to how the degree of natural recruitment affects

161 stock enhancement outcomes relative to harvest regulations. Our simulation exercise was meant 
162 to produce strategic insights into the trade-offs inherent in common fisheries management

163 actions in light of ecological constraints, rather than to generate tactical insights informing

164 management of a particular fishery.

\section{METHODS}

166 The potential effects of stocking and harvest regulations, specifically minimum-length limits

167 (MLLs) on biological, social, and economic outcomes were investigated using an integrated

168 bioeconomic recreational-fisheries model adapted from earlier work (Johnston et al. 2010, 2013).

169 The model included three main components: 1) a deterministic age- and size-structured

170 biological sub-model to describe the fish population dynamics, 2) a social sub-model to describe

171 angler effort dynamics, and 3) a management component, which allowed for different MLLs,

172 stocking sizes and stocking densities to be investigated (Figure 1). We used the model to

173 evaluate how well stocking different sizes of fish - fry, fingerlings, and adults (Appendix S1:

174 Figures S1 and S2) - at a variety of stocking densities performed relative to various MLLs in

175 terms of achieving biological, social, and economic management objectives, and the trade-offs

176 involved, for a single-lake fishery. This evaluation was done for naturally-reproducing northern

177 pike, representing a stock enhancement scenario, and for non-reproducing common carp,

178 representing a culture-based stocking scenario. Six performance measures covering a range of

179 commonly used ecological, social and economic objectives were evaluated. In addition, the age

180 structure and composition (wild vs. hatchery origin fish) of the fish population was examined for

181 some simulations as a further conservation objective. The simulations were run until the

182 population reached an equilibrium prior to the commencement of fishing or implementation of

183 management policies and then run for additional time until the model reached a new equilibrium

184 after the changes were introduced. In the stocking scenarios, stocking occurred annually at the 
185 beginning of each year. Information from an interdisciplinary study on fish stocking and anglers 186 in Lower Saxony, Germany (www.besatz-fisch.de), was used to inform the biological and social 187 sub-models (Arlinghaus et al. 2014, Hühn et al. 2014, Arlinghaus et al. 2015). Model equations 188 can be found in Table 1 and parameter values in Appendix S1: Table S1. Software based on the 189 model presented here is freely available at http://www.ifishman.de/en/practioner/software/ in

190 English or German, which can be used to reproduce the results presented here and run 191 simulations for a range of other freshwater species.

192

\section{Biological sub-model}

The biological sub-model included the following key ecological processes: density-dependent growth, reproduction, and density- and size-dependent survival during the early life stage (age-0 fish) and later life stages. These processes are essential to properly represent the ecological changes induced by the density increase through stocking (Lorenzen 2005). A bi-phasic model developed by Lester et al. (2004) was used to describe somatic growth. This model assumed that the annual growth in length of immature fish was linear and dependent on biomass density to represent density-dependent growth (Table 1, eqn. 2a-2b), while mature fish only realized a proportion of the annual growth potential (Table 1, eqn. 2c) due to the diversion of resources to reproduction. Thus, post-maturation growth was also density dependent. To create a more realistic size distribution and simulate the cumulative effects of differential size-dependent mortality (Walters and Martell 2004), 11 size classes (i.e., growth trajectories) within an age class were modelled. For simplicity, stocked and wild fish were assumed to have the same growth rates, but relative survival and reproductive fitness could differ (see below). Maturation was assumed to be size and age dependent as is typical in fish (Table 1, eqn. 3a). Reproduction was a linear function of female mass (Walters and Martell 2004) (Table 1, eqn. 3b), and the 
208 potential for differential relative reproductive success between hatchery and wild fish (Lorenzen 209 2005) was explicitly included in the model (Table 1, eqn. 3b, $\rho$, Appendix S1: Table S1). In the 210 case of carp, natural reproduction was assumed to be zero, and in the pike simulations we 211 assumed various scenarios for the degree of natural recruitment to represent healthy and 212 disturbed ecosystems.

213 Differing from earlier applications (Johnston et al. 2010, 2013, Johnston et al. 2015), the survival 214 of larvae to age-1 was assumed to be size and density-dependent (Table 1, eqns. 4a-f and 5a-d) to 215 better represent the outcomes of stock enhancement using hatchery reared fry or juveniles 216 (Lorenzen 2005). To that end, we modified and implemented a method pioneered by Lorenzen 217 (2005), where recruitment to age-1 was "unpacked" so that pre- and post-stocking survival of 218 age-0 fish (fry or fingerlings) were described independently, allowing all fish to experience 219 density-dependent and size-dependent mortality - two processes which are commonly 220 experienced by fishes in this early life stage (Lorenzen 1996, 2005, Hazlerigg et al. 2012). We 221 modified the methods of Lorenzen (2005) by representing a Ricker-type stock-recruitment model 222 rather than a Beverton-Holt stock-recruit relationships, because a Ricker recruitment model has 223 been used to describe the early survival for pike (Edeline et al. 2008) and carp (Brown and 224 Walker 2004, based on data presented in Koehn et al. 2000) (see Appendix S1 for derivation). In 225 the pre-stocking phase (Table 1, eqns. 4a-f), wild and hatchery origin larvae (i.e., offspring of 226 stocked fish) underwent the same density-dependent survival bottleneck. During this phase it 227 was possible for a proportion of hatchery larvae to transition to wild strain fish due to natural 228 selection similar to Lorenzen (2005) (Table 1, eqn. 4f, $h^{2}$, Appendix S1: Table S1). The 229 potential for differential survival of age-0 hatchery fish relative to age-0 wild fish was also 230 included in the model (Table 1, eqn. 4f, $\gamma$, Appendix S1: Table S1), because empirical data has 
231 shown stocked fishes often have lower relative survival fitness (Lorenzen 2006, Lorenzen et al.

232 2012, Hühn et al. 2014). In the post-stocking phase (Table 1, eqns. 5a-d), the age-0 fish that

233 survived the pre-stocking phase as well as age-0 fish stocked that year (fry or fingerlings)

234 experienced further density-dependent survival, but at a reduced intensity because fish were

235 larger and, thus, were less vulnerable to size-dependent mortality than smaller fish (Lorenzen

236 2005). Consequently, in our model, stocked fingerlings experienced lower natural mortality than

237 smaller fry. Similar to Coggins et al. (2007), fish surviving to age-1 were allocated to a growth

238 trajectory assuming a normal distribution. Although carp did not reproduce, stocked fry or

239 fingerlings were still assumed to experience size- and density-dependent mortality.

240 Natural mortality rates of age-1 and older fish were also assumed to be size- and density-

241 dependent using an empirical relationship presented by Lorenzen (1996, 2000) (Table 1, eqn.

242 6b). To introduce density-dependence in survival, we assumed that the allometric exponent of

243 size-dependent mortality relationship changed with density (Table 1, eqn. 6d), but that the

244 mortality rate of very large fish changed very little with density (see Appendix S1 for

245 derivation). Thus, changes in density had a greater impact on the natural mortality rate of small

246 fish compared to larger fish, agreeing with empirical studies and population dynamical theory of

247 stock enhancements (Lorenzen 2005). Incorporating size- and density-dependence into post-

248 recruitment survival allowed for increased mortality of small fish from predation by, and

249 competition with, larger fish, including fish stocked at larger sizes and older ages than age-0.

250 Model predictions in the absence of density-dependent survival of age-1 and older fish was

251 explored in the supplementary material (Appendix S1: Figures S6, S7, and S8). In scenarios in

252 which older fish (> age-0) were stocked, fish were added to the abundance of surviving hatchery

253 origin fish in the appropriate age category and allocated normally among the growth trajectories 
254 (Table 1, eqn. 6a). The possibility of differential survival of fish of hatchery origin relative to 255 wild fish beyond the first year of life was also explicitly included in the model (Table 1, eqn. 6k, $256 \quad \gamma_{2}$, Appendix S1: Table S1).

257 To account for the size-dependent processes inherent to fishing mortality, a sigmoidal 258 vulnerability curve was used to determine vulnerability of fish to capture (Table 1, eqns. 6f-g, 259 Appendix S1: Figure S1), as is typical in recreational fisheries models (Post et al. 2003, Arlinghaus et al. 2009, Allen et al. 2013). MLLs were used to determine which fish were legally

261 harvestable (Table 1, eqn. 6i). No bag limit was assumed; thus, all fish of legal size were 262 harvested. To account for illegal harvest (Sullivan 2002, Johnston et al. 2015), a percentage of 263 undersized fish were also harvested (Table 1, eqn. 6i). Undersized fish that were released 264 experienced hooking mortality (Table 1, eqn .6j) - an important process in recreational fisheries 265 (Post et al. 2003, Coggins et al. 2007, Johnston et al. 2015).

\section{Social sub-model}

267 In the social sub-model, annual angling effort was determined by the fishery quality of past 268 fishing experiences (Table 1, eqn. 7d), and constrained by available fishing time in line with 269 empirical data (Table 1, eqn. 7d, $d_{\max }$, Appendix S1: Table S1). Note that our use of the term 270 fishing quality encompasses all dimensions that affect the angler utility, including: expected 271 catch rate, average size of fish caught, catch rate of trophy fish (as per Arlinghaus et al. 2014,

272 fish larger than a threshold size, $L_{T}$, Appendix S1: Table S1), the number of other anglers seen 273 while fishing (a measure of crowding), MLL (which measure preferences for retention of fish for 274 own consumption), license fees to fish within the water, preference for target species, stocking 275 frequency (an independent effect of knowing that a fishery is stocked), and the composition of 
276 the catch (percent wild fish in the catch). Following random utility theory, the benefits anglers

277 derived from each fishery attribute, called part-worth utilities (Appendix S1: Figure S3), were

278 summed to determine the overall utility gained from fishing (Table 1, eqn. 7a) (Hunt et al. 2011,

279 Fenichel et al. 2013a). Using the utility model, anglers responded dynamically to changes in the

280 perceived quality of the fishery over time. The probability of fishing was determined primarily

281 by the utility experienced in the previous year (Table 1, eqn. 7a-b), but a fishing-behavior

282 persistence term (Table 1, eqn. 7c, $\varphi$, Appendix S1: Table S1) accounted for the fact that

283 previous experiences and fishing habits also influence anglers' fishing decisions (Adamowicz

284 1994) by including previous experiences at a discounted rate.

285 The theoretical utility-based sub-model of angler behavior was informed empirically by results

286 from a stated discrete-choice experiment conducted on German anglers in Lower Saxony

287 (Arlinghaus et al. 2014). This choice experiment exposed anglers to stocking-related attributes as

288 well as a large range of catch rates, thereby allowing the (dis)utility of very low catches near zero

289 to be explicitly estimated. For application in the present study, the parameter values for angler

290 preferences $\left(u_{1}-u_{10}\right.$, Appendix S1: Table S1) differ somewhat from those reported by

291 Arlinghaus et al. (2014). The choice model data were reanalyzed assuming that the part-worth

292 utility function of MLL (Table 1, eqn 9f) was quadratic rather than linear, because the quadratic

293 form best described the data for pike and carp (Arlinghaus et al. unpublished data). Arlinghaus et

294 al. (2014) found that the two stocking attributes did not have a significant influence on angler

295 utility. Thus, we assumed that anglers did not know that pike were stocked and were unable to

296 identify hatchery versus wild origin pike, which is likely. By contrast, for carp we assumed that

297 anglers were aware that carp were stocked and of hatchery origin, because these are culture-

298 based fisheries. The parameters from the choice model were species-specific, but for simplicity 
299 represented the average angler as estimated by Arlinghaus et al. (2014). Hence, angler behavior 300 differed based on the species targeted, but all anglers were assumed to behave the same when 301 fishing for the same species. An exploration of angler heterogeneity is reserved for future work.

302 While the choice model allowed for variation in license cost $€_{\mathrm{L}}$, daily bag limit $D B L$,

303 preference for target species, and stocking frequency, these aspects were not investigated in this 304 study. Thus, levels of these attributes were held constant (Appendix S1: Table S1). Our model 305 was designed to represent a single-lake fishery, such as those run by angling clubs in central 306 Europe. Managers of such fisheries have control over input and output regulations, as well as 307 over what size and density of fish stocked, without involvement of public agencies as is typical 308 for central Europe (Daedlow et al. 2011).

\section{Range of MLLs, stocking strategies, and performance measures examined}

In the model scenarios, MLLs ranged from zero to mandatory total catch-and-release (i.e., the maximum size fish could achieve, $0-L_{\max }$, Appendix S1: Table S1). The size of fish stocked and

312 the range of stocking densities explored reflected information from a survey of over 2000

313 angling clubs (61\% response rate) throughout Germany (Arlinghaus et al. 2015). Accordingly, in 314 the pike scenarios, fry, fingerlings and adults were assumed to be about $2 \mathrm{~cm}, 20 \mathrm{~cm}$, and age-2 $315(35-40 \mathrm{~cm})$, respectively, and in the carp scenarios about $4 \mathrm{~cm}, 15 \mathrm{~cm}$, and age- $2(40 \mathrm{~cm})$, respectively ( $L_{s}$, Appendix S1: Table S1). These sizes were commonly reported in the datasets.

317 For pike, the range of stocking densities of all three stocking sizes initially modelled were chosen

318 to reflect the range in annual stocking expenditures reported by angling clubs across Germany, 319 i.e., a mean of $50 € \mathrm{ha}^{-1} \mathrm{yr}^{-1}$ for pike (range $3-154 € \mathrm{ha}^{-1} \mathrm{yr}^{-1}$, 5th and 95 th percentile respectively). Thus, the range of stocking densities for each of the three size classes we tested ( 
$321 J_{0_{\mathrm{S}}}$ for fry and fingerlings, $N_{\mathrm{S}, t}$ for adults, Appendix S1: Table S1) resulted in the associated

322 range in stocking costs being identical across size classes (Table 2), thereby allowing a direct

323 comparison of the effect of varying stocking sizes for the same monetary investment. For carp,

324 the expenditure range reported by German angling clubs was much greater (mean $210 € \mathrm{ha}^{-1} \mathrm{yr}^{-1}$,

325 range $7-710 € \mathrm{ha}^{-1} \mathrm{yr}^{-1}$, 5th and 95th percentile respectively). For comparative purposes we

326 investigated stocking expenditures in a similar range to pike $\left(0,5\right.$, and $\left.100 € \mathrm{ha}^{-1} \mathrm{yr}^{-1}\right)$ instead for

327 carp (Table 2), translated into numerical stocking abundance. Average angler density in

328 Germany and in the five study clubs involved in our stocking project, measured as the number of

329 anglers licensed to fish a given area of water, was approximately 5 licensed anglers ha ${ }^{-1}$, ranging

330 from about 1 to 10 licensed anglers $\left(\mathrm{ha}^{-1}\right)$. Thus, as a surrogate for latent fishing pressure, we

331 used these three angler densities in our model simulations but allowed realized fishing pressure

332 to vary in response to changes in fishing quality following the utility model.

333 We considered six main performance measures for each of the policies we examined. Two

334 measures related to biological objectives: 1) augmentation (i.e., increased density) of the overall

335 population, and 2) the density of fish fully vulnerable to the fishery, assumed to be those

336 surviving until their third birthday (age-2 and older fish at the end of the year) (Figure S1). In

337 addition, the age structure and composition (wild vs. hatchery origin fish) of the fish population

338 was examined for some simulations as a further conservation objective. Two measures addressed

339 social objectives: 3) the average catch rate, which is often used as a surrogate of angler well-

340 being (Cox et al. 2003), and contrasted it with 4) a more integrated measure of average angler

341 welfare (benefit), net willingness-to-pay (WTP) (Table 1, eqn 8a). Net WTP is a measure which

342 quantifies the change in satisfaction (inclusive value) relative to the status quo expressed in

343 monetary terms (Edwards 1991, Cole and Ward 1994, Loomis and Fix 1999). As status quo, we 
344 used the unstocked and unregulated (no MLL) scenario. To address economic considerations, we 345 calculated 5) the per capita costs associated with stocked fish surviving until they were fully 346 vulnerable to the fishery (i.e., their third birthday, Table 1, eqn 8e), as well as 6) an integrative 347 measure of the net economic benefit (aggregated angler welfare minus costs, Table 1, eqn 8c). 348 Net economic benefit was measured as aggregated social welfare, the sum of individual angler 349 welfare (WTP) across all licensed anglers, minus the financial cost of stocking. Stocking costs 350 were determined based on empirical fish size-cost relationships estimated from Germany 351 (Appendix S1: Figure S2). We used these metrics to evaluate and implicitly rank policy 352 outcomes. Additionally, we examined the size structure and composition (wild vs. hatchery 353 origin) of the fish population in some scenarios to evaluate size/age truncation effects from 354 fishing and replacement of wild fish by hatchery origin fish as a further commonly applied 355 conservation objective (Rogers et al. 2010, Camp et al. 2017).

356 Outline of analyses

357 In scenario 1 (Table 2), we evaluated how well annually stocking of various sizes of fish - fry, 358 fingerlings and adults - at a range of realistic densities preformed relative to the use of a range of 359 MLLs in relation to the six performance measures outlined above. This was done for pike, and 360 latent fishing pressure was assumed to be moderate at 5 licensed anglers ha ${ }^{-1}$.

361 Variations on the base scenario 1 (Table 2) were then used to investigate the sensitivity of 362 outcomes to some of the model assumptions. In scenario 2 (Table 2), we compared naturally363 reproducing pike and non-reproducing carp, when stocking expenditures were the same for both 364 species. We evaluated results at low (1 licenses $\left.\mathrm{ha}^{-1}\right)$ and high (10 licenses ha $\left.{ }^{-1}\right)$ latent fishing 
365 pressure, and when the range in stocking densities reflected low $\left(5 € \mathrm{ha}^{-1}\right)$ to moderate $\left(100 € \mathrm{ha}^{-}\right.$

$36{ }^{1}$ ) stocking costs for both species.

367 In scenarios 3 and 4, for pike only, we examined how sensitive the model predictions were to 368 modifications of some of the key model assumptions. In these scenarios (Table 2), we examined 369 results for low and moderate stocking densities $\left(5 € \mathrm{ha}^{-1}\right.$ to $100 € \mathrm{ha}^{-1}$, respectively) and 370 moderate latent fishing pressure $\left(5\right.$ licenses $\left.\mathrm{ha}^{-1}\right)$. Four biological assumptions were examined in 371 two sets of scenarios. 1) In scenarios 3A and 3B (Table 2), we tested the hypothesis that stock 372 enhancement may be more beneficial in habitats where natural reproduction is impaired (Rogers 373 et al. 2010). We examined two cases; one where the productivity parameter ( $\alpha$, Appendix S1:

374 Table S1) in the stock-recruitment relationship related to the slope near the origin was reduced 375 by half (Table 2 , scenario $3 \mathrm{~A}$ ), and a second where the strength of density-dependence ( $\beta$, 376 Appendix S1: Table S1) in the stock-recruitment relationship was doubled (Table 2, scenario 377 3B), resulting in greater inter-specific competition effectively reducing habitat capacity. In both 378 cases, maximum recruitment was reduced. 2) We examined two scenarios, one in which stocked 379 fish had reduced fitness (Table 2, scenario 4A), and a second in which stocked fish had reduced 380 fitness but whose offspring evolved to wild-type fish in the F1 generation (Table 2, scenario 4B). 381 In both scenarios 4A and 4B (Table 2), hatchery origin fish had reduced reproductive success, 382 and reduced survival in both the juvenile and adult stages (relative survival of stocked age-0 fish 383 was $50 \%$, of stocked adults was $90 \%$, and relative reproductive success was $56 \%$ compared to 384 wild fish) following empirical data (Hühn et al. 2014). In scenario 4B (Table 2), we relaxed the 385 base assumption that larvae produced by spawners of hatchery origin retained a hatchery origin 386 phenotype (Table 1 eqn. $4 \mathrm{f}, h^{2}=0$ ), and tested the opposite extreme where all larvae produced 387 by hatchery origin spawners transitioned to wild type due to natural selection (Table 1 eqn. $4 \mathrm{f}$, 
$\left.388 h^{2}=1\right)($ Lorenzen 2005). These scenarios were not examined for carp because it is unrealistic to 389 assume wild recruitment of this species in central and northern Europe.

\section{RESULTS}

392 From a biological and conservation perspective, in the base scenario (Table 2, scenario 1) where

393 hatchery and wild pike were assumed to have equal fitness, increasing MLLs generally increased 394 total pike density and the density of vulnerable pike, although this pattern was less evident for 395 total pike density when fingerlings were stocked (Figure 2). Density increased rapidly around an 396 MLL of $40 \mathrm{~cm}$ as MLLs began to protect the age-2 cohort from harvest (Appendix S1: Figure 397 S4). Total pike densities increased with increased stocking density for all sizes stocked, 398 particularly when MLLs were low $(<40 \mathrm{~cm})$ and the pike population was overfished at a latent 399 license density of 5 angling licenses $\mathrm{ha}^{-1}$ in the absence of stocking. Total densities were highest 400 when fingerlings were stocked and lowest when fry were stocked, and stocking pike fry had 401 minimal effects on total pike density at all MLLs $>40 \mathrm{~cm}$ (Figure 2, left column). By contrast, 402 adult stocking resulted in the greatest increases in vulnerable pike density (i.e., catchable size), 403 whereas stocking fry and fingerlings had very little effect on this metric (Figure 2, second 404 column). Any benefits of stocking to pike density, however, came at the cost of severe wild stock 405 replacement by hatchery origin fish (Figure 3). Even at low annual stocking densities, stocked 406 fingerlings and adults at equilibrium replaced most of the wild fish. Replacement of wild stocks 407 was less severe when fry were stocked at low densities and MLLs were high, but was a concern 408 at high fry stocking densities, despite the lack of additive effects on the overall pike stock.

409 Replacement was less severe at high MLLs, particularly for fry, suggesting that they improve the 
410 buffering capacity of wild populations against invasion by hatchery phenotypes by reducing

411 fishing mortality of adults.

412 From a social perspective of the fishing quality, stocking pike had positive impacts on average

413 catch rates, but the catch-rate effects were much more pronounced and dependent on stocking

414 density when adult pike were stocked relative to fry and fingerlings (Figure 2, third column).

415 MLLs did not influence catch rates as much when fry and fingerlings were stocked as they did

416 when adults were stocked. Yet, despite the potential for large increases in pike catch rates due to

417 stocking (particularly the stocking of immediately catchable adults), the average benefit to an

418 angler (measured by average net WTP) was largely uninfluenced by stocking pike of any size or

419 density (Figure 2, fourth column), although net WTP was generally slightly higher when adults

420 were stocked. MLLs had a stronger effect on net WTP than stocking, with the benefits initially

421 increasing and then decreasing with increasing MLLs. These findings revealed that intermediate

422 MLLs maximized angler well-being.

423 From an economic perspective, high stocking densities generally increased the per capita costs

424 associated with stocked pike surviving to be fully vulnerable to the fishery (Figure 2, fifth

425 column). By this metric, adult stocking was the most cost effective, followed by fingerlings. Fry

426 were the least cost effective. Survivor costs were generally highest when MLLs were low $(<40$

$427 \mathrm{~cm}$ ) but decreased rapidly when MLLs reached $40 \mathrm{~cm}$ and protected fish from harvest, and then

428 slowly increased as MLLs increased further as density-dependent processes became more

429 important. Importantly, however, the net economic benefits of stocking were negative for most

430 stocking strategies evaluated $\left(10-154 € \mathrm{ha}^{-1} \mathrm{yr}^{-1}\right)$ when fishing pressure was moderate (5 licenses

$\left.431 \mathrm{ha}^{-1}\right)$ (Figure 2, right column). Only very low stocking densities $\left(<10 € \mathrm{ha}^{-1} \mathrm{yr}^{-1}\right)$, resulted in a

432 positive net benefit. When stocking was absent, use of MLLs up to about $110 \mathrm{~cm}$ produced a 
433 positive net economic benefit (peaking at $8.8 € \mathrm{ha}^{-1} \mathrm{yr}^{-1}$ at an MLL of $\sim 60 \mathrm{~cm}$ ) at intermediate 434 fishing pressures.

435 Stocking outcomes in reproducing (pike) versus non-reproducing (carp) populations

436 A direct comparison of the outcomes for reproducing pike and non-reproducing carp with the

437 same stocking expenditures $\left(0,5\right.$ or $\left.100 € \mathrm{ha}^{-1}\right)$ under low and high latent fishing pressure (1

438 angler ha ${ }^{-1}$ or 10 anglers $\mathrm{ha}^{-1}$, Table 2 scenarios $2 \mathrm{~A}$ and $2 \mathrm{~B}$ ) revealed several similarities to

439 results above, but also important differences in the relative effects of stocking compared to

440 MLLs. Similar to pike, stocking carp enhanced total carp density and the density of vulnerable

441 carp (Figure 4), with higher stocking densities having larger effects. Like pike, stocking carp

442 fingerlings produced the highest total densities of carp. Stocking adults generally produced

443 higher densities of vulnerable carp and higher catch rates than stocking of either fry or

444 fingerlings (Figure 4), except under high latent fishing pressure (10 anglers ha $\left.{ }^{-1}\right)$ and low MLLs

$445 \quad(<50 \mathrm{~cm})$. Unlike pike, where stocking pike at low densities into a self-sustaining population

446 (i.e., under low latent fishing pressure, 1 angler ha ${ }^{-1}$, or when MLLs $>50 \mathrm{~cm}$ protected adults

447 from harvest) had little impact on the fish density, the density of vulnerable fish, and catch rates,

448 stocking carp of any size was always beneficial and much less influenced by MLLs compared to

449 the pike scenarios (Figure 4). Even stocking fry improved carp density, vulnerable carp density,

450 and catch rates, whereas stocking pike fry only had an effect when the pike population was

451 heavily exploited (i.e., high latent fishing pressure of 10 anglers ha ${ }^{-1}$, and low MLLs $<40 \mathrm{~cm}$ ),

452 and only enhanced total pike density having little impact on vulnerable pike density or catch

453 rates (Figure 4). 
454 Similar to pike, MLLs were more important for determining net WTP in carp than variation in 455 stocking size or number (Figure 4). However, stocking carp increased net WTP more than 456 stocking pike did, and unlike pike where stocking only performed better than MLLs at high 457 fishing pressure and low MLLs, stocking carp always resulted in a highly positive net WTP that 458 was much greater than the use of MLLs alone (Figure 4). Carp net WTP was also much less 459 influenced by latent fishing pressure than the pike's net WTP.

460 The per capita costs of fish surviving to a vulnerable age were much lower for carp than pike, but 461 as in the case of pike the costs tended to be lowest when MLLs were around $40 \mathrm{~cm}$ and increased 462 with stocking density (Figure 4). Also, similar to pike, carp fry were least cost-effective to stock. 463 However, unlike pike, the most cost-effective stocking size for carp was context-dependent. Low 464 densities of carp fingerlings were generally most cost-effective, but as stocking densities 465 increased, adult carp became more cost-effective than fingerlings in most cases (Figure 4). 466 Finally, like pike, the net economic benefit of stocking carp was not strongly influenced by the 467 size of fish stocked, with adults and fingerlings performing slightly better than fry (Figure 4). 468 However, unlike pike, stocking carp was much more likely to result in a positive net benefit, 469 occurring at lower latent fishing pressures, under a broader range of stocking densities, and being 470 of higher magnitude (Figure 5). It should be noted, at higher latent effort, even pike stocking 471 resulted in a positive net benefit. Moreover, the net economic benefit from stocking carp was 472 more likely to exceed the net benefit from the use of MLLs alone; something which only 473 occurred for pike at low MLLs when latent fishing pressure was high. Thus, overall stocking of 474 carp outperformed stocking of pike economically and socially.

\section{The ecological constraints on stocking wild fish populations}


476 The model outcomes were generally robust to some key assumptions made about ecological

477 constraints on the production of wild pike. Changes in population productivity and habitat

478 capacity (Table 2, scenarios $3 \mathrm{~A}$ and 3B), as expected, reduced total pike density and vulnerable

479 pike density in both the unstocked and stocked scenarios (Figure 5). Despite these differences,

480 the patterns in terms of the performance of stocking were generally qualitatively similar to the

481 unaltered scenario, i.e., reduced habitat quality did not improve the prospects of stocking

482 generating additive effects on the pike stock and fishing quality. One exception involved

483 stocking pike fingerlings at high density when habitat capacity was poor. In this case, total pike

484 density declined with increasing MLLs rather than staying relatively static in the unaltered case

485 (Figure 5). Reduced habitat capacity and productivity also reduced catch rates, but the effects on

486 catch rates were less severe (Figure 5). That said, reductions in baseline catch rates in the

487 unstocked and unregulated scenario due to reduced productivity were orders of magnitude

488 smaller than the baseline and diminished habitat capacity scenarios (e.g., at 5 licenses ha ${ }^{-1}$, and

489 no MLL or stocking; $1.910^{-6}$ pike d $^{-1}$, for baseline and poor habitat capacity, $2.810^{-13}$ pike d $^{-1}$,

490 for low productivity scenario). As a result, changes in habitat capacity had no discernable effect

491 on net WTP, but reduced productivity resulted in much higher net WTP under all stocked and

492 unstocked scenarios (Figure 5). Reductions in habitat capacity and productivity increased the per

493 capita costs of stocked fry and fingerlings surviving to a vulnerable age, particularly when they

494 were stocked at high stocking densities (Figure 5). Similar to net WTP, changes in habitat

495 capacity had little impact on the net economic benefits of pike stocking, while reduced

496 productivity increased net benefit in all scenarios. However, this effect was not enough to exceed

497 the benefit of using moderate to high MLLs alone in the management of pike in a habitat-

498 constrained fishery (Figure 5). 
499 Stocked pike, like many other fishes, are known to suffer from lower fitness relative to wild 500 fishes, so we also examined this key assumption for systematic effects (Table 2, scenarios 4A 501 and 4B). The realistic assumption that stocked fish had generally lower fitness (i.e., lower 502 reproductive success, and lower survival) than similarly-sized wild conspecifics caused 503 reductions in total pike density, vulnerable density, and catch rates relative to the scenario of 504 equal fitness. Reductions were most pronounced when fingerlings were stocked and least 505 pronounced when adults were stocked (Figure 5). Lowered fitness of stocked fish increased the 506 per capita costs of stocked fry and, to a lesser extent, the number stocked fingerlings surviving to 507 vulnerable sizes, but had little influence on net WTP or net economic benefit of pike stocking. 508 Simulating strong natural selection by introducing a heritability of one (i.e., $100 \%$ transition of 509 hatchery spawned fish to wild origin, Table 2, scenario 4B) reversed some of the effects on total 510 fish density that low fitness introduced but had little influence on other output measures (Figure 511 5). Thus, the results presented were robust to these model sensitivities.

\section{DISCUSSION}

513 Our model integrated a size-structured fish population model (which included multiple size- and 514 density-dependent feedbacks) with a mechanistic sub-model of adaptive angler behavior.

515 Through key size- and density-dependent ecological processes we explicitly accounted for the 516 compensatory response of the fish population and how they respond to the change in density 517 induced by stocking or harvesting. The coupled social-ecological model thus allowed the 518 systematic study of how ecological processes drive the biological, social and economic outcome 519 of commonly applied management interventions in recreational-fisheries management. We show 520 that the expected benefits of stocking versus managing the fishery solely with harvest regulations 521 vary greatly depending on the ecological condition of the population being supplemented along a 
522 gradient of reproducing and self-sustaining to non-reproducing. The evaluation of outcomes also

523 varies strongly with the metric that is used to judge performance, identifying some key trade-

524 offs, e.g., among conservation and fisheries benefits in the case of stock enhancements in

525 naturally self-sustaining populations. Both hypotheses initially stated were supported. First,

526 stocking promises to have additive ecological and large social effects when natural reproduction

527 of the target species is lacking or when fish large enough to have escaped strong juvenile

528 mortality compensation are stocked in self-sustaining populations. However, in the latter case

529 this comes at the costs of replacement of wild fish by hatchery fish over time, creating a

530 fundamental trade-off among successful stock enhancement and wild fish conservation (sensu

531 Rogers et al. 2010, Amoroso et al. 2017, Camp et al. 2017). Second, harvest regulations socially

532 and economically outperform stocking measures when managing naturally reproducing

533 populations.

534 Conservation and catch outcomes

535 Our results underscore the importance of ecological processes for determining the outcomes of

536 common recreational-fisheries management actions. Like other studies (e.g., Lorenzen 2005,

537 Camp et al. 2014), we found density-dependent growth and size- and density-dependent

538 mortality responses of fish populations constrained the contribution of stocking to the exploited

539 population and limited the catch rates that anglers could enjoy. For example, stocking fry into a

540 self-sustaining population (e.g., pike at low latent effort or high MLLs where the stock was not

541 overfished) produced no additive effects to the vulnerable population and to catch rates relative

542 to the use of MLLs alone. These model predictions agree well with empirical findings for stock-

543 enhanced pike and other species (e.g., Li et al. 1996, Skov et al. 2011, Hühn et al. 2014), and

544 findings of previous stocking models (e.g., Lorenzen 2005, Camp et al. 2014). Stocked 
545 fingerlings that escaped more of the early mortality bottleneck, on the other hand, were predicted 546 to augment the overall population beyond levels achieved by MLLs alone, particularly when

547 hatchery fish had a high relative fitness. However, in naturally reproducing populations high

548 size-dependent natural mortality rates of stocked fingerlings resulted in only minimal increases

549 in the densities of fish vulnerable to capture, while the largest additive effects on vulnerable

550 density and thus catch rates were predicted from the stocking of large, recruited fishes in such

551 situations. These findings are consistent with empirical results for a range of species (e.g., Li et

552 al. 1996, Baer and Brinker 2008) and theoretical studies (e.g., Rogers et al. 2010, Garlock et al.

553 2017). Our findings are also consistent with a recent pike stocking experiment that found that

554 stocking age-0 fingerlings enhanced stocks one year later (age-1), but the additive effect was no

555 longer present in the age- 2 cohort when the fish became vulnerable to the fishery and size-

556 dependent mortality had regulated the cohort's abundance back to carrying capacity (Arlinghaus

557 et al. 2015, Guillerault et al. 2018). The reason for the superior performance of large-sized

558 stocked fishes in naturally recruiting situations is that stocked adults experience much less

559 natural mortality than fingerlings because of the allometry of the size-mortality relationship

560 (Lorenzen 2000). At the same time, they may be large enough to be immediate vulnerable to

561 capture by fishing gear (Lorenzen et al. 2012). The benefits from stocking large fish in both

562 naturally reproducing and non-reproducing situations that we found in our model are generally

563 consistent with other models (Askey et al. 2013, Camp et al. 2014, Garlock et al. 2017) and

564 empirical studies (e.g., Wiley et al. 1993, Yule et al. 2000, Meyer et al. 2012). Our model

565 supports the trend seen in some countries to stock increasingly larger fish including catchable

566 fish in stock-enhancement efforts (Halverson 2008), which is likely a response to fry and small

567 fingerlings rarely producing sustained outcomes for ecological reasons. However, the more 
568 successful stock enhancement efforts in naturally reproducing stocks become, the more likely

569 these efforts are to replace the wild stock component (Rogers et al. 2010, van Poorten et al.

570 2011), and potentially increase angling impacts by attracting increased fishing pressure (Baer et

571 al. 2007), thereby creating a fundamental, trade-off among fisheries benefits and conservation

572 (Camp et al. 2017, Amoroso et al. 2017).

573 Despite abundant ecological risks (e.g., Laikre et al. 2010, van Poorten et al. 2011), our findings

574 and related work (Cowx 1994, Lorenzen et al. 2012, Sass et al. 2017) suggest stocking can, when

575 properly conducted, play an important role in rehabilitating fisheries that are no longer self-

576 sustaining or creating or maintaining fishing opportunities when local fishing pressures are high.

577 Specifically, we found that stocking fish populations that were not self-sustaining (e.g., carp or

578 heavily overexploited pike at low MLLs) was successful in establishing and enhancing the

579 fisheries for the benefit of anglers and conservation. In these culture-based situations, stocking

580 fish of small size also elevated catch rates, because otherwise the population would not persist.

581 Interestingly, unlike the case in pike, we found that carp fingerlings contributed more to the

582 vulnerable population than adults in two situations, 1) when stocking densities were low, and 2)

583 when stocking densities were high, fishing pressure was high, and MLLs were low (overfished

584 stocks). Ecological processes were important for determining stocking outcomes in these cases.

585 In the first case, similar to what Lorenzen (1995) and Hunt et al. (2014) found, density-

586 dependent processes resulted in a trade-off between the number of fish stocked and fish size,

587 which had impacts on natural mortality rates. At low stocking densities, fingerling growth rates

588 were fast and size- and density-dependent mortalities were reduced, resulting in more fingerlings

589 surviving to the vulnerable stage. The reverse was the case at higher stocking densities, except

590 when the catchable-sized adults experienced high fishing mortality rates under high fishing 
591 pressure and liberal harvest limits, resulting in low residence times of stocked adults. Thus, the

592 possible enhancement effects of different fish sizes are tightly coupled to the degree of natural

593 recruitment, stocking rate, local harvesting pressure and the harvest regulations in place. Models

594 such as ours (available at http://www.ifishman.de/en/practioner/software/) and others (Varkey et

595 al. 2016, Garlock et al. 2017), can help to define species-specific expectations and inform

596 management policies as to which life stage is likely to perform best, but adaptive stocking

597 experiments are then needed to identify the most suitable stocking strategy for a given target

598 species and system (Arlinghaus et al. 2017).

599 Ecological processes are also responsible for the prediction that the conservation benefits from

600 stocking recruitment-limited populations may actually be slim. Recruitment limitations due to

601 habitat bottlenecks are among the most often cited arguments (Cowx 1994) for so called

602 compensatory stock-enhancement efforts in impaired populations (Lorenzen et al. 2012).

603 However, we found that reductions in maximum habitat capacity for recruits and generally a

604 reduced productivity did not render stocking relatively more beneficial to the population or the

605 fishery, particularly when small sizes were used in stocking. Our results agree with a recent

606 empirical study by Guillerault et al. (2018) who reported that the additive effects of pike stocking

607 were largely independent of the quality of the habitat for the target species in lakes. Our findings

608 contrast those of other studies (e.g., Rogers et al. 2010, Ziegler et al. 2017) who reported that

609 stocking is increasingly beneficial when natural reproduction is impaired from habitat loss.

610 However, even then the size-at-stocking is bound to determine stocking outcomes, and only sizes

611 beyond recruitment bottlenecks are likely to perform well (Lorenzen 2005). Varying assumptions

612 in related models and ours can explain the divergent study findings. For example, Rogers et al.

613 (2010) assumed that habitat degradation only affected the wild-spawned fish and did not affect 
614 the hatchery-released fish. By contrast, we assumed that all fish, including the offspring from 615 surviving stocked fish, were constrained by the conditions of the waterbody. Hence in our study, 616 even stocking adults, which elevate catch rates and increase spawning stock in the short-term, 617 will not produce long-term biological benefits by improving recruitment, but it will benefit 618 anglers by creating a put-and-take or a put-grow-and-take fishery. Similarly, Ziegler et al. (2017) 619 found that stocking larger individuals allowed fish to escape the high predation mortality when 620 predation refugia utilized by young-of-year walleye (Sander vitreus) was removed from lakes, 621 and Li et al. (1996) reported that fingerling stocking enhanced a walleye abundance index more 622 than fry stocking, but only in lakes where natural recruitment was essentially absent. Under 623 conditions of low habitat quality where natural recruitment is constrained, stocking is a bandage 624 solution used to increase abundance and improve catch rates, rather than addressing the 625 underlying problem (Sass et al. 2017). In such situations, habitat restoration promises to be the 626 only tool able to sustainably elevate the productivity and carrying capacity of a given ecosystem 627 for fish (Sass et al. 2017). Although our model did not explicitly allow habitat management to be 628 explored, changes to the parameters of the stock-recruitment relationship can be used to inform 629 how well this practice preforms compared to stocking or MLLs.

630 The realistic assumption of reduced fitness of stocked fish relative to wild conspecifics

631 (Lorenzen et al. 2012, Hühn et al. 2014, Arlinghaus et al. 2015) can further minimize the benefits 632 of stocking. For example, in a replicated pond study, Hühn et al. (2014) found that cultured 633 juvenile pike fry performed half as well in terms of growth and juvenile mortality when forced 634 into competition with wild recruits, but did as well as wild recruits when stocked in ponds with 635 no wild pike. Despite their lower fitness, however, some stocked fry established in the stock 636 enhancement treatments leading to the replacement of wild recruits rather than increasing the 
637 year class abundance (Hühn et al. 2014). The circumvention of sexual selection during artificial 638 breeding can also reduce reproductive fitness (Thériault et al. 2011). Given the lower fitness of 639 hatchery fish, even those held for only brief periods in the hatchery (Araki et al. 2007, Thériault 640 et al. 2011, Christie et al. 2014), establishment of hatchery fish in natural stocks can ultimately 641 also lead to a reduced productivity of the fishery (Chilcote et al. 2011). We found that reducing 642 the fitness of hatchery-origin fish reduced the benefits associated with stocking fry or fingerlings, 643 in agreement with Lorenzen (2005) and Rogers et al. (2010), although if, as has been suggested 644 (Lorenzen 2005), natural selection causes hatchery fish to evolve wild-type phenotypes this 645 could partially compensate for the lower stocking success resulting from differential survival.

646 Despite lower fitness, we found that releasing low fitness juvenile or adult pike in larger numbers 647 could still produce fisheries benefits, simply due to numerical effects. The caveats include the 648 possible replacement of the wild stock components by hatchery fish and a possible reduction in 649 long-term sustainability.

650 Alternatively, hatchery fish could survive well to recapture but show low reproductive success 651 relative to wild spawners (Lorenzen et al. 2012). If the phenotypes to be released survive well, 652 but do reproduce effectively, stock enhancements could be of less conservation concern, while 653 still delivering fisheries benefits. We did not examine this scenario in our model, nor did we 654 evaluate other factors such as differential growth or catchability of hatchery and wild fish 655 (Mezzera and Largiadèr 2001, Biro and Post 2008, Klefoth et al. 2012), and these processes will 656 positively affect the fisheries performance of stocking programs by offering greater returns of 657 hatchery fish that have higher catchability (Lorenzen et al. 2012). Moreover, the high 658 catchability could reduce the residence times (time between stocking and recapture) of hatchery 659 fish minimizing the risk of introgression (Mezzera and Largiadèr 2001, Baer et al. 2007). 
660 Stocking triploids is an alternative to effectively avoid interbreeding of hatchery fish and wild 661 fishes, thereby minimizing the impacts of wild stocks in the long term while providing fishing 662 opportunities (Koenig et al. 2011, Lorenzen et al. 2012).

\section{Social outcomes}

664 From a social perspective, we found that stocking naturally reproducing pike populations had 665 little effect on angler well-being as long as a threshold catch rate was achieved in the fishery. 666 Socially, we found intermediate MLLs generally outperformed stock enhancements in naturally 667 reproducing situations, but, in line with Rogers et al. (2010), stocking can benefit naturally 668 reproducing fisheries that experience high fishing mortality. In the latter case, recruitment 669 overfishing limited egg production, because not enough adults were surviving to reproduce.

670 Thus, while stocking can be effective for managing heavily exploited populations, a more

671 sustainable approach would be using restrictive harvest regulations, which can then be combined

672 with put-growth-and take type of enhancements to satisfy angler demands (Arlinghaus et al. 673 2016).

674 Similar to other studies (e.g., Johnston et al. 2010, Camp et al. 2016), our results challenge a 675 common assumption that angler utility (or satisfaction), is determined primarily or exclusively 676 by angler catch rates (e.g., Carpenter et al. 1994, Post et al. 2003, Rogers et al. 2010). We found 677 the success of stocking, as measured by net WTP, was not tightly correlated with catch rates, 678 even when stocking created large differences in catch rates. Although catch rate was a highly 679 significant attribute in the choice experiment used to inform angler behavior in our study 680 (Arlinghaus et al. 2014), the lognormal form of the part-worth utility function for catch rate 681 (Appendix S1: Figure S3) meant that the marginal gains in utility that came with increased catch 
682 rates rapidly diminished as catch rates exceeded a certain minimally acceptable threshold.

683 Empirical studies have found similar relationships between catch and satisfaction (e.g., Patterson 684 and Sullivan 2013, Beardmore et al. 2015, Hyman et al. 2016). In other words, anglers were very 685 dissatisfied when catch rates were extremely low, but once catch rates were "good enough" 686 (roughly 1 fish daily, Arlinghaus et al. 2014) they had little further impact on angler satisfaction.

687 As a consequence, it has been found empirically that intermediate stocking rates attract the 688 greatest fishing effort, because low stocking rates produce catch rates low enough to affect

689 anglers' behavior and high stocking rates reduce fish growth and affect anglers' satisfaction with 690 the size of fish caught, thereby attracting less fishing effort (Mee et al. 2016). We argue that a 691 diminishing marginal return in utility from increasing catch rates is consistent with economic 692 (Beardmore et al. 2015) and motivational theory (Finn and Loomis 2001), and is likely found in 693 most recreational fisheries. That said, some anglers have been implied to have linear or 694 accelerating preferences for catch rates (e.g., Varkey et al. 2016), such as those targeting high695 catch-rate small-bodied cyprinid species in Germany (Beardmore et al. 2015). If such 696 relationships exist, our model predictions may not hold.

697 The non-linear relationship between catch and utility explains, in part, why MLLs were much 698 more important than the stocking strategy for determining angler well-being (and thus 699 satisfaction) in naturally reproducing fish in our study. When MLLs were sufficiently high (>40 $700 \mathrm{~cm}$ ) to offer some protection to catchable fish, then catch rates were "good enough" using MLLs 701 alone and any improvements to catch rates from stocking had minimal impacts on angler 702 satisfaction and behavior. A second reason why MLLs impacted angler satisfaction was because 703 harvest regulations also affect anglers directly through the perceived restrictions they might have 704 on harvest. Other studies have confirmed that regulations can affect angler use (e.g., Beard et al. 
705 2003, Johnston et al. 2011, Haglund et al. 2016). The quadratic (i.e., hump shape) form of the 706 part-worth-utility relationship for MLLs (Appendix S1: Figure S3) implies that there is a balance 707 between desires to conserve the fish resource and perceived ability to harvest (Johnston et al. 708 2010), thus, generally intermediate MLLs were preferred by the majority of anglers in our 709 model.

710 While utilizing MLLs may represent a more sustainable approach to managing naturally 711 reproducing populations, culture-based fisheries maintained by stocking can generate substantial 712 social benefits that would not occur in the absence of stocking (Arlinghaus et al. 2016). We 713 found that if fish reproduction was nonexistent (carp) or impaired (overexploited pike), then 714 stocking positively influenced angler satisfaction, because without stocking catch rates were low 715 enough to be a matter of concern. However, in such situations the differences among stocking 716 strategies were not pronounced, because all stocking strategies resulted in catch rates that were 717 "good enough". Anglers often prefer stocking over other management measures, because it is 718 relatively easy to implement, less restrictive, and generally perceived to help fish stocks and 719 maintains catch rates (Arlinghaus and Mehner 2003a, Dorow et al. 2009, Garlock and Lorenzen 720 2017). Thus, stocking in culture-based fisheries can potentially be used to provide fishing 721 opportunities that draw fishing pressure away from wild stocks or increase participation (Fayram 722 et al. 2006, Baer et al. 2007, Mee et al. 2016). That said, there is a need to inform and maybe 723 even "educate" anglers about which forms of stocking are beneficial and which are unlikely to 724 generate additive effects (Fujitani et al. 2017). Otherwise, decision-makers will continue to 725 experience strong pro-stocking social norms of anglers and be constantly challenged to re-invest 726 license money back into the waters (Riepe et al. 2017), despite knowing that many of these 727 stocking efforts will likely not benefit the fishery and challenge conservation objectives. 
729 The effects of stocking on fish abundance, catch rates, and angler welfare ultimately affected the 730 economic feasibility of stocking strategies relative to the management of fisheries based on the 731 “cost-free” MLL. Stocking few fish was generally more cost effective than stocking high 732 densities due to size- and density-dependent regulatory processes, and these processes were also 733 important for determining which size of fish was most cost effective. Similar to other studies 734 (Santucci Jr and Wahl 1993, Leber et al. 2005, Garlock et al. 2017), we found that fingerlings 735 were more cost effective than fry, because fingerlings experienced less mortality from the early

736 life-stage bottleneck than fry did. Likewise, in agreement with Wiley et al. (1993) we found that

737 stocking catchable adults was generally more cost-effective than stocking sub-catchable

738 fingerlings, because of the strong natural mortality (from size and density dependence) that

739 fingerlings experienced prior to becoming vulnerable to the fishery. The faster fish reach

740 vulnerable sizes, the more effective stocking will be, making fish growth rates an important

741 predictor of stocking outcomes (Garlock et al. 2017). In addition, minimizing mortality of fish,

742 particularly fry and fingerlings, using MLLs before they become fully vulnerable to the fishery,

743 improved the cost-effectiveness of stocking, while more restrictive regulations reduced cost-

744 effectiveness because fish were "lost" due to density-dependent mortality. The benefits of

745 stocking larger fish, however, requires that there are sufficient survival benefits to offset the

746 costs of producing larger fish. For example, in carp, low stocking densities minimized size-

747 dependent mortality of fingerlings making them more cost effective than adults. Moreover, high

748 mortality rates from fishing (high latent effort) for adults, which were fully vulnerable to harvest

749 at the time of stocking, outweighed any benefits of size for determining natural mortality rates,

750 until MLLs offered some protection. Our findings are similar to Diana and Wahl (2009) who 
751 reported that stocking medium-sized largemouth bass (Micropterus salmoides) fingerlings was

752 most cost-effective, because stocking larger fish did not provide additional survival benefits.

753 Despite adults being generally more cost-effective, they require more space and long production 754 periods making them expensive to produce even at low stocking densities. Monetary stocking 755 costs may not be of great concern if only a few lakes close to urban areas are stocked to satisfy 756 anglers (Cole and Ward 1994, Post and Parkinson 2012), or for angling clubs in Germany or 757 elsewhere in central Europe that have few stocks to manage, high license income and little 758 alternative uses for the income than stocking. But costs may be a problem for North American 759 agencies charged with managing hundreds if not thousands of stocks among which they must 760 allocate a limited budget (Cowley et al. 2003). In this context, our research suggests that low 761 stocking rates of adults may be cost-effective in many situations, not only in put-and-take urban 762 lakes. However, an evaluation of whether these fish can be produced in a cost-effective manner 763 needs to be evaluated (Garlock et al. 2017), and any additional issues from domestication and 764 long holding times in hatcheries that could reduce survival post-release need to be evaluated 765 (Lorenzen et al. 2012).

766 In practice, management objectives often focus on improving fishing opportunities or 767 maximizing license sales (Askey et al. 2013, Dabrowska et al. 2014, Hunt et al. 2017), rather 768 than on individual angler satisfaction as we did, particularly if fisheries agencies depend on 769 license income for funding. By contrast, local angling clubs under private fishing right systems 770 in central Europe who are sufficiently funded likely focus more on angler satisfaction-objectives 771 and not whether stocking or any other measures recruits new members to clubs. When we 772 examined whether the socioeconomic benefits (social welfare) of stocking outweighed the 773 financial costs of stocking (assuming financial costs of changing MLLs were zero) we found a 
774 striking difference between the economic performance of stocking into naturally reproducing and

775 non-reproducing populations. Moderate MLLs in the absence of stocking maximized the net

776 economic benefit from fishing for pike, while the economic benefit of stocking pike rarely

777 exceeded the use of MLLs alone. This is because MLLs were sufficient to preserve fishery

778 benefits without the added costs from culturing fish. Stocking was only the economically best

779 option when MLLs offered little protection to the pike population and recruitment overfishing

780 was occurring under higher levels of latent fishing pressure. By contrast, we found it was

781 economically advisable to create a culture-based fishery using carp, particularly when adults

782 were stocked at low densities. Our results are in agreement with other stocking models

783 (Lorenzen 2005, Rogers et al. 2010) that reported stocking was much more advisable in culture-

784 based situations compared to stock-enhancement scenarios. Such information can inform the

785 allocation of stocking resources within the landscape of lakes, with and without natural fish

786 populations, to maximize the benefits the angling community receives while avoiding incurring

787 unneeded costs (Cowley et al. 2003).

788 The reasons behind our findings relate to the two components that determined net economic

789 benefit - net WTP and latent fishing effort. In this context, the definition of the status quo

790 situation (unregulated and unstocked) used to calculate the net WTP was very important for the

791 findings. When catch rates approached zero in the status quo scenario, as occurred when the

792 population was heavily overexploited (pike) or lacked natural reproduction (carp), anglers were

793 willing to pay much more to improve the situation because of the large disparity between the

794 regulated/stocked scenarios and the status quo case. Whereas if catch rates in the status quo

795 situation approached "good enough" in scenarios where the population was self-sustaining, then

796 there was much less gained from the stock-enhanced scenario, because of the above-mentioned 
797 nonlinear relationship between angler satisfaction and catch rates. The second important factor

798 determining the net economic benefit generated by a given policy was latent fishing effort,

799 because it determined the aggregated angler welfare (net WTP multiplied by latent effort) of a

800 given policy. When net per angler WTP was low, more anglers and lower stocking densities

801 were required to produce a positive net economic benefit for the fishery as a whole. Such a

802 situation was rare for pike, even at low stocking densities, unless latent angling pressure was

803 moderate to high. By contrast, stocking carp often produced a positive net economic benefit,

804 except when there were not sufficient anglers to benefit from the culture-based fishery. It should

805 be cautioned, however, that our results are largely the result of the nonlinear relationship

806 between catch rates and angler satisfaction. A greater sensitivity of angler utility and behavior to

807 catch rates not approaching zero, as has been assumed in other modelling exercises (e.g., Allen et

808 al. 2013, Camp et al. 2014), could change predictions about the net economic benefits and

809 success of stocking strategies.

810 In the face of financial constraints, our results are good news for managers facing tough

811 budgetary decisions. If one has a limited budget to allocate, our results suggest that creating

812 culture-based fisheries with a desired species, rather than stocking naturally reproducing

813 populations provides the best investment. In doing so, managers create more fishing

814 opportunities, greater benefits to anglers, and a better return on their investment. Stocking may

815 also have the added benefit of drawing fishing effort away from wild stocks, but only if

816 additional effort attracted to the system does not put additional pressure on wild stocks (Fayram

817 et al. 2006, Baer et al. 2007, Meyer et al. 2012). The recommendation to stock a nonnative

818 species such as carp also assumes that one is not concerned with the possible negative ecological

819 consequences of high carp biomasses (e.g., water quality impacts, habitat degradation, 
820 competition with other species, etc. Matsuzaki et al. 2009, Weber and Brown 2009, Vilizzi et al.

821 2015). However, as carp do not regularly recruit in central Europe (Kottelat and Freyhof 2007),

822 environmental impacts may be controlled in what effectively becomes a put-grow-and take

823 fishery. Research has found that, if overall biomass is kept within limits $\left(<50 \mathrm{~kg} \mathrm{ha}^{-1}\right)$, impacts

824 on water quality (Mehner et al. 2004, Vilizzi et al. 2015) and aquatic ecosystems (Barthelmes

825 and Brämick 2003) may be limited. Thus, if anglers follow economic principles and minimize

826 costs when making stocking decisions, the low stocking intensities suggested from our research

827 should minimize conflicts among conservation and fisheries objectives for this species.

828 Allocating stocking funds to carp does not mean a loss for pike anglers (or other naturally

829 occurring species). Our study has a clear message: if fish populations are self-sustaining, we

830 suggest that stocking is not economically advisable and will only rarely increase angler welfare.

831 Managers can use MLLs or other forms of harvest controls, for example harvest slots (Gwinn et

832 al. 2015), to achieve the same or greater benefits, without bearing the costs associated with

833 stocking. However, overly restrictive MLLs may not be an option either, because harvest

834 contributes substantially to angler welfare in many cultures (Arlinghaus et al. 2014). The use of

835 harvest restrictions has the additional benefit of avoiding the possible negative ecological effects

836 of stocking fish, such as replacement of the wild stock (Rogers et al. 2010, van Poorten et al.

837 2011, Camp et al. 2014), effects on genetic integrity, spread or disease, etc. (Cowx 1994, Araki

838 et al. 2007, Lorenzen et al. 2012), as well as negative impacts of the welfare on other

839 stakeholders (e.g., conservation lobby groups) that we did not account for in our model. 
841 Our model has a number of limitations that are worth noting. In the biological sub-model, the

842 impacts of stocking were strongly dependent on the strength of the size- and density-dependent

843 compensatory responses at the different life stages. While we did observe effects from density-

844 dependent mortality, we did not observe large declines in the number of fry or fingerlings

845 surviving to age-1 at extremely high stocking densities as one might expect from a Ricker stock-

846 recruitment relationship (Fayram et al. 2005), nor did we see overall densities reaching a

847 maximum carrying capacity at high stocking densities for any fish size. This is a result of the

848 stocking densities we investigated, and density-dependent mortality in age-1 and older fish.

849 Thus, it is possible that our predicted outcomes from stocking are overly optimistic, because

850 density-dependent feedbacks were not sufficiently strong. Moreover, our conclusions that

851 stocking is generally not beneficial for naturally-reproducing pike and beneficial only in low

852 densities for non-reproducing carp are unlikely to be affected by decreased mortality at higher

853 stocking densities because catch had such little impact on angler utility. However, reduced

854 natural mortality rates of small fish due to changes in the size- and density-dependent survival

855 relationships could result in fingerlings being a more effective size to stock than adults. We did,

856 however, find that our model predictions were robust to the assumption of density-dependent

857 mortality of fish age-1 and older. Model predictions in the absence of density-dependent

858 mortality for fish of age-1 and older were qualitatively similar (Appendix S1: Figures S6, S7,

859 and S8). The only differences of note were that compared to stocking carp adults, stocking carp

860 fingerlings did not produce higher vulnerable densities and catch rates or lower survivor costs

861 under high latent effort. In addition, the inability of pike populations to compensate for the low

862 density of predators in the system caused by heavy exploitation resulted in a greater range of 
863 MLLs where populations were unsustainable and higher WTP, survivor costs, and net benefits,

864 although the patterns were qualitatively the same as the density-dependent scenarios.

865 In terms of the social sub-model, we assumed that MLLs have no direct monetary cost. While

866 this may be reasonable because the implementation framework is already in place, other

867 associated costs, such as enforcement costs, were not included in our model. Our model was also

868 based on a specific, mechanistic model of angler behavior. As discussed previously, the

869 lognormal relationship between catch and utility had a strong influence on our results, and other

870 functional forms in this relationship may alter the outcomes. An additional limitation of our

871 model was that we made the simplifying assumption that all anglers had identical time-invariant

872 preferences. In reality, preferences may shift over time (Hunt et al. 2011), and particularly

873 assumptions about angler heterogeneity might affect model outcomes substantially (Johnston et

874 al. 2010, 2013, Matsumura et al. 2017). Thus, further investigations using preferences from

875 different angler populations composed of diverse angler types are needed to test the robustness of

876 our findings.

877 Another aspect that our long-term equilibrium dynamics model did not consider was the

878 temporal variability in the fishery. Seasonality and stochasticity are inherent characteristics of

879 fisheries. Differences in catch can develop because anglers differ not only in their skill (Dorow et

880 al. 2010, Ward et al. 2013) but also in when they go fishing (Hunt et al. 2007). Thus, after a

881 stocking event, particularly of large fishes, there is the potential that those anglers who come first

882 and spend more time fishing shortly after stocking will reap more benefits than anglers who

883 arrive later. Changes in fish behavior can further inflate the disproportionate distribution of

884 benefits, if stocked fish alter their behavior over time to become less vulnerable to fishing gear

885 (e.g., van Poorten and Post 2005, Askey et al. 2006, Klefoth et al. 2013). However, any short- 
886 term catch rate boosts from stocking would likely not affect social outcomes, because of the non-

887 linearity in the catch-utility relationship, but they could alter predictions about biological

888 enhancement.

889 Finally, the results we presented in our study relate to the benefits of stocking a single lake with 890 a single-species population. In reality, individual fisheries are embedded in the broader landscape 891 and therefore require broader management perspectives (Lester et al. 2003, Hunt et al. 2011, Mee 892 et al. 2016). It is important for managers to understand how changes in regulations will effect 893 target-species substitution and site substitution (Gentner and Sutton 2008, Sutton and Ditton 894 2005) in multi-species fisheries. Furthermore, stocking strategies that work locally may not be 895 the best regional solution (Askey et al. 2013, Varkey et al. 2016), and managers must figure out 896 how to allocate limited stocking resources optimally within the landscape (Cowley et al. 2003). 897 Hence, our work should be extended to broader spatial scales to investigate the optimal policy 898 mixes in a landscape of diverse fisheries and diverse angler populations.

900 One of the key findings from our study and related work (e.g., Askey et al. 2013, Camp et al.

9012017 , Garlock et al. 2017) is that the stocking strategies considered to be the most successful will 902 strongly depend on ecological processes of the managed species and the performance measure 903 used to judge management success. We found that the presence or absence of natural 904 reproduction, and the strength of size- and density-dependent processes regulating the 905 population, were key for determining whether stocking can produce additive effects and elevate 906 fishing quality or not. However, we also found that a move away from mere biological objectives 907 (increased abundance), to social (increased angler satisfaction) or economic objectives (return on 
908 investment) can result in different conclusions about the most appropriate management strategy.

909 For self-sustaining populations, from both conservation and economic perspectives, stocking is

910 rarely beneficial, while it is necessary for culture-based fisheries.

911 A strength of our study was the ability to evaluate the outcomes of various management tools

912 and strategies not only from a biological perspective, but also in terms of social benefits and

913 economic feasibility by using a conceptually rigorous cost-benefit analysis. For naturally

914 reproducing species, the additive effects promised by some forms of stocking do not necessarily

915 translate into an increase in angler well-being, and the practice is often economically inefficient.

916 In addition, stocking runs the strong risk of the pervasive replacement of wild fishes by stocked

917 ones (van Poorten et al. 2011), and potentially increases mortality of wild fish if fishing pressure

918 increases after stocking (Baer et al. 2007). By contrast, in non-reproducing species stocking has

919 additive effects, increases angler satisfaction, and when conducted properly is economically

920 advisable. These results highlight that a species' reproductive ecology in combination with

921 normative metrics creates important trade-offs. The key trade-off is generally between economic

922 efficiency and conservation concerns (Camp et al. 2017), which often results in opposing

923 recommendations about which is the "best" strategy. Yet, in some situations, for example

924 stocking fish into severely depleted populations, stocking can create a win-win for both

925 conservation and anglers' interests, particularly when local broodstock are used and stocking is a

926 temporary practice that is paired with habitat enhancement efforts. Similarly, using economic

927 objectives to inform stocking decisions may bring about lower stocking densities that minimize

928 conservation concerns (e.g. water quality and carp).

929 Our findings that stocking self-sustaining populations provided little benefit to angler welfare

930 and rarely produced a positive return on investment, despite increased abundance, are 
931 noteworthy because they contradict recommendations stemming from traditional metrics, such as

932 population density or catch rate, often used to evaluate management success. Our results also

933 challenge the common assumption that catch is the primary driver of angler utility and behavior,

934 and underscores early insights by Cole and Ward (1994) that managing according to angler

935 benefits is bound to lead to different results than managing fishing opportunities (i.e., catch or

936 supply). Our study demonstrates the usefulness of using a social-ecological modelling

937 framework, because only through an integrated model with a mechanistic description of behavior

938 could we uncover these insights. While some studies have linked angler behavior to catch-related

939 fishery quality (e.g., Rogers et al. 2010, Askey et al. 2013, Camp et al. 2014), our study differed

940 from these because angler behavior was explicitly determined by numerous catch and non-catch

941 related attributes and informed by the preferences of real anglers (Arlinghaus et al. 2014). A

942 further benefit of using an integrated bioeconomic modelling framework is it forces managers to

943 be transparent about their objectives and normative framework (Fenichel et al. 2013b). It is

944 ultimately the tight interplay of ecology and the human dimensions that will determine the 945 success of any management action.

\section{ACKNOWLEDGEMENTS}

947 Financial support for this study was provided by the German Ministry for Education and

948 Research (BMBF) through the Besatzfisch-Project funded in the Program for Social-Ecological

949 Research (grant no. 01UU0907, www.besatz-fisch.de). We thank Maja Schlüter and Daniel

950 Gwinn for contributions and discussions in an early phase of this project. We would also like to

951 thank the two reviewers for their positive comments that improved the clarity to the manuscript. 


\section{LITERATURE CITED}

Adamowicz, W. L. 1994. Habit formation and variety seeking in a discrete choice model of recreational demand. Journal of Agricultural and Resource Economics 19:19-31.

Allen, M. S., R. N. M. Ahrens, M. J. Hansen, and R. Arlinghaus. 2013. Dynamic angling effort influences the value of minimum-length limits to prevent recruitment overfishing. Fisheries Management and Ecology 20:247-257.

Amoroso, R. O., M. D. Tillotson, and R. Hilborn. 2017. Measuring the net biological impact of fisheries enhancement: pink salmon hatcheries can increase yield, but with apparent costs to wild populations. Canadian Journal of Fisheries and Aquatic Sciences 74:1233-1242.

Araki, H., B. Cooper, and M. S. Blouin. 2007. Genetic effects of captive breeding cause a rapid, cumulative fitness decline in the wild. Science 318:100-103.

Arlinghaus, R. 2006. Overcoming human obstacles to conservation of recreational fishery resources, with emphasis on central Europe. Environmental Conservation 33:46-59.

Arlinghaus, R., J. Alós, B. Beardmore, K. Daedlow, M. Dorow, M. Fujitani, D. Hühn, W. Haider, L. M. Hunt, B. M. Johnson, F. Johnston, T. Klefoth, S. Matsumura, C. Monk, T. Pagel, J. R. Post, T. Rapp, C. Riepe, H. Ward, and C. Wolter. 2017. Understanding and managing freshwater recreational fisheries as complex adaptive social-ecological systems. Reviews in Fisheries Science \& Aquaculture 25:1-41.

Arlinghaus, R., B. Beardmore, C. Riepe, J. Meyerhoff, and T. Pagel. 2014. Species-specific preferences of German recreational anglers for freshwater fishing experiences, with emphasis on the intrinsic utilities of fish stocking and wild fishes. Journal of Fish Biology 85:1843-1867. 
975 Arlinghaus, R., E.-M. Cyrus, E. Eschbach, M. Fujitani, D. Hühn, F. Johnston, T. Pagel, C. Riepe, 976 and (eds.). 2015. Hand in Hand für eine nachhaltige Angelfi scherei: Ergebnisse und Empfehlungen aus fünf Jahren praxisorientierter Forschung zu Fischbesatz und seinen

Arlinghaus, R., K. Lorenzen, B. M. Johnson, S. J. Cooke, and I. G. Cowx. 2016. Management of 981 freshwater fisheries: addressing habitat, people and fishes. Pages 557-579 in J. F. Craig,

983

984 985 986 987 988 989 990 991 992 993 994 995 996 Alternativen. Berichte des IGB Vol. 28. Leibniz-Institute of Freshwater Ecology and Inland Fisheries, Berlin, Germany. editor. Freshwater Fisheries Ecology. John Wiley \& Sons, Ltd.

Arlinghaus, R., S. Matsumura, and U. Dieckmann. 2009. Quantifying selection differentials caused by recreational fishing: development of modeling framework and application to reproductive investment in pike (Esox lucius). Evolutionary Applications 2:335-355.

Arlinghaus, R., and T. Mehner. 2003a. Management preferences of urban anglers: habitat rehabilitation versus other options. Fisheries 28:10-17.

Arlinghaus, R., and T. Mehner. 2003b. Socio-economic characterisation of specialised common carp (Cyprinus carpio L.) anglers in Germany, and implications for inland fisheries management and eutrophication control. Fisheries Research 61:19-33.

Arlinghaus, R., and T. Mehner. 2004. A management-orientated comparative analysis of urban and rural anglers living in a metropolis (Berlin, Germany). Environmental Management 33:331-344.

Arlinghaus, R., T. Mehner, and I. G. Cowx. 2002. Reconciling traditional inland fisheries management and sustainability in industrialized countries, with emphasis on Europe. Fish and Fisheries 3:261-316. 
997 998

999

1000

1001

1002

1003

1004

1005

1006

1007

1008

1009

1010

1011

1012

1013

1014

1015

1016

1017

1018

Askey, P. A., S. A. Richards, and J. R. Post. 2006. Linking angling catch rates and fish learning under catch-and-release regulations. North American Journal of Fisheries Management 26:1020-1029.

Askey, P. J., E. A. Parkinson, and J. R. Post. 2013. Linking fish and angler dynamics to assess stocking strategies for hatchery-dependent, open-access recreational fisheries. North American Journal of Fisheries Management 33:557-568.

Baer, J., K. Blasel, and M. Diekmann. 2007. Benefits of repeated stocking with adult, hatcheryreared brown trout, Salmo trutta, to recreational fisheries? Fisheries Management and Ecology 14:51-59.

Baer, J., and A. Brinker. 2008. Are growth and recapture of hatchery-reared and resident brown trout (Salmo trutta L.) density dependent after stocking? Ecology of Freshwater Fish 17:455-464.

Bajer, P., and P. Sorensen. 2010. Recruitment and abundance of an invasive fish, the common carp, is driven by its propensity to invade and reproduce in basins that experience wintertime hypoxia in interconnected lakes. Biological Invasions 12:1101-1112.

Barthelmes, D., and U. Brämick. 2003. Variability of a cyprinid lake ecosystem with special emphasis on the native fish fauna under intensive fisheries management including common carp (Cyprinus carpio) and silver carp (Hypophthalmichthys molitrix). Limnologica - Ecology and Management of Inland Waters 33:10-28.

Beard, T. D., Jr., S. P. Cox, and S. R. Carpenter. 2003. Impacts of daily bag limit reductions on angler effort in Wisconsin walleye lakes. North American Journal of Fisheries Management 23:1283-1293. 
1019 Beardmore, B., L. M. Hunt, W. Haider, M. Dorow, and R. Arlinghaus. 2015. Effectively

1020

1021

1022

1023

1024

1025

1026

1027

1028

1029

1030

1031

1032

1033

1034

1035

1036

1037

1038

1039

1040

1041

managing angler satisfaction in recreational fisheries requires understanding the fish species and the anglers. Canadian Journal of Fisheries and Aquatic Sciences 72:500-513.

Biro, P. A., and J. R. Post. 2008. Rapid depletion of genotypes with fast growth and bold personality traits from harvested fish populations. Proceedings of the National Academy of Sciences 105:2919-2922.

Brown, P., and T. I. Walker. 2004. CARPSIM: stochastic simulation modelling of wild carp (Cyprinus carpio L.) population dynamics, with applications to pest control. Ecological Modelling 176:83-97.

Camp, E. V., R. N. M. Ahrens, M. S. Allen, and K. Lorenzen. 2016. Relationships between angling effort and fish abundance in recreational marine fisheries. Fisheries Management and Ecology 23:264-275.

Camp, E. V., S. L. Larkin, R. N. M. Ahrens, and K. Lorenzen. 2017. Trade-offs between socioeconomic and conservation management objectives in stock enhancement of marine recreational fisheries. Fisheries Research 186, Part 2:446-459.

Camp, E. V., K. Lorenzen, R. N. M. Ahrens, and M. S. Allen. 2014. Stock enhancement to address multiple recreational fisheries objectives: an integrated model applied to red drum Sciaenops ocellatus in Florida. Journal of Fish Biology 85:1868-1889.

Carpenter, S. R., A. Muñoz-del-Rio, S. Newman, P. W. Rasmussen, and B. M. Johnson. 1994. Interactions of anglers and walleyes in Escanaba Lake, Wisconsin. Ecological Applications 4:822-832.

Casselman, J. M., and C. A. Lewis. 1996. Habitat requirements of northern pike (Essox lucius). Canadian Journal of Fisheries and Aquatic Sciences 53:161-174. 
1042 Chilcote, M. W., K. W. Goodson, and M. R. Falcy. 2011. Reduced recruitment performance in 1043 natural populations of anadromous salmonids associated with hatchery-reared fish. Canadian Journal of Fisheries and Aquatic Sciences 68:511-522.

1045 1046

1047 1048 1049 1050 1051 1052 1053 1054 1055 1056 1057 1058 1059 1060 1061 1062 1063 1064 Cowx, I. G. 1994. Stocking strategies. Fisheries Management and Ecology 1:15-30. 
1065 Cox, S. P., C. J. Walters, and J. R. Post. 2003. A model-based evaluation of active management 1066 of recreational fishing effort. North American Journal of Fisheries Management 23:12941302.

1068

1069

1070

1071

1072

1073

1074

1075

1076

1077

1078

1079

1080

1081

1082

1083

1084

1085

1086

Dabrowska, K., W. Haider, and L. Hunt. 2014. Examining the impact of fisheries resources and quality on licence sales. Journal of Outdoor Recreation and Tourism 5-6:58-67.

Daedlow, K., T. D. Beard Jr, and R. Arlinghaus. 2011. A property rights-based view on management of inland recreational fisheries: contrasting common and public fishing rights regimes in Germany and the U.S.A. Pages 13-38 in T. D. Beard Jr, R. Arlinghaus, and S. Sutton, editors. Proceedings of the 5th World Recreational Fishing Conference, American Fisheries Society Symposium 75. American Fisheries Society, Bethesda.

Diana, M. J., and D. H. Wahl. 2009. Growth and Survival of Four Sizes of Stocked Largemouth Bass. North American Journal of Fisheries Management 29:1653-1663.

Dorow, M., and R. Arlinghaus. 2012. The relationship between personal commitment to angling and the opinions and attitudes of German anglers towards the conservation and management of the European eel Anguilla anguilla. North American Journal of Fisheries Management 32:466-479.

Dorow, M., B. Beardmore, W. Haider, and R. Arlinghaus. 2009. Using a novel survey technique to predict fisheries stakeholders' support for European eel (Anguilla anguilla L.) conservation programs. Biological Conservation 142:2973-2982.

Dorow, M., B. Beardmore, W. Haider, and R. Arlinghaus. 2010. Winners and losers of conservation policies for European eel, Anguilla anguilla: an economic welfare analysis for differently specialised eel anglers. Fisheries Management and Ecology 17:106-125. 
1087 Dudgeon, D., A. H. Arthington, M. O. Gessner, Z.-I. Kawabata, D. J. Knowler, C. Lévêque, R. J.

1088

1089

1090

1091

1092

1093

1094

1095

1096

1097

1098

1099

1100

1101

1102

1103

1104

1105

1106

1107

1108

1109

Naiman, A.-H. Prieur-Richard, D. Soto, M. L. J. Stiassny, and C. A. Sullivan. 2006.

Freshwater biodiversity: importance, threats, status and conservation challenges. Biological Reviews 81:163-182.

Edeline, E., T. B. Ari, L. A. Vøllestad, I. J. Winfield, J. M. Fletcher, J. B. James, and N. C. Stenseth. 2008. Antagonistic selection from predators and pathogens alters food-web structure. Proceedings of the National Academy of Sciences 105:19792-19796.

Edwards, S. F. 1991. A critique of three "economics" arguments commonly used to influence fishery allocations. North American Journal of Fisheries Management 11:121-130.

FAO. 2012. (Food and Agricultural Organization of the United Nations). FAO Technical Guidelines for Responsible Fisheries: Recreational Fisheries. No. 13. FAO, Rome. 176 pp.

Fayram, A. H., M. J. Hansen, and T. J. Ehlinger. 2006. Influence of walleye stocking on angler effort in Wisconsin. Human Dimensions of Wildlife 11:129-141.

Fayram, A. H., M. J. Hansen, and N. A. Nate. 2005. Determining optimal stocking rates using a stock-recruitment model: An example using walleye in Northern Wisconsin. North American Journal of Fisheries Management 25:1215-1225.

Fenichel, E. P., J. K. Abbott, and B. Huang. 2013a. Modelling angler behaviour as a part of the management system: synthesizing a multi-disciplinary literature. Fish and Fisheries 14:137-157.

Fenichel, E. P., B. Gentner, and R. Arlinghaus. 2013b. Normative considerations for recreational fishery management: a bioeconomic framework for linking positive science and normative fisheries policy decisions. Fisheries Management and Ecology 20:223-233. 
1110 Finn, K. L., and D. K. Loomis. 2001. The importance of catch motives to recreational anglers: the effects of catch satiation and deprivation. Human Dimensions of Wildlife 6:173-187.

1112 Fujitani, M., A. McFall, C. Randler, and R. Arlinghaus. 2017. Participatory adaptive management leads to environmental learning outcomes extending beyond the sphere of science. Science Advances 3.

1115 Garlock, T. M., E. V. Camp, and K. Lorenzen. 2017. Using fisheries modeling to assess candidate species for marine fisheries enhancement. Fisheries Research 186, Part 2:460467.

Garlock, T. M., and K. Lorenzen. 2017. Marine angler characteristics and attitudes toward stock

Gentner, B., and S. Sutton. 2008. Substitution in recreational fishing. Pages 150-169 in Ø. Aas, editor. Global Challenges in Recreational Fisheries. Blackwell Publishing Ltd.

Guillerault, N., D. Hühn, J. Cucherousset, R. Arlinghaus, and C. Skov. 2018. Stocking for pike population enhancement.in C. Skov and A. Nilsson, editors. Biology and Ecology of Pike. CRC Press, Boca Raton.

Gwinn, D. C., M. S. Allen, F. D. Johnston, P. Brown, C. R. Todd, and R. Arlinghaus. 2015. Rethinking length-based fisheries regulations: the value of protecting old and large fish with harvest slots. Fish and Fisheries 16:259-281.

Haglund, J. M., D. A. Isermann, and G. G. Sass. 2016. Walleye population and fishery responses

1131 Halverson, M. A. 2008. Stocking trends: a quantitative review of governmental fish stocking in the United States, 1931 to 2004. Fisheries 33:69-75. 
1133 Hazlerigg, C. R. E., K. Lorenzen, P. Thorbek, J. R. Wheeler, and C. R. Tyler. 2012. Density-

1134

1135

1136

1137

1138

1139

1140

1141

1142

1143

1144

1145

1146

1147

1148

1149

1150

1151

1152

1153

1154 dependent processes in the life history of fishes: evidence from laboratory populations of zebrafish Danio rerio. PLoS ONE 7:e37550.

Hühn, D., K. Lübke, C. Skov, and R. Arlinghaus. 2014. Natural recruitment, density-dependent juvenile survival, and the potential for additive effects of stock enhancement: an experimental evaluation of stocking northern pike (Esox lucius) fry. Canadian Journal of Fisheries and Aquatic Sciences 71:1508-1519.

Hunt, L. M., R. Arlinghaus, N. Lester, and R. Kushneriuk. 2011. The effects of regional angling effort, angler behavior, and harvesting efficiency on landscape patterns of overfishing. Ecological Applications 21:2555-2575.

Hunt, L. M., A. E. Bannister, D. A. R. Drake, S. A. Fera, and T. B. Johnson. 2017. Do fish drive recreational fishing license sales? North American Journal of Fisheries Management 37:122-132.

Hunt, L. M., B. N. Boots, and P. C. Boxall. 2007. Predicting fishing participation and site choice while accounting for spatial substitution, trip timing, and trip context. North American Journal of Fisheries Management 27:832-847.

Hunt, T. L., K. Giri, P. Brown, B. A. Ingram, P. L. Jones, L. J. B. Laurenson, and A. M. Wallis. 2014. Consequences of fish stocking density in a recreational fishery. Canadian Journal of Fisheries and Aquatic Sciences 71:1554-1560.

Hyman, A. A., S. L. McMullin, and V. DiCenzo. 2016. Dispelling assumptions about stockedtrout fisheries and angler satisfaction. North American Journal of Fisheries Management 36:1395-1404. 
1155 Johnston, F. D., R. Arlinghaus, and U. Dieckmann. 2010. Diversity and complexity of angler 1156 behaviour drive socially optimal input and output regulations in a bioeconomic 1157 recreational-fisheries model. Canadian Journal of Fisheries and Aquatic Sciences $1158 \quad 67: 1507-1531$.

1159 Johnston, F. D., R. Arlinghaus, and U. Dieckmann. 2013. Fish life history, angler behaviour and 1160 optimal management of recreational fisheries. Fish and Fisheries 14:554-579.

1161 Johnston, F. D., R. Arlinghaus, J. Stelfox, and J. R. Post. 2011. Decline in angler use despite 1162 increased catch rates: anglers' response to the implementation of a total catch-and-release 1163 regulation. Fisheries Research 110:189-197.

1164 Johnston, F. D., B. Beardmore, and R. Arlinghaus. 2015. Optimal management of recreational 1165 fisheries in the presence of hooking mortality and noncompliance — predictions from a 1166 bioeconomic model incorporating a mechanistic model of angler behavior. Canadian 1167 Journal of Fisheries and Aquatic Sciences 72:37-53.

1168 Klefoth, T., T. Pieterek, and R. Arlinghaus. 2013. Impacts of domestication on angling 1169 vulnerability of common carp, Cyprinus carpio: the role of learning, foraging behaviour 1170 and food preferences. Fisheries Management and Ecology 20:174-186.

1171 Klefoth, T., C. Skov, J. Krause, and R. Arlinghaus. 2012. The role of ecological context and predation risk-stimuli in revealing the true picture about the genetic basis of boldness evolution in fish. Behavioral Ecology and Sociobiology 66:547-559.

1174 Koehn, J., A. Brumley, and P. Gehrke. 2000. Managing the impacts of carp. Bureau of Rural 1175 Sciences, Department of Agriculture, Fisheries and Forestry, Canberra, Australia. 
1176 Koenig, M. K., J. R. Kozfkay, K. A. Meyer, and D. J. Schill. 2011. Performance of diploid and 1177 triploid rainbow trout stocked in Idaho alpine lakes. North American Journal of Fisheries $1178 \quad$ Management 31:124-133.

1179 Kottelat, M., and J. Freyhof. 2007. Handbook of European Freshwater Fishes. Kottelat, Cornol, 1180 Switzerland and Freyhof, Berlin, Germany.

Laikre, L., M. K. Schwartz, R. S. Waples, and N. Ryman. 2010. Compromising genetic diversity in the wild: unmonitored large-scale release of plants and animals. Trends in Ecology \& Evolution 25:520-529.

Leber, K. M., R. N. Cantrell, and P. S. Leung. 2005. Optimizing cost-effectiveness of size at release in stock enhancement programs. North American Journal of Fisheries Management 25:1596-1608.

Lester, N. P., T. R. Marshall, K. Armstrong, W. I. Dunlop, and B. Ritchie. 2003. A broad scale 1188 approach to management of Ontario's recreational fisheries. North American Journal of Fisheries Management 23:1312-1328.

Lester, N. P., B. J. Shuter, and P. A. Abrams. 2004. Interpreting the von Bertalanffy model of somatic growth in fishes: the cost of reproduction. Proceedings of the Royal Society of London. Series B: Biological Sciences 271:1625-1631.

1193 Lewin, W. C., R. Arlinghaus, and T. Mehner. 2006. Documented and potential biological 1194 impacts of recreational fishing: insights for management and conservation. Reviews in Fisheries Science 14:305-367.

Li, J., Y. Cohen, D. H. Schupp, and I. R. Adelman. 1996. Effects of walleye stocking on population abundance and fish size. North American Journal of Fisheries Management 16:830-839. 
1199 Loomis, J., and P. Fix. 1999. A statistical approach to estimating costs of propagating hatchery

1200 rainbow trout. North American Journal of Fisheries Management 19:110-119.

1201 Lorenzen, K. 1995. Population dynamics and management of culture-based fisheries. Fisheries

$1202 \quad$ Management and Ecology 2:61-73.

1203 Lorenzen, K. 1996. The relationship between body weight and natural mortality in juvenile and 1204 adult fish: a comparison of natural ecosystems and aquaculture. Journal of Fish Biology $1205 \quad 49: 627-642$.

1206 Lorenzen, K. 2000. Allometry of natural mortality as a basis for assessing optimal release size in 1207 fish-stocking programmes. Canadian Journal of Fisheries and Aquatic Sciences 57:2374$1208 \quad 2381$.

1209 Lorenzen, K. 2005. Population dynamics and potential of fisheries stock enhancement: practical 1210 theory for assessment and policy analysis. Philosophical Transactions of the Royal 1211 Society B: Biological Sciences 360:171-189.

1212 Lorenzen, K. 2006. Population management in fisheries enhancement: Gaining key information 1213 from release experiments through use of a size-dependent mortality model. Fisheries $1214 \quad$ Research 80:19-27.

1215 Lorenzen, K. 2014. Understanding and managing enhancements: why fisheries scientists should $1216 \quad$ care. Journal of Fish Biology 85:1807-1829.

1217 Lorenzen, K., M. C. M. Beveridge, and M. Mangel. 2012. Cultured fish: integrative biology and 1218 1219 management of domestication and interactions with wild fish. Biological Reviews 87:639-660.

1220 Margenau, T., S. AveLallemant, D. Giehtbrock, and S. Schram. 2008. Ecology and management 1221 of northern pike in Wisconsin. Hydrobiologia 601:111-123. 
1222 Matsumura, S., B. Beardmore, W. Haider, U. Dieckmann, and R. Arlinghaus. 2017. Ecological,

1223

1224

1225

1226

1227

1228

1229

1230

1231

1232

1233

1234

1235

1236

1237

1238

1239

1240

1241

1242

1243

angler and spatial heterogeneity drive social and ecological outcomes in an integrated landscape model of freshwater recreational fisheries. bioRxiv.

Matsuzaki, S.-i., N. Usio, N. Takamura, and I. Washitani. 2009. Contrasting impacts of invasive engineers on freshwater ecosystems: an experiment and meta-analysis. Oecologia 158:673-686.

Mee, J. A., J. R. Post, H. Ward, K. L. Wilson, E. Newton, and A. Cantin. 2016. Interaction of ecological and angler processes: experimental stocking in an open access, spatially structured fishery. Ecological Applications 26:1693-1707.

Mehner, T., R. Arlinghaus, S. Berg, H. Dörner, L. Jacobsen, P. Kasprzak, R. Koschel, T. Schulze, C. Skov, C. Wolter, and K. Wysujack. 2004. How to link biomanipulation and sustainable fisheries management: a step-by-step guideline for lakes of the European temperate zone. Fisheries Management and Ecology 11:261-275.

Meyer, K. A., B. High, and F. S. Elle. 2012. Effects of stocking catchable-sized hatchery rainbow trout on wild rainbow trout abundance, survival, growth, and recruitment. Transactions of the American Fisheries Society 141:224-237.

Mezzera, M., and C. R. Largiadèr. 2001. Evidence for selective angling of introduced trout and their hybrids in a stocked brown trout population. Journal of Fish Biology 59:287-301.

Patterson, W. F., and M. G. Sullivan. 2013. Testing and refining the assumptions of put-and-take rainbow trout fisheries in Alberta. Human Dimensions of Wildlife 18:340-354.

Paukert, C. P., J. A. Klammer, R. B. Pierce, and T. D. Simonson. 2001. An overview of northern pike regulations in North America. Fisheries 26:6-13. 
1244 Post, J. R., C. Mushens, A. Paul, and M. Sullivan. 2003. Assessment of alternative harvest

1245

1246

1247

1248

1249

1250

1251

1252

1253

1254

1255

1256

1257

1258

1259

1260

1261

1262

1263

1264

1265

1266

regulations for sustaining recreational fisheries: model development and application to bull trout. North American Journal of Fisheries Management 23:22-34.

Post, J. R., and E. A. Parkinson. 2012. Temporal and spatial patterns of angler effort across lake districts and policy options to sustain recreational fisheries. Canadian Journal of Fisheries and Aquatic Sciences 69:321-329.

Post, J. R., M. Sullivan, S. Cox, N. P. Lester, C. J. Walters, E. A. Parkinson, A. J. Paul, L. Jackson, and B. J. Shuter. 2002. Canada's recreational fisheries: the invisible collapse? Fisheries 27:6-17.

Radomski, P. J., G. C. Grant, P. C. Jacobson, and M. F. Cook. 2001. Visions for recreational fishing regulations. Fisheries 26:7-18.

Riepe, C., M. Fujitani, J. Cucherousset, T. Pagel, M. Buoro, F. Santoul, R. Lassus, and R. Arlinghaus. 2017. What determines the behavioral intention of local-level fisheries managers to alter fish stocking practices in freshwater recreational fisheries of two European countries? Fisheries Research 2017.

Rogers, M. W., M. S. Allen, P. Brown, T. Hunt, W. Fulton, and B. A. Ingram. 2010. A simulation model to explore the relative value of stock enhancement versus harvest regulations for fishery sustainability. Ecological Modelling 221:919-926.

Santucci Jr, V. J., and D. H. Wahl. 1993. Factors influencing survival and growth of stocked walleye (Stizostedion vitreum) in a centrarchid-dominated impoundment. Canadian Journal of Fisheries and Aquatic Sciences 50:1548-1558.

Sass, G. G., A. L. Rypel, and J. D. Stafford. 2017. Inland fisheries habitat management: lessons learned from wildlife ecology and a proposal for change. Fisheries 42:197-209. 
1267 Skov, C., A. Koed, L. Baastrup-Spohr, and R. Arlinghaus. 2011. Dispersal, growth, and diet of

1268

1269

1270

1271

1272

1273

1274

1275

1276

1277

1278

1279

1280

1281

1282

1283

1284

1285

1286

1287

1288 stocked and wild northern pike fry in a shallow natural lake, with implications for the management of stocking programs. North American Journal of Fisheries Management 31:1177-1186.

Sullivan, M. G. 2002. Illegal angling harvest of walleyes protected by length limits in Alberta. North American Journal of Fisheries Management 22:1053-1063.

Sutton, S. G., and R. B. Ditton. 2005. The substitutability of one type of fishing for another. North American Journal of Fisheries Management 25:536-546.

Thériault, V., G. R. Moyer, L. S. Jackson, M. S. Blouin, and M. A. Banks. 2011. Reduced reproductive success of hatchery coho salmon in the wild: insights into most likely mechanisms. Molecular Ecology 20:1860-1869.

Tufts, B. L., J. Holden, and M. DeMille. 2015. Benefits arising from sustainable use of North America's fishery resources: economic and conservation impacts of recreational angling. International Journal of Environmental Studies 72:850-868.

van Poorten, B. T., R. Arlinghaus, K. Daedlow, and S. S. Haertel-Borer. 2011. Social-ecological interactions, management panaceas, and the future of wild fish populations. Proceedings of the National Academy of Sciences.

van Poorten, B. T., and J. R. Post. 2005. Seasonal fishery dynamics of a previously unexploited rainbow trout population with contrasts to established fisheries. North American Journal of Fisheries Management 25:329-345.

Varkey, D. A., M. K. McAllister, P. J. Askey, E. Parkinson, A. Clarke, and T. Godin. 2016. Multi-criteria decision analysis for recreational trout fisheries in British Columbia, 

Canada: A Bayesian network implementation. North American Journal of Fisheries Management 36:1457-1472.

1291

1292

1293

1294

1295

1296

1297

1298

1299

1300

1301

1302

1303

1304

1305

1306

1307

1308

1309

1310
Vilizzi, L., A. S. Tarkan, and G. H. Copp. 2015. Experimental evidence from causal criteria analysis for the effects of common carp Cyprinus carpio on freshwater ecosystems: a global perspective. Reviews in Fisheries Science \& Aquaculture 23:253-290.

Walters, C. J., and S. J. D. Martell. 2004. Fisheries Ecology and Management. Princeton University Press, Princeton, NJ, USA.

Ward, H. G. M., P. J. Askey, and J. R. Post. 2013. A mechanistic understanding of hyperstability in catch per unit effort and density-dependent catchability in a multistock recreational fishery. Canadian Journal of Fisheries and Aquatic Sciences 70:1542-1550.

Weber, M. J., and M. L. Brown. 2009. Effects of common carp on aquatic ecosystems 80 years after "carp as a dominant": ecological insights for fisheries management. Reviews in Fisheries Science 17:524-537.

Wedekind, H., V. Hilge, and W. Steffens. 2001. Present status, and social and economic significance of inland fisheries in Germany. Fisheries Management and Ecology 8:405414.

Wiley, R. W., R. A. Whaley, J. B. Satake, and M. Fowden. 1993. Assessment of stocking hatchery trout: a Wyoming perspective. North American Journal of Fisheries Management 13:160-170.

Yule, D. L., R. A. Whaley, P. H. Mavrakis, D. D. Miller, and S. A. Flickinger. 2000. Use of strain, season of stocking, and size at stocking to improve fisheries for rainbow trout in reservoirs with walleyes. North American Journal of Fisheries Management 20:10-18. 
1311 Ziegler, J. P., E. J. Golebie, S. E. Jones, B. C. Weidel, and C. T. Solomon. 2017. Social-

1312 ecological outcomes in recreational fisheries: the interaction of lakeshore development

1313 and stocking. Ecological Applications 27:56-65.

1314

1315 
1317 Table 1. Bioeconomic model equations. Parameter values and their sources for northern pike

1318 (Esox lucius) and common carp (Cyprinus carpio) are listed in Appendix S1: Table S1.

1319 Derivations of some of the equations can be found in Appendix S1. PWU = part-worth utility.

\begin{tabular}{|c|c|c|}
\hline & Equation & Description \\
\hline & Age-structured fish population & \\
\hline & $N_{a g}$ & $\begin{array}{l}\text { Density of fish within age class } a \text { and } \\
\text { growth trajectory }\end{array}$ \\
\hline & $L_{a g}$ & $\begin{array}{l}\text { Length of fish within age class } a \text { and } \\
\text { growth trajectory } g\end{array}$ \\
\hline $1 \mathrm{a}$ & $N_{\text {total }}=\sum_{a} \sum_{g} N_{a g}$ & Total fish population density \\
\hline $1 b$ & $B_{\text {total }}=\sum_{a} \sum_{g} N_{a g} W_{a g}$ & Total fish biomass density \\
\hline \multirow[t]{2}{*}{$1 \mathrm{c}$} & $D_{L^{2}}=\sum_{a} \sum_{g} N_{a g} L_{a g}^{2}$ & Total effective density \\
\hline & Growth & \\
\hline $2 \mathrm{a}$ & $L_{a g, t+1}=L_{a g, t}+h_{g, t} p_{a g}$ & $\begin{array}{l}\text { Length of fish within age class } a \text { and } \\
\text { growth trajectory } g \text { at time } t+1\end{array}$ \\
\hline $2 \mathrm{~b}$ & $h_{g, t}=h_{\max } \sigma_{L g} /\left[1+B_{\text {total }, t} / B_{1 / 2}\right]$ & $\begin{array}{l}\text { Maximum annual growth of a fish within } \\
\text { growth trajectory } g \text {, which was dependent } \\
\text { on the total fish biomass density at the } \\
\text { beginning of the year }\end{array}$ \\
\hline $2 \mathrm{c}$ & $p_{a g}= \begin{cases}1-\frac{G}{3+G}\left(1+L_{a g} / h_{g}\right) & \text { if mature } \\
1 & \text { if immature }\end{cases}$ & $\begin{array}{l}\text { Proportion of the annual growth potential } \\
\text { which a fish of age } a \text { and growth } \\
\text { trajectory } g \text { allocates to growth }\end{array}$ \\
\hline \multirow[t]{2}{*}{$2 \mathrm{~d}$} & $W_{a g}=w L_{a g}^{l}$ & $\begin{array}{l}\text { Mass of a fish of age } a \text { and growth } \\
\text { trajectory } g\end{array}$ \\
\hline & Maturation and Reproduction & \\
\hline $3 a$ & $L_{\mathrm{mat}, a}=b_{1}+b_{2} a$ & $\begin{array}{l}\text { Threshold length a fish of age } a \text { must } \\
\text { achieve to mature }\left(L_{a g}>L_{\text {mat }, a}=\text { mature }\right)\end{array}$ \\
\hline
\end{tabular}




\begin{tabular}{|c|c|c|}
\hline $3 b$ & $\begin{array}{l}N_{0_{\mathrm{W}, t}}=\Phi \delta \sum_{a=a_{\operatorname{mat}}}^{a_{\max }} \sum_{g} \omega W_{a g_{\mathrm{W}}, t} N_{a g_{\mathrm{W}}, t}, \\
N_{0_{\mathrm{H}}, t}=\Phi \delta \rho \sum_{a=a_{\operatorname{mat}}}^{a_{\max }} \sum_{g} \omega W_{a g_{\mathrm{H}}, t} N_{a g_{\mathrm{H}}, t}\end{array}$ & $\begin{array}{l}\text { Density of wild }\left(N_{0_{\mathrm{W}}}\right) \text { and hatchery }\left(N_{\mathrm{O}_{\mathrm{H}}}\right. \\
\text { ) origin larvae produced by spawners at } \\
\text { time } t \text {. NOTE: } N_{0_{\mathrm{W}}} \text { and } N_{0_{\mathrm{H}}} \text { were } \\
\text { assumed to be zero when modelling carp. }\end{array}$ \\
\hline & Mortality age-0 pre-stocking & \\
\hline $4 a$ & $s_{1, t}=\alpha_{1} \mathrm{e}^{-\beta_{1}\left(N_{0_{\mathrm{W}}, t}+N_{\left.0_{\mathrm{H}}, t\right)}\right.}$ & $\begin{array}{l}\text { Survival of fish during the pre-stocking } \\
\text { phase at time } t\end{array}$ \\
\hline $4 \mathrm{~b}$ & $\alpha_{1}=\left(\frac{L_{0}}{L_{s}}\right)^{\frac{M_{1}^{*}}{h_{\max }}}$ & $\begin{array}{l}\text { Maximum survival rate of larvae during } \\
\text { the pre-stocking phase (see Appendix S1 } \\
\text { for derivation) }\end{array}$ \\
\hline $4 \mathrm{c}$ & $\beta_{1}=\frac{\ln \frac{L_{0}}{L_{s}}}{\ln \frac{L_{0}}{L_{\mathrm{rec}}}} \beta$ & $\begin{array}{l}\text { Strength of the density-dependence during } \\
\text { the pre-stocking phase (see Appendix S1 } \\
\text { for derivation) }\end{array}$ \\
\hline $4 \mathrm{~d}$ & $M_{1}^{*}=h_{\max } \frac{\ln \alpha}{\ln \frac{L_{0}}{L_{\mathrm{rec}}}}$ & $\begin{array}{l}\text { natural mortality rate of an age- } 0 \text { fish of } \\
1 \mathrm{~cm} \text { at zero density }\end{array}$ \\
\hline $4 \mathrm{e}$ & $L_{\mathrm{rec}}=L_{0}+h_{\max }$ & Maximum average length at recruitment \\
\hline $4 \mathrm{f}$ & $\begin{array}{l}J_{0_{\mathrm{w}}, t}=s_{1, t}\left(N_{0_{\mathrm{w}}, t}+h^{2} N_{0_{\mathrm{H}}, t}\right) \\
J_{0_{\mathrm{H}}, t}=s_{1, t} \gamma\left(1-h^{2}\right) N_{0_{\mathrm{H}}, t}\end{array}$ & $\begin{array}{l}\text { Density of age- } 0 \text { wild } J_{0_{\mathrm{w}}, t} \text { and hatchery } \\
J_{0_{\mathrm{H}}, t} \text { origin fish surviving the pre-stocking } \\
\text { phase at time } t\end{array}$ \\
\hline & Mortality age-0 post-stocking & \\
\hline $5 \mathrm{a}$ & $s_{2, t}=\alpha_{2} \mathrm{e}^{-\beta_{2}\left(J_{\mathrm{w}_{\mathrm{W}}, t}+J_{\mathrm{H}_{\mathrm{H}}, t}+J_{0, t}\right)}$ & $\begin{array}{l}\text { Survival of fish during the pre-stocking } \\
\text { phase at time } t\end{array}$ \\
\hline $5 b$ & $\alpha_{2}=\frac{\alpha}{\alpha_{1}}$ & $\begin{array}{l}\text { Maximum survival rate of larvae during } \\
\text { the post-stocking phase (see Appendix S1 } \\
\text { for derivation) }\end{array}$ \\
\hline $5 \mathrm{c}$ & $\beta_{2}=\frac{\beta-\beta_{1}}{\alpha_{1} e^{-\beta_{1}\left(N_{O_{\mathrm{W}}, t}+N_{O_{\mathrm{H}}, t}\right)}}$ & $\begin{array}{l}\text { Strength of the density-dependence during } \\
\text { the post-stocking phase (see Appendix S1 } \\
\text { for derivation) }\end{array}$ \\
\hline $5 \mathrm{~d}$ & $\begin{array}{l}N_{1 g_{\mathrm{w}}, t+1}=s_{2, t} \sigma_{N g} J_{0_{\mathrm{w}}, t} \\
N_{1 g_{\mathrm{H}}, t+1}=s_{2, t} \gamma \sigma_{N g}\left(J_{0_{\mathrm{H}}, t}+J_{0_{\mathrm{s}}, t}\right)\end{array}$ & $\begin{array}{l}\text { Density of wild } N_{1 g_{\mathrm{W}}, t+1} \text { and hatchery } \\
N_{1 g_{\mathrm{H}}, t+1} \text { origin fish of age } a=1 \text { and } \\
\text { growth trajectory } g \text { at time } t+1\end{array}$ \\
\hline & Stocking and Mortality age-1 and older fish & \\
\hline $6 \mathrm{a}$ & $N_{a g_{\mathrm{H}}, t}=\left\{\begin{array}{cl}N_{a g_{\mathrm{H}}, t}+\sigma_{N g} N_{\mathrm{S}, t} & \text { if } a=a_{\mathrm{S}} \\
N_{a g_{\mathrm{H}}, t} & \text { if } a \neq a_{\mathrm{S}}\end{array}\right.$ & $\begin{array}{l}\text { Density of hatchery origin fish after } \\
\text { recruited fish were stocked }\end{array}$ \\
\hline
\end{tabular}




\begin{tabular}{|c|c|c|}
\hline $6 \mathrm{~b}$ & $M_{a g, t}=M_{r, L_{\max }}\left(\frac{L_{a g, t}}{L_{\max }}\right)^{c_{t}}$ & $\begin{array}{l}\text { Instantaneous natural mortality rate of a } \\
\text { fish of length } L_{a g} \text { at time } t\end{array}$ \\
\hline $6 \mathrm{c}$ & $M_{r, L_{\max }}=\frac{h_{\max }}{L_{\max }}$ & $\begin{array}{l}\text { Reference instantaneous natural mortality } \\
\text { rate at length } L_{\max }\end{array}$ \\
\hline $6 \mathrm{~d}$ & $c_{t}=\frac{\ln \left[1+(1-\Upsilon) D_{\mathrm{rel}, t}\right]}{\ln \left(M_{r, L_{\max }}\right)}-1$ & $\begin{array}{l}\text { Allometric exponent of size-dependent } \\
\text { mortality relationship at time } t\end{array}$ \\
\hline $6 e$ & $D_{\text {rel }, t}=\frac{D_{L^{2}}-D_{\text {Equilib }}}{D_{\text {Equilib }}}$ & Relative effective density at time $t$ \\
\hline $6 f$ & $v_{a g, t}=\frac{1}{1+\exp \left(-y\left(L_{a g, t}-L_{50}\right)\right)}$ & $\begin{array}{l}\text { Proportion of fish of age } a \text { and growth } \\
\text { trajectory } g \text { vulnerable to capture by } \\
\text { anglers at time } t\end{array}$ \\
\hline $6 g$ & $L_{50}=z L_{\max }+L_{\text {shift }}$ & Size at $50 \%$ vulnerability to capture \\
\hline $6 \mathrm{~h}$ & $C_{a g, t}=q E_{t} v_{a g, t}$ & $\begin{array}{l}\text { Instantaneous catch rate of fish of age } a \\
\text { and growth trajectory } g \text { at time } t\end{array}$ \\
\hline $6 \mathrm{i}$ & $f_{\mathrm{H}, a g}= \begin{cases}1 & \text { if } L_{a g} \geq M L L \\
f_{\mathrm{n}} & \text { if } L_{a g}<M L L\end{cases}$ & $\begin{array}{l}\text { Proportion of captured fish of age } a \text { and } \\
\text { growth trajectory } g \text { harvested by anglers }\end{array}$ \\
\hline $6 j$ & $F_{a g, t}=f_{\mathrm{H}, a g} C_{a g, t}+f_{\mathrm{h}} C_{a g, t}\left(1-f_{\mathrm{H}, a g}\right)$ & $\begin{array}{l}\text { Instantaneous fishing mortality rate of fish } \\
\text { of age } a \text { and growth trajectory } g \text { at time } t\end{array}$ \\
\hline $6 \mathrm{k}$ & $\begin{array}{l}S_{a g_{\mathrm{W}}, t}=\mathrm{e}^{-\left(M_{a g, t}+F_{a g, t}\right)} \\
S_{a g_{\mathrm{H}}, t}=\mathrm{e}^{-\left(M_{a g, t} / \gamma_{2}+F_{a g, t}\right)}\end{array}$ & $\begin{array}{l}\text { Survival of wild } s_{a g_{\mathrm{w}}, t} \text { and hatchery } s_{a g_{\mathrm{H}}, t} \\
\text { origin fish of age } a \text { and growth trajectory } \\
g\end{array}$ \\
\hline 61 & $\begin{array}{l}N_{a+1, g_{\mathrm{W}}, t+1}=N_{a g_{\mathrm{W}}, t} s_{a g_{\mathrm{W}}, t} \\
N_{a+1, g_{\mathrm{H}}, t+1}=N_{a g_{\mathrm{H}}, t} s_{a g_{\mathrm{H}}, t}\end{array}$ & $\begin{array}{l}\text { Density of wild } N_{a+1, g_{\mathrm{W}}, t+1} \text { and hatchery } \\
N_{a+1, g_{\mathrm{H}}, t+1} \text { origin fish of age } a+1 \text { and } \\
\text { growth trajectory } g \text { at time } t+1\end{array}$ \\
\hline & Angler-effort dynamics & \\
\hline $7 \mathrm{a}$ & $\begin{array}{l}U_{\mathrm{f}}=U_{\mathrm{in}}+U_{\mathrm{Spp}}+U_{\mathrm{Cost}} \\
+U_{\overline{\mathrm{c}}_{\mathrm{D}}}+U_{\bar{l}}+U_{l_{\max }}+U_{\bar{A}_{\mathrm{D}}} \\
+U_{M L L}+U_{D B L}+U_{\mathrm{Stock}}+U_{\mathrm{Comp}}\end{array}$ & $\begin{array}{l}\text { Conditional indirect utility gained by an } \\
\text { angler from choosing to fish (where } U_{\text {in }} \\
\text { is the basic utility gained from fishing, } \\
U_{\text {Spp }} \text { is the PWU of preferred species, } \\
U_{\text {Cost }} \text { is the PWU of annual license cost, } \\
U_{\overline{\mathrm{c}}_{\mathrm{D}}} \text { is the PWU of average daily catch, } \\
U_{\bar{l}} \text { is the PWU of average size of fish } \\
\text { caught annually, } U_{l_{\max }} \text { is the PWU of } \\
\text { trophy catch rate, } U_{\bar{A}_{\mathrm{D}}} \text { is the PWU of } \\
\text { anglers seen, } U_{M S L} \text { is the PWU of }\end{array}$ \\
\hline
\end{tabular}




\begin{tabular}{|c|c|c|}
\hline & & $\begin{array}{l}\text { minimum-length limit } M L L, U_{D B L} \text { is the } \\
\text { PWU of daily bag limit } D B L, U_{\text {Stock }} \text { is } \\
\text { the PWU of stocking frequency, and } \\
U_{\text {Comp }} \text { is the PWU of catch composition). }\end{array}$ \\
\hline $7 b$ & $p_{\mathrm{f}, t}=\frac{\exp \left(\hat{U}_{\mathrm{f}}\right)}{\left[\exp \left(\hat{U}_{\mathrm{f}}\right)+\exp \left(U_{\text {out }}\right)+\exp \left(U_{\mathrm{no}}\right)\right]}$ & $\begin{array}{l}\text { Probability an angler chooses to fish, over } \\
\text { the alternatives of not fishing or fishing } \\
\text { elsewhere (where } \hat{U}_{\mathrm{f}} \text { applies to the } \\
\text { previous year, } U_{\text {no }} \text { is the utility gained } \\
\text { from not fishing, and } U_{\text {out }} \text { is the utility } \\
\text { gained from fishing elsewhere) }\end{array}$ \\
\hline $7 \mathrm{c}$ & $p_{\mathrm{F}, t}=(1-\varphi) p_{\mathrm{f}, t}+\varphi \hat{p}_{\mathrm{F}}$ & $\begin{array}{l}\text { Realized probability an angler of type } j \\
\text { fishes (where } \hat{p}_{\mathrm{F} j} \text { applies to the previous } \\
\text { year) }\end{array}$ \\
\hline $7 d$ & $E_{t}=p_{\mathrm{F}, t} d_{\max } A_{\mathrm{L}} \Psi$ & $\begin{array}{l}\text { Total annual realized fishing effort density } \\
\text { at time } t\end{array}$ \\
\hline & Response variables & \\
\hline $8 \mathrm{a}$ & $W T P=\frac{U_{\text {base }}-U_{\text {scenario }}}{u_{1}}$ & Willingness to pay \\
\hline $8 \mathrm{~b}$ & $W=A_{L} W T P$ & Aggregated social welfare \\
\hline $8 \mathrm{c}$ & $N B=W-€_{\mathrm{s}}$ & Net economic benefit \\
\hline $8 \mathrm{~d}$ & $€_{\mathrm{S}}= \begin{cases}J_{0_{\mathrm{S}}} \theta L_{\mathrm{S}}^{\lambda} & a_{\mathrm{S}}=0 \\
N_{\mathrm{S}} \theta L_{\mathrm{S}}^{\lambda} & a_{\mathrm{S}}>0\end{cases}$ & Cost of stocking \\
\hline $8 \mathrm{e}$ & $€_{\mathrm{ind}}=\left\{\begin{array}{cc}€_{\mathrm{S}} / J_{0_{\mathrm{S}}, t} s_{2, t} \gamma \sum_{g} \prod_{a=1}^{2} \sigma_{N g} s_{a g_{\mathrm{H}}, t} & a_{\mathrm{S}}=0 \\
€_{\mathrm{S}} / N_{\mathrm{S}, t} \sum_{g} \prod_{a=a_{\mathrm{S}}}^{2} \sigma_{N g} s_{a g_{\mathrm{H}}, t} & a_{\mathrm{S}}>0\end{array}\right.$ & $\begin{array}{l}\text { Cost per stocked individual surviving } \\
\text { from the time of stocking until the end of } \\
\text { age } 2\end{array}$ \\
\hline & Part-worth-utility (PWU) functions & \\
\hline $9 \mathrm{a}$ & $U_{\mathrm{oj}}=u_{1} €_{\mathrm{L}}$ & PWU of annual license cost \\
\hline $9 \mathrm{~b}$ & $U_{\overline{\mathrm{c}}_{\mathrm{D}}}=u_{2} \log _{10} \bar{C}_{\mathrm{D}}$ & PWU of daily catch $\bar{C}_{\mathrm{D}}$ \\
\hline $9 \mathrm{c}$ & $U_{\bar{l}}=u_{3} \log _{10}\left(\frac{\bar{l}}{\bar{l}_{\text {ref }}}\right)$ & $\begin{array}{l}\text { PWU of average size of fish caught } \\
\text { annually } \bar{l}\end{array}$ \\
\hline $9 \mathrm{~d}$ & $U_{l_{\max }}=u_{4} l_{\max }$ & $\begin{array}{l}\text { PWU of the catch rate } l_{\max } \text { of trophy-sized } \\
\text { fish }\left(L_{a g}>L_{T}\right)\end{array}$ \\
\hline
\end{tabular}




\begin{tabular}{|l|l|l|}
\hline $9 \mathrm{e}$ & $U_{\bar{A}_{\mathrm{D}}}=u_{5} \bar{A}_{\mathrm{D}}$ & $\begin{array}{l}\text { PWU of the number of anglers seen in a } \\
\text { day } \bar{A}_{\mathrm{D}} \text { per } 10 \text { ha }\end{array}$ \\
\hline $9 \mathrm{f}$ & $U_{M L L}=u_{6} M L L+u_{7} M L L^{2}$ & PWU of minimum-size limit $M L L$ \\
\hline $9 \mathrm{~g}$ & $U_{D B L}=u_{8} D B L$ & PWU of daily bag limit \\
\hline $9 \mathrm{~h}$ & $U_{\text {Stock }}=u_{9} 1$ & $\begin{array}{l}\text { PWU of stocking frequency (stocking } \\
\text { occurs annually) }\end{array}$ \\
\hline $9 \mathrm{i}$ & $U_{\text {Comp }}=u_{10} \frac{\bar{C}_{\mathrm{D}_{\mathrm{W}}}}{\bar{C}_{\mathrm{D}_{\text {Toal }}}}$ & PWU of catch composition (\% wild fish) \\
\hline
\end{tabular}


Table 2. Parameters used in model scenarios. Bold font indicates changes in the parameters relative to the base case, scenario 1.

1321 Scenarios 2A and 2B compare pike and carp, scenarios 3A and 3B compare assumptions about productivity and habitat changes, and

1322 scenarios 4A and 4B compare assumptions about relative fitness and heritability.

\begin{tabular}{|c|c|c|c|c|c|c|c|}
\hline \multirow[t]{2}{*}{ Variable } & \multicolumn{7}{|c|}{ Scenarios } \\
\hline & 1 (Base) & $2 \mathrm{~A}$ & $2 \mathrm{~B}$ & $3 \mathrm{~A}$ & $3 \mathrm{~B}$ & $4 \mathrm{~A}$ & $4 B$ \\
\hline Species & Pike & Pike & Carp & Pike & Pike & Pike & Pike \\
\hline Latent & Moderate & Low, High & Low, High & Moderate & Moderate & Moderate & Moderate \\
\hline Fishing & & 1,10 & 1,10 & 5 & 5 & 5 & 5 \\
\hline Pressure & licenses $\mathrm{ha}^{-1}$ & licenses ha $\mathbf{~}_{-1}$ & licenses $\mathbf{h a}_{-1}$ & licenses $\mathrm{ha}^{-1}$ & licenses $\mathrm{ha}^{-1}$ & licenses $\mathrm{ha}^{-1}$ & licenses $\mathrm{ha}^{-1}$ \\
\hline Expenditure & $0-154 € \mathrm{ha}^{-1}$ & $0,5,100 € \mathrm{ha}^{-1}$ & $0,5,100 € \mathbf{h a}^{-1}$ & $0,5,100 € \mathrm{ha}^{-1}$ & $0,5,100 € \mathrm{ha}^{-1}$ & $0,5,100 € \mathrm{ha}^{-1}$ & $0,5,100 € h^{-1}$ \\
\hline Habitat & Normal & Normal & Normal & $\begin{array}{c}\text { Reduced } \\
\alpha / 2\end{array}$ & $\begin{array}{c}\text { Reduced } \\
2 * \beta\end{array}$ & Normal & Normal \\
\hline $\begin{array}{l}\text { Relative } \\
\text { Fitness }\end{array}$ & Equal & Equal & n.a. & Equal & Equal & Unequal & Unequal \\
\hline $\begin{array}{l}\text { Stocked Fish } \\
\text { Recognition }\end{array}$ & Unidentified & Unidentified & Identified & Unidentified & Unidentified & Unidentified & Unidentified \\
\hline
\end{tabular}




\section{FIGURE CAPTIONS}

1325 Figure 1. Schematic of modelled fishery components and their interactions (modified from 1326 Johnston et al. 2013).

1327 Figure 2. The effects of stocking pike fry $(2 \mathrm{~cm})$, fingerlings $(20 \mathrm{~cm})$ and adults (age-2, 35-40 $1328 \mathrm{~cm}$ ) at a range of densities across a range of minimum-length limits (MLLs) and a range of 1329 stocking densities $\left(0-L_{\max }\right)$ calibrated to reflect the range of annual expenditures $\left(0-154 € \mathrm{ha}^{-1}\right)$ 1330 on pike stocking by angling-clubs in Germany (Table 2, scenario 1). Effects of stocking and 1331 MLLs on total fish density, density of vulnerable fish (age-2 and older fish at year end), catch 1332 rates, change in angler welfare (net willingness-to-pay, WTP) relative to the unregulated and 1333 unstocked case, per capita costs of stocked fish surviving to a vulnerable size (their third 1334 birthday), and net economic benefit, were evaluated. Latent fishing pressure was moderate (5 1335 licenses $\mathrm{ha}^{-1}$ ). Very close contour lines indicate rapid changes in the performance measure.

Figure 3. Age structure of a pike population under three different minimum-length limits

1337 (MLLs, no MLL, $48 \mathrm{~cm}$, and $120 \mathrm{~cm}$ ), when fry, fingerlings and adults were stocked at low $(3 €$ $\left.1338 \mathrm{ha}^{-1}\right)$, or high $\left(154 € \mathrm{ha}^{-1}\right)$ densities, or not stocked at all. The abundance of fish older than age- 6 1339 were not presented for visual clarity. The percentages listed in the corner of each panel represent 1340 the percent of the population that is composed of wild-origin fish under low (tightly hashed bar) 1341 and high (coarsely hashed bar) stocking densities.

1342 Figure 4. The effect of stocking pike and carp fry, fingerlings and adults at densities that 1343 represent annual stocking expenditures of 0,5 , and $100 € \mathrm{ha}^{-1}$ (Table 2, scenario 2). For pike, 1344 these expenditures corresponded to densities of 0,159 and 3174 fry ha $^{-1}(2 \mathrm{~cm}), 0,3$ and 58 1345 fingerlings ha ${ }^{-1}(20 \mathrm{~cm})$, and 0,1 and 24 adults ha $^{-1}$ (age-2), respectively, and for carp to 
1346 densities of 0,98 and 1967 fry ha $^{-1}(4 \mathrm{~cm}), 0,8$ and 155 fingerlings ha ${ }^{-1}(15 \mathrm{~cm})$ and 0,1 and 23 1347 adults ha ${ }^{-1}(40 \mathrm{~cm})$, respectively. Effects of stocking and MLLs on total fish density, density of 1348 vulnerable fish (age-2 and older fish at year end), catch rates, change in angler welfare (net 1349 willingness-to-pay, WTP) relative to the status quo, per capita costs of stocked fish surviving to a 1350 fully vulnerable size (their third birthday), and net economic benefit, were evaluated under low 1351 and high latent fishing pressure ( 1 and 10 licenses ha ${ }^{-1}$, respectively). The grey areas indicate 1352 situations where the benefit to anglers was not greater than the status quo (no stocking and no 1353 MLL), or where there was no positive net economic benefit.

1354 Figure 5. The sensitivity of pike model outcomes to changes in model assumptions, under 1355 annual stocking expenditures of 0,5 , and $100 € \mathrm{ha}^{-1}$, and moderate latent fishing pressure, 5 1356 licenses $\mathrm{ha}^{-1}$ (Table 2, scenarios 3 and 4). For pike, these expenditures corresponded to densities 1357 of 0,159 and 3174 fry ha $^{-1}(2 \mathrm{~cm}), 0,3$ and 58 fingerlings ha ${ }^{-1}(20 \mathrm{~cm})$, and 0,1 and 24 adults ha $^{-}$ $1358{ }^{1}$ (age-2), respectively. The left column represents the unmodified, base model (Table 2, scenario 1359 1). The second and third columns represent lower stock productivity ( $\alpha / 2$, Table 2 scenario 3A) 1360 and lower habitat capacity resulting in stronger density-dependence $(2 \cdot \beta$, Table 2 scenario $3 \mathrm{~B})$, 1361 respectively. The fourth and fifth columns represent the reduced fitness scenario (relative 1362 survival of stocked age-0 fish was 50\%, of stocked adults was $90 \%$, and relative reproductive 1363 success was 56\% compared to wild fish), with zero heritability (Table 2 scenario 4A), and 100\% 1364 heritability (Table 2 scenario 4B). The grey areas indicate situations where the benefit to anglers 1365 was not greater than the status quo (no stocking and no MLL), or where there was no positive net 1366 economic benefit. 


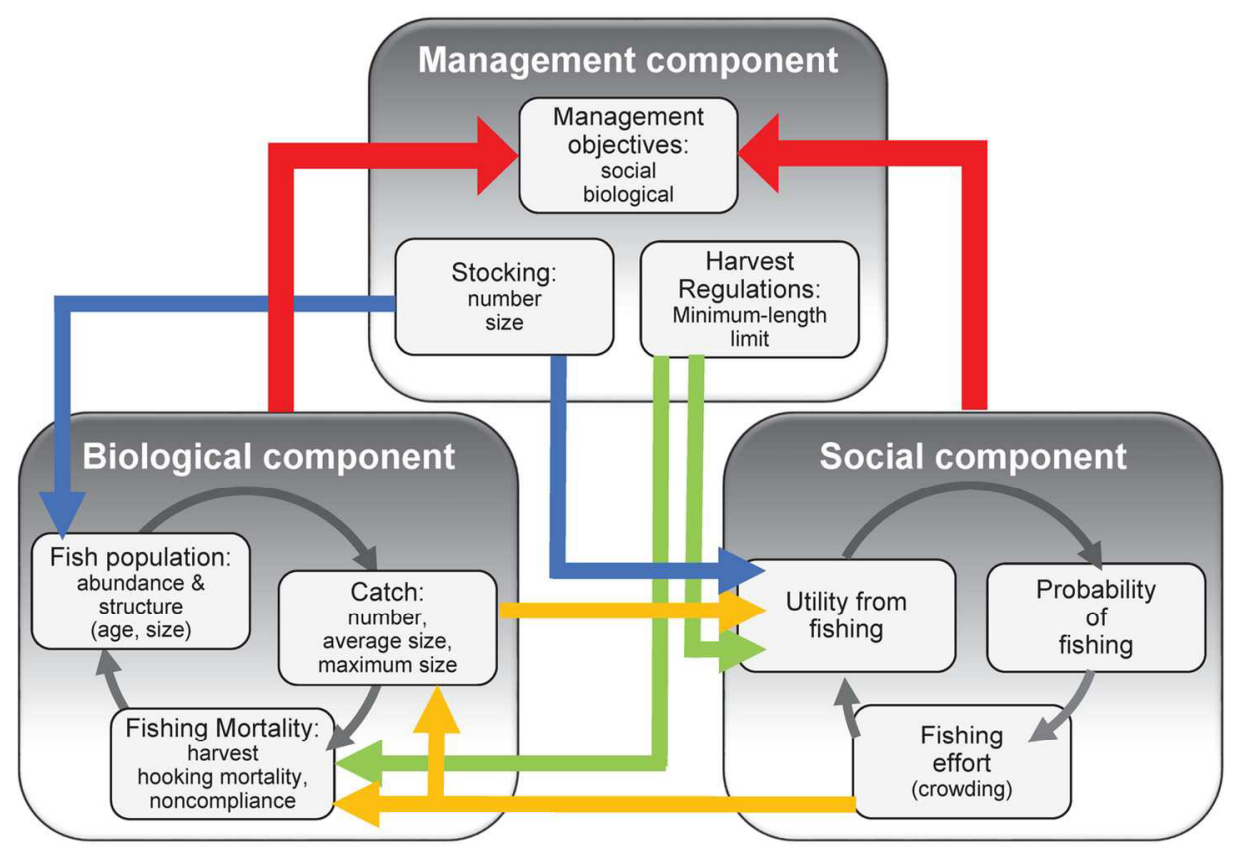

$132 \times 89 \mathrm{~mm}(300 \times 300 \mathrm{DPI})$ 

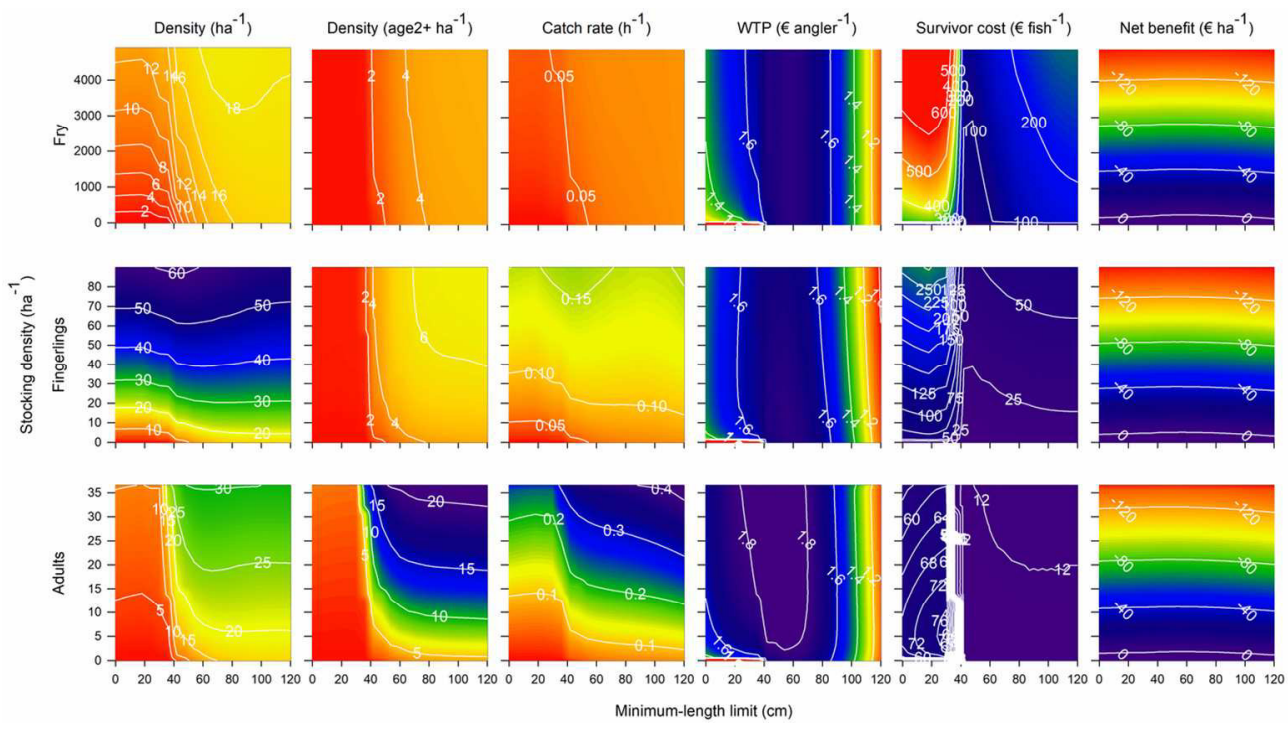

$121 \times 66 \mathrm{~mm}(300 \times 300 \mathrm{DPI})$ 

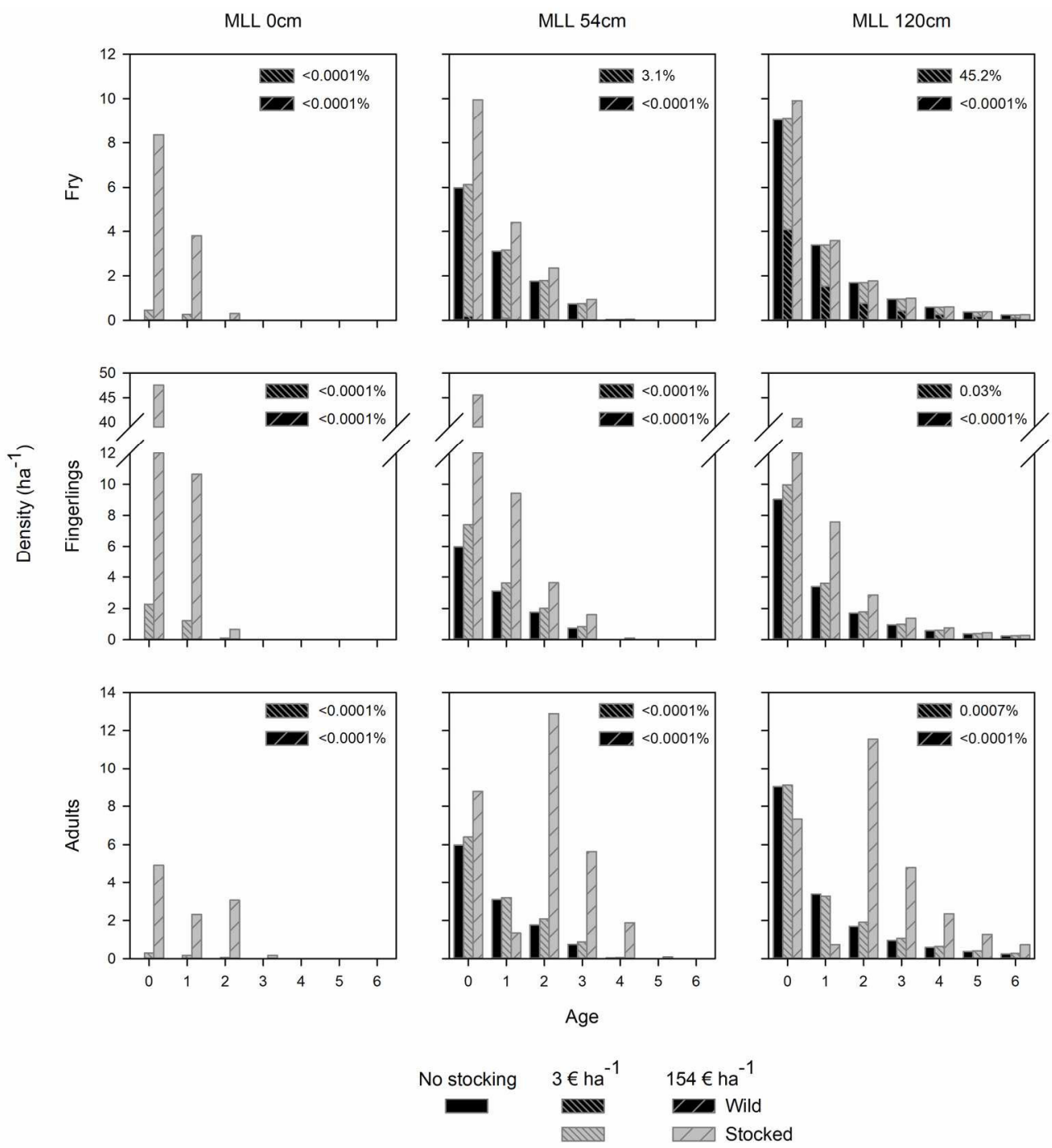

$170 \times 189 \mathrm{~mm}(300 \times 300$ DPI $)$ 

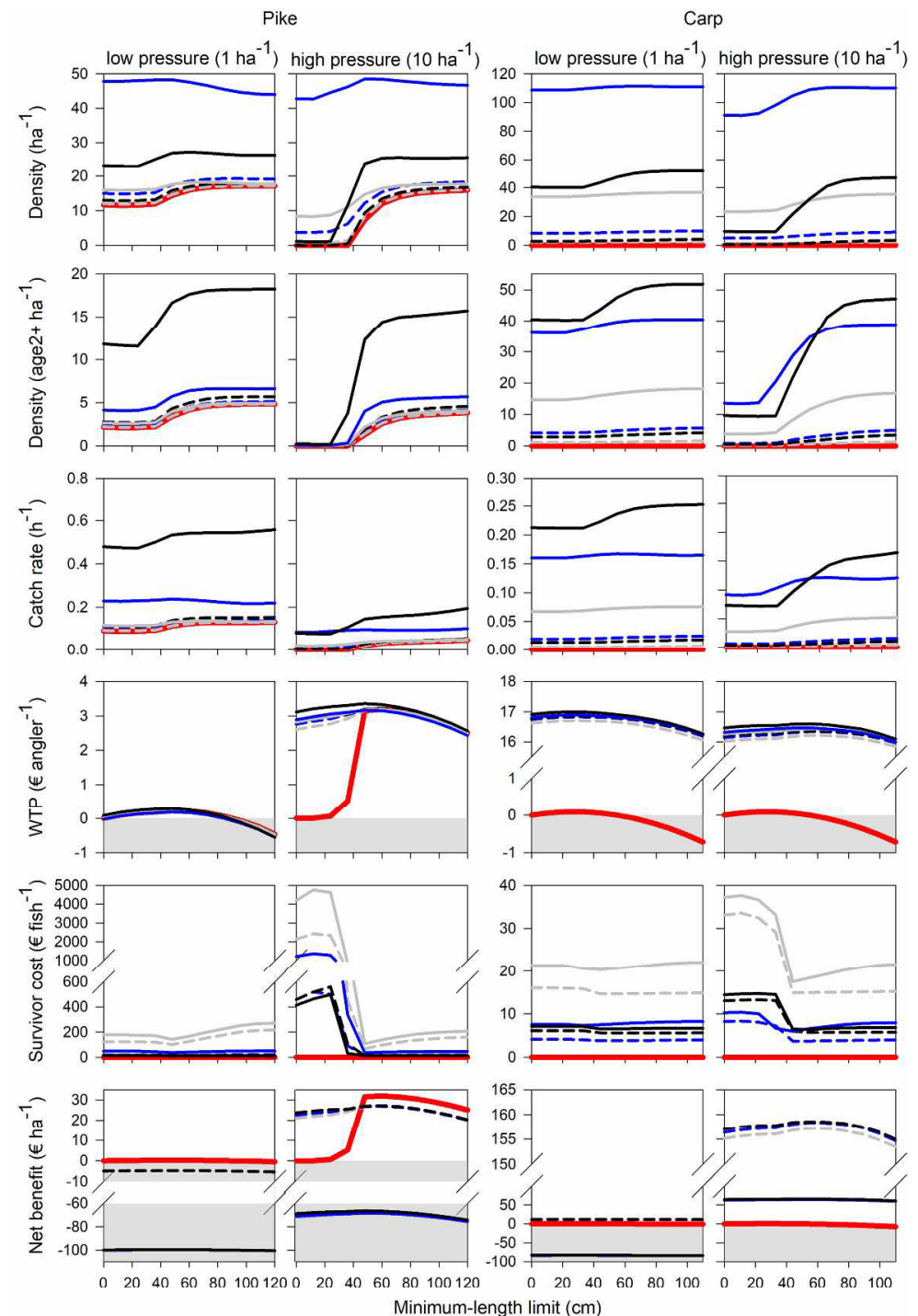
Minimum-length limit (cm)

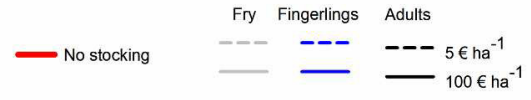

$203 \times 324 \mathrm{~mm}(300 \times 300$ DPI) 

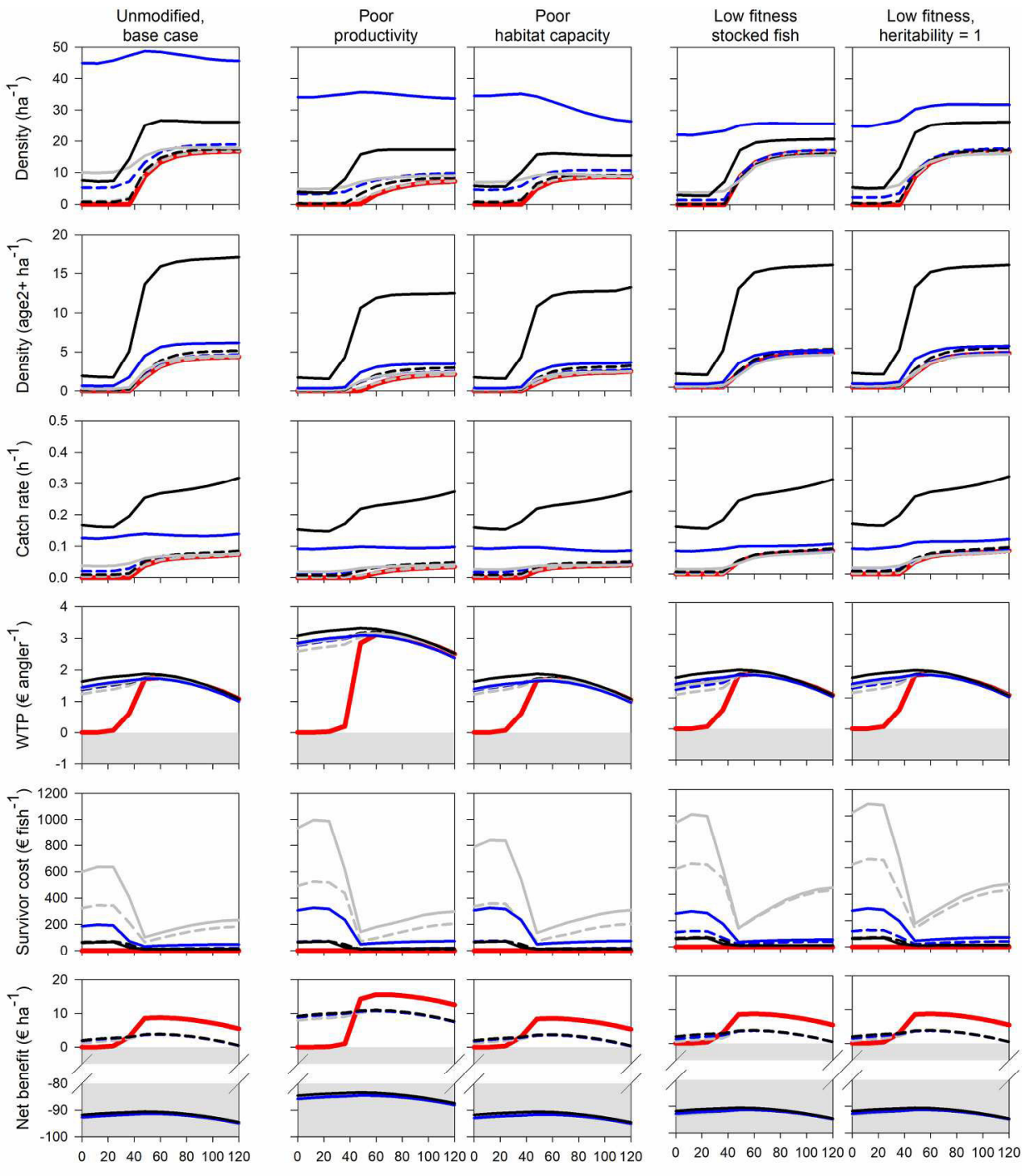

Minimum-length limit (cm)

No stocking

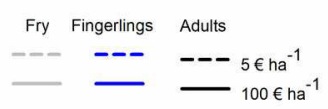

$193 \times 244 \mathrm{~mm}(300 \times 300$ DPI $)$ 


\section{Supplementary material for:}

How ecological processes shape the outcomes of stock enhancement and harvest regulations in recreational fisheries

\section{Published in Ecological Applications}

Fiona D. Johnston ${ }^{1,5^{*}}$, Micheal S. Allen ${ }^{3}$, Ben Beardmore ${ }^{4}$, Carsten Riepe ${ }^{1}$, Thilo Pagel ${ }^{1}$, Daniel Hühn ${ }^{1}$, and Robert Arlinghaus ${ }^{1,2}$

${ }^{1}$ Department of Biology and Ecology of Fishes, Leibniz-Institute of Freshwater Ecology and Inland Fisheries, Müggelseedamm 310, 12587 Berlin, Germany

${ }^{2}$ Division of Integrative Fisheries Management, Integrative Research Institute for the Transformation of Human-Environment Systems, and Albrecht-Daniel-Thaer Institute of Agriculture and Horticulture, Faculty of Life Sciences, Humboldt-Universität zu Berlin, Philippstrasse 13, Haus 7, 10115 Berlin, Germany

${ }^{3}$ Program for Fisheries and Aquatic Sciences, School of Forest Resources and Conservation, The University of Florida, 7922 NW 71st St. Gainesville, Florida 32653-3071, USA.

${ }^{4}$ Wisconsin Department of Natural Resources, Madison, WI 53703, USA.

${ }^{5}$ Department of Biological Sciences, University of Calgary, 2500 University Dr. N.W., Calgary, Alberta, T2N 1N4, Canada.

*Corresponding author: fiona.johnston@ucalgary.ca 


\section{APPENDIX S1}

\section{Supplemental tables}

Table S1. Bioeconomic model parameter values and their sources for northern pike (Esox Lucius) and common carp (Cyprinus carpio).

\begin{tabular}{|c|c|c|c|}
\hline \multirow[t]{2}{*}{ Symbol } & \multirow[t]{2}{*}{$\begin{array}{l}\text { Description } \\
\text { (unit, where applicable) }\end{array}$} & \multicolumn{2}{|c|}{$\begin{array}{l}\text { Value or range for fish life-history } \\
\text { types (source, where applicable) }\end{array}$} \\
\hline & & Pike & Carp \\
\hline \multicolumn{4}{|c|}{ Index variables } \\
\hline$t$ & year $(y)$ & $0-150$ & $0-150$ \\
\hline$a$ & Age class $(\mathrm{y})$ & $0-a_{\max }$ & $0-a_{\max }$ \\
\hline$a_{\max }$ & Maximum age of a fish (y) & $15(5)$ & $20(18)$ \\
\hline$g$ & Growth trajectory within an age class & $1-11$ & $1-11$ \\
\hline \multicolumn{4}{|l|}{ Growth } \\
\hline$L_{\max }$ & $\begin{array}{l}\text { Mean maximum size a fish can attain at maximum } \\
\text { age }\left(a=a_{\mathrm{max}}\right) \text { in an environment free of } \\
\text { intraspecific competition }\left(B_{\text {total }}=0\right)(\mathrm{cm})\end{array}$ & 120 & 110 \\
\hline$L_{0}$ & Length of fish at hatch $(\mathrm{cm})$ & $0.8(7)$ & $0.6(9)$ \\
\hline$h_{\max }$ & Mean maximum annual growth increment $(\mathrm{cm})$ & $24.0(10)$ & $21.3(14)^{* *}$ \\
\hline$\sigma_{L g}$ & $\begin{array}{l}\text { Proportional deviations from the mean } h_{\max } \text { in the } \\
\text { positive and negative direction, assuming a range } \\
\text { of } 3 \text { standard deviation units and a coefficient of } \\
\text { variation of } 0.1\end{array}$ & -0.3 to 0.3 & -0.3 to 0.3 \\
\hline$B_{1 / 2}$ & $\begin{array}{l}\text { biomass density at which the growth increment is } \\
\text { halved }\left(\mathrm{kg} \mathrm{ha}^{-1}\right)\end{array}$ & $100.0(10)$ & $454.5(14)^{* *}$ \\
\hline$G$ & Annual reproductive investment & $0.58(10)$ & $0.49(14) * *$ \\
\hline$w$ & $\begin{array}{l}\text { Scaling constant for length-mass relationship (g } \\
\mathrm{cm}^{-l} \text { ) }\end{array}$ & $0.0048(19)$ & $0.020(17)$ \\
\hline$l$ & Allometric exponent for length-mass relationship & $3.059(19)$ & $2.97(17)$ \\
\hline \multicolumn{4}{|c|}{ Maturation } \\
\hline$b_{1}$ & Intercept of the maturation reaction norm $(\mathrm{cm})$ & $36.6(7)^{*}$ & $30.8(6)^{*}$ \\
\hline$b_{2}$ & Slope of the maturation reaction norm $\left(\mathrm{cm} \mathrm{y}^{-1}\right)$ & $-3.25(7)^{*}$ & $-3.31(6)^{*}$ \\
\hline \multicolumn{4}{|c|}{ Reproduction } \\
\hline$\omega$ & Relative fecundity $\left(\mathrm{g}^{-1}\right)$ & $34(11)$ & $220(16)$ \\
\hline
\end{tabular}




\begin{tabular}{|c|c|c|c|}
\hline$\delta$ & Hatching success & $0.75(12)$ & $0.75(3)$ \\
\hline$\Phi$ & Sex ratio (\% female spawners) & $0.5(13)$ & $0.5(4)$ \\
\hline$\rho$ & $\begin{array}{l}\text { reproductive success of hatchery strain fish } \\
\text { relative to wild fish }\end{array}$ & 1.0 or $0.56(8)$ & n.a. \\
\hline \multicolumn{4}{|c|}{ Mortality } \\
\hline$\alpha$ & Maximum survival rate of larvae to age- 1 & $1.7110^{-4}(10)$ & $2.0010^{-5}(4)$ \\
\hline$\beta$ & $\begin{array}{l}\text { Strength of density-dependence on larvae to age- } 1 \\
\text { survival (ha) }\end{array}$ & $6.8710^{-6}(10)$ & $2.0010^{-8}(4)$ \\
\hline$h^{2}$ & $\begin{array}{l}\text { Proportion of hatchery larvae that transitioned to } \\
\text { wild strain fish due to natural selection }\end{array}$ & 0.0 or 1.0 & n.a. \\
\hline$\gamma$ & $\begin{array}{l}\text { Relative survival of age- } 0 \text { hatchery fish relative to } \\
\text { age- } 0 \text { wild fish }\end{array}$ & 1.0 or $0.5(8)$ & n.a. \\
\hline$\sigma_{N g}$ & $\begin{array}{l}\text { Proportion of fish in a growth trajectory } g \\
\text { assuming a normal distribution with a mean } h_{\max } \\
\text { and a coefficient of variation of } 0.1\end{array}$ & $\begin{array}{l}0.37 \text { to } 7.5610^{-6} \\
\text { (calculated) }\end{array}$ & $\begin{array}{l}0.37 \text { to } 7.5610^{-6} \\
\text { (calculated) }\end{array}$ \\
\hline$D_{\text {Equilib }}$ & $\begin{array}{l}\text { Unexploited equilibrium effective density, which } \\
\text { was considered to be the } D_{L^{2}} \text { after model } \\
\text { stabilization but prior to the introduction of } \\
\text { stocking and fishing }\left(\mathrm{cm}^{2} \mathrm{ha}^{-1}\right)\end{array}$ & $\begin{array}{c}32168.4 \\
\text { (calculated) }\end{array}$ & $\begin{array}{c}277123 \\
\text { (calculated) }\end{array}$ \\
\hline$\Upsilon$ & $\begin{array}{l}\text { Strength of density-dependence on the allometry } \\
\text { of size-dependent natural mortality (see } \\
\text { supplement for derivation) }\end{array}$ & $0.27(15)$ & $0.27(15)$ \\
\hline$y$ & Steepness of size-dependent vulnerability curve & 0.3 & 0.3 \\
\hline$z$ & $\begin{array}{l}\text { Size as a proportion of } L_{\max } \text { used when calculating } \\
\text { the size } L_{50} \text { at which } 50 \% \text { of the fish are } \\
\text { vulnerable to capture }\end{array}$ & 0.18 & 0.18 \\
\hline$L_{\text {shift }}$ & $\begin{array}{l}\text { Bias correction factor for the minimum size of fish } \\
\text { that can be captured that is used when calculating } \\
\text { the size } L_{50}(\mathrm{~cm}) \text {. See Johnston et al. } 2013 \text { for } \\
\text { more details. }\end{array}$ & 10 & 10 \\
\hline$q$ & Catchability reflecting skill level $\left(\mathrm{ha} \mathrm{h}^{-1}\right)$ & 0.20 & 0.20 \\
\hline$f_{\mathrm{h}}$ & Proportion of fish dying from hooking mortality & 0.05 & 0.05 \\
\hline$f_{\mathrm{n}}$ & $\begin{array}{l}\text { Proportion of fish below the minimum-size limit } \\
M S L \text { harvested illegally }\end{array}$ & 0.05 & 0.05 \\
\hline$\gamma_{2}$ & $\begin{array}{l}\text { Relative survival of recruited hatchery origin fish } \\
\text { relative to wild fish }\end{array}$ & $\begin{array}{l}\text { Immature } \\
1.0 \text { or } 0.5(8) \\
\quad \text { Mature } \\
1.0 \text { or } 0.9(8)\end{array}$ & n.a. \\
\hline
\end{tabular}




\begin{tabular}{|c|c|c|c|}
\hline \multicolumn{4}{|c|}{ Stocking } \\
\hline$L_{s}$ & length of fish at stocking $(\mathrm{cm})$ & $2.0,20.0, \bar{L}_{a_{S}}$ & 4.0, $15.0,40.0$ \\
\hline$a_{\mathrm{S}}$ & $\begin{array}{l}\text { Age at which recruited fish (adults) were stocked } \\
\text { (y) }\end{array}$ & $2(2)$ & $2(2)$ \\
\hline$J_{0_{\mathrm{s}}}$ & The density of age- 0 fish stocked $\left(\mathrm{ha}^{-1}\right)$ & $\begin{array}{l}\text { Fry } \\
0 \text { to } 4887 \\
\text { Fingerlings } \\
0 \text { to } 90(2)\end{array}$ & $\begin{array}{l}\text { Fry } \\
0 \text { to } 1967 \\
\text { Fingerlings } \\
0 \text { to } 155(2)\end{array}$ \\
\hline$N_{\mathrm{S}, t}$ & $\begin{array}{l}\text { The density of recruited fish of age } a_{\mathrm{S}} \text { stocked } \\
\left(\mathrm{ha}^{-1}\right)\end{array}$ & 0 to $39(2)$ & 0 to $23(2)$ \\
\hline$\theta$ & $\begin{array}{l}\text { Linear coeffient of allometric stocking cost to size } \\
\text { relationship }\end{array}$ & $0.009459(2)$ & $0.003535(2)$ \\
\hline$\lambda$ & $\begin{array}{l}\text { Exponent of the allometric stocking cost to size } \\
\text { relationship }\end{array}$ & $1.736(2)$ & $1.923(2)$ \\
\hline \multicolumn{4}{|c|}{ Angling regulations } \\
\hline$M L L$ & Minimum-length limit (cm) & $0-L_{\max }$ & $0-L_{\max }$ \\
\hline$D B L$ & Daily bag limit $\left(\mathrm{d}^{-1}\right)$ & 10 & 10 \\
\hline$A_{\mathrm{L}}$ & $\begin{array}{l}\text { Density of angling licenses issued } \\
\text { (= density of licensed anglers) }\end{array}$ & $1,5,10$ & $1,5,10$ \\
\hline$€_{\mathrm{L}}$ & Annual angling license cost $(€)$ & 100 & 100 \\
\hline \multicolumn{4}{|c|}{ Angler Effort Dynamics } \\
\hline$\varphi$ & $\begin{array}{l}\text { Persistence of fishing behaviour (= relative } \\
\text { influence of last year's realized fishing probability } \\
\text { on the current year's realized fishing probability) }\end{array}$ & $0.5(10)$ & $0.5(10)$ \\
\hline$d_{\max }$ & $\begin{array}{l}\text { Maximum number of days that an angler would } \\
\text { fish annually irrespective of fishing quality (d) }\end{array}$ & 20 & 20 \\
\hline$\Psi$ & Average time an angler will fish in a day (h) & $3(2)$ & $3(2)$ \\
\hline $\bar{l}_{\text {ref }}$ & Reference average size of fish caught $(\mathrm{cm})$ & 37 & 36 \\
\hline$L_{T}$ & Threshold length defining trophy-sized fish $(\mathrm{cm})$ & 100 & 90 \\
\hline$U_{\text {no }}$ & utility gained from not fishing & $0.2489(1) \neq$ & $0.2489(1) \ddagger$ \\
\hline$U_{\text {out }}$ & utility gained from fishing elsewhere & $0.4371(1) \ddagger$ & $0.4371(1) \ddagger$ \\
\hline$U_{\text {in }}$ & basic utility gained from fishing in the region & $-0.686(1) \ddagger$ & $-0.686(1) \ddagger$ \\
\hline$U_{\mathrm{Spp}}$ & PWU of fishing for most preferred species & $0.0655(1) \ddagger$ & $0.0655(1) \ddagger$ \\
\hline$u_{1}$ & Cost coefficient & $-0.518(1) \ddagger$ & $-0.518(1) \ddagger$ \\
\hline$u_{2}$ & Daily catch coefficient & $0.1230(1) \ddagger$ & $0.1219(1) \ddagger$ \\
\hline$u_{3}$ & Average size coefficient & $1.2357(1) \ddagger$ & $1.2263(1) \ddagger$ \\
\hline
\end{tabular}




\begin{tabular}{llcc}
\hline$u_{4}$ & Trophy catch coefficient & $0.0254 * 100(1) \ddagger$ & $0.0357 * 100(1) \ddagger$ \\
$u_{5}$ & Crowding coefficient & $-0.0424 * 0.5(1) \ddagger$ & $-0.0392 * 0.5(1) \ddagger$ \\
$u_{6}$ & MLL linear coefficient & $0.005(1) \ddagger$ & $0.0032(1) \ddagger$ \\
$u_{7}$ & MLL quadratic coefficient & $-0.0001(1) \ddagger$ & $-0.0001(1) \ddagger$ \\
$u_{8}$ & Daily bag limit linear coefficient & $-0.0104(1) \ddagger$ & $0.0085(1) \ddagger$ \\
$u_{9}$ & Stocking frequency coefficient & $0.1006(1) \ddagger$ & $0.0632(1) \ddagger$ \\
$u_{10}$ & Catch composition coefficient & $0.0595(1) \ddagger$ & $0.1013(1) \ddagger$ \\
\hline
\end{tabular}

n.a., not applicable.

(1) Arlinghaus et al. (2014); (2) Arlinghaus et al. Unpublished data; (3) Babiak et al. (1997); (4) Brown and Walker (2004); (5) Craig and Kipling (1983); (6) Crivelli (1981); (7) Frost and Kipling (1967); (8) Hühn et al. (2014); (9) Jelkić et al. (2012); (10) Johnston et al. (2013); (11) Kipling and Frost (1969); (12) Kipling and Frost (1970); (13) Le Cren et al. (1977); (14) (Lorenzen 1996b) and Vilizzi et al. (2013); (15) derived from Post et al. (1999), see supplement; (16) Tempero et al. (2006); (17) Vilizzi et al. (2013), worldwide average; (18) Weber et al. (2011); (19) Willis (1989).

* calculated from the source data by determining maturity ogives and then calculating the probabilistic maturation norm. See Heino et al. (2002) and Barot et al. (2004) for methods. The slope represents the age and size at which the probability of maturation is $50 \%$.

** calculated from source data using method described in Johnston et al. (2013).

$\ddagger$ parameter values used were modified slightly from those reported by Arlinghaus et al. (2014) so that the $U_{M L L}$, the part-worth utility function of MLL, was quadratic in form rather linear. This was done because the quadratic form best described the data for pike and carp a quadratic. 


\section{Supplemental figures}

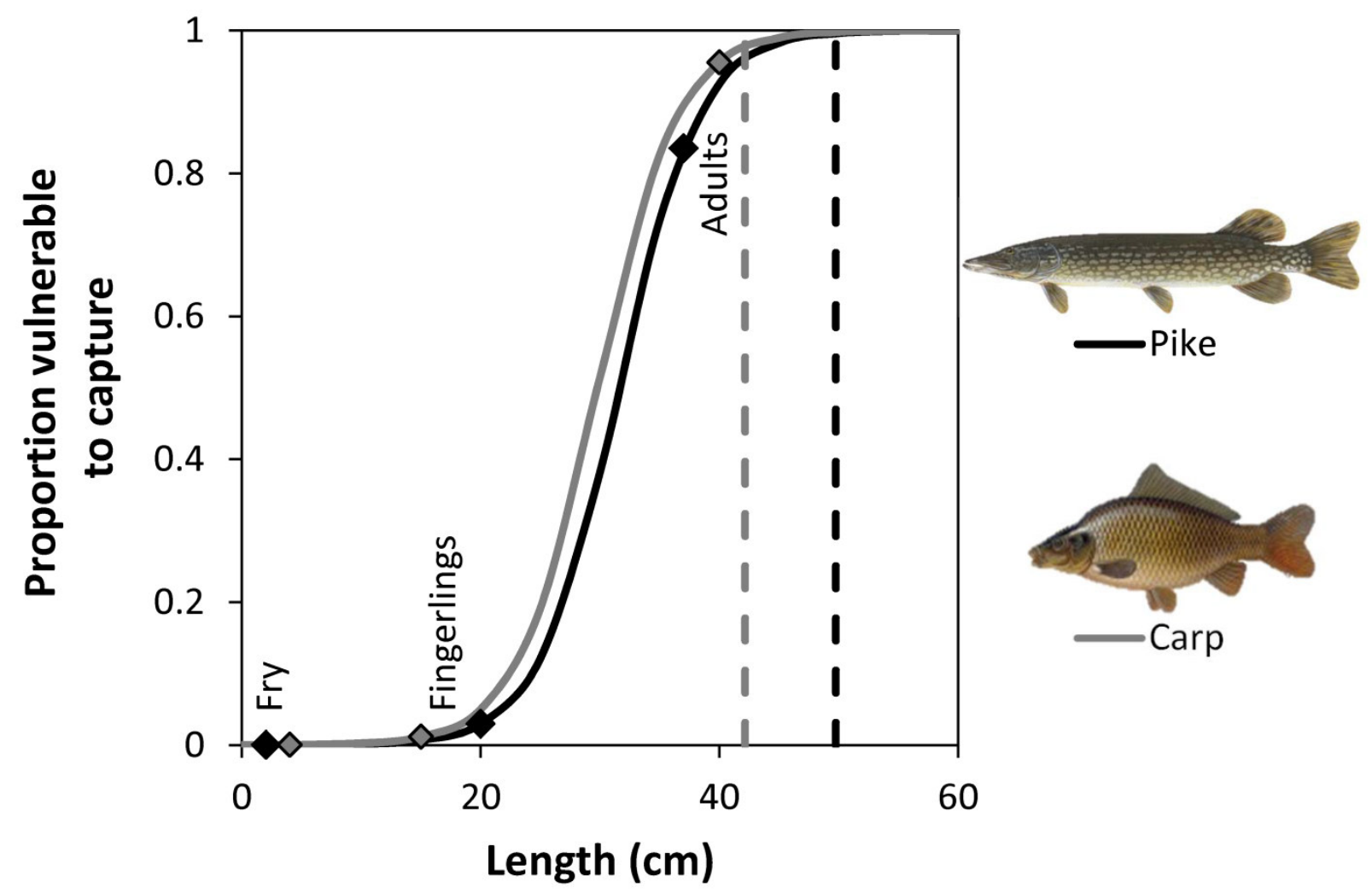

Figure S1. Size-dependent vulnerability of fish to capture by anglers. The black and gray diamonds illustrate the average size at stocking of pike and carp, respectively, for fry, fingerlings and adults. The vertical dashed lines represent the average size a fish achieves by its third birthday (age- 2 at the end of the year) for pike (black) and carp (gray), which we use to define the vulnerable population. 


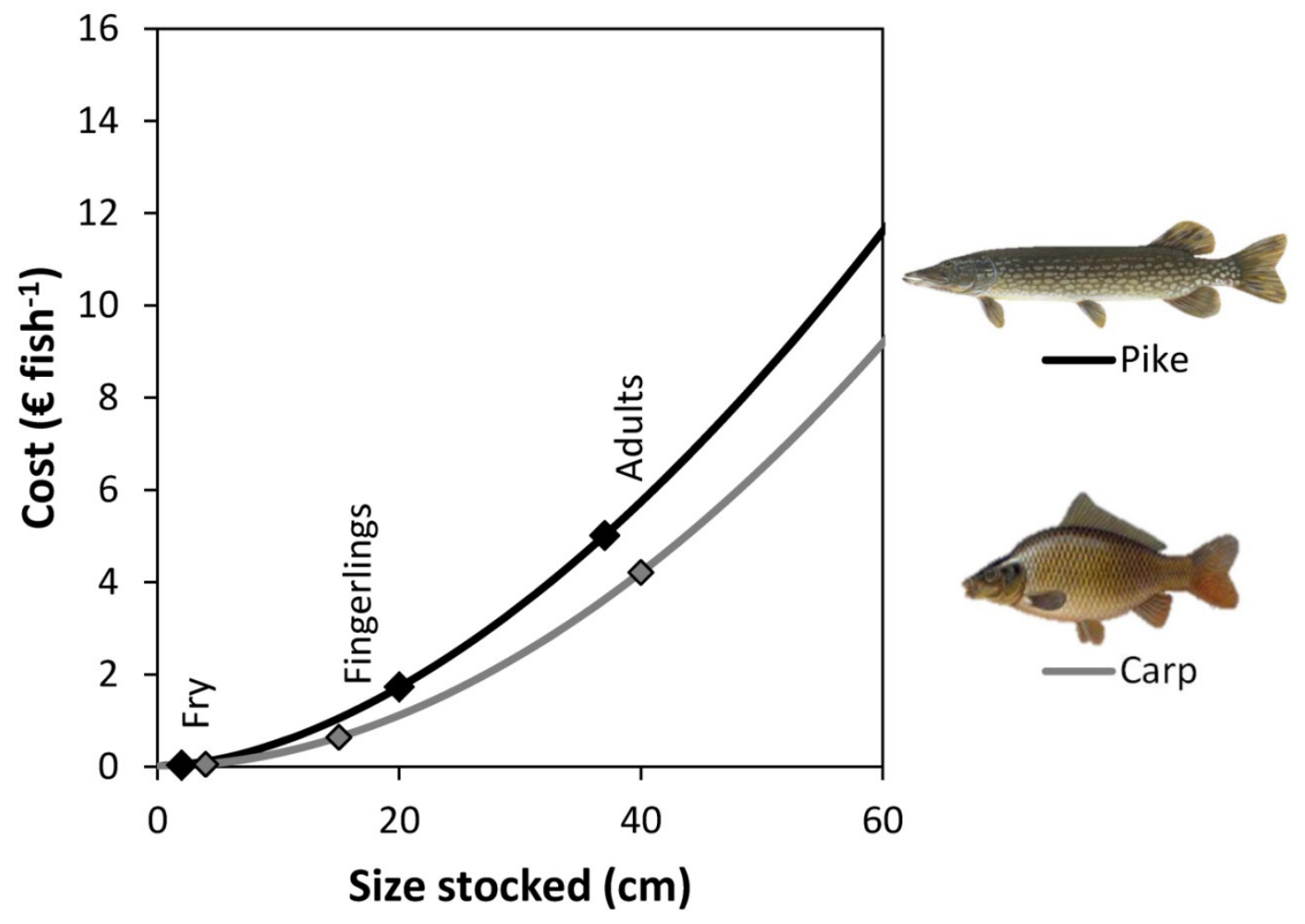

Figure S2. Species- and size-dependent stocking cost relationship determined from information provided by German angling clubs (Arlinghaus et al. 2015). 


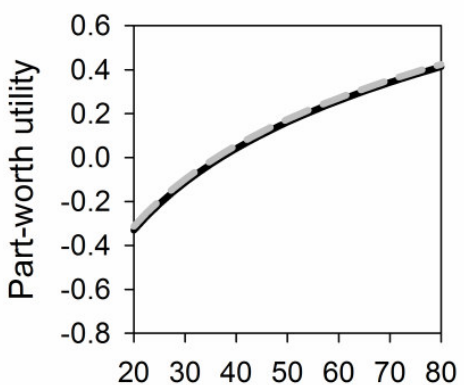

Average size $(\mathrm{cm})$

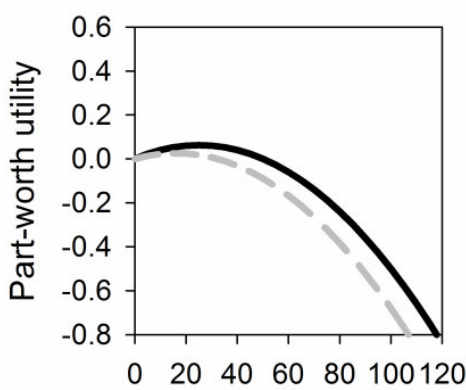

Minimum-length limit (cm)

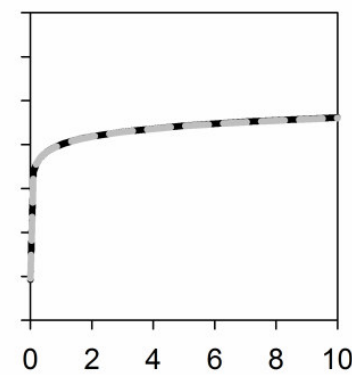

Daily catch

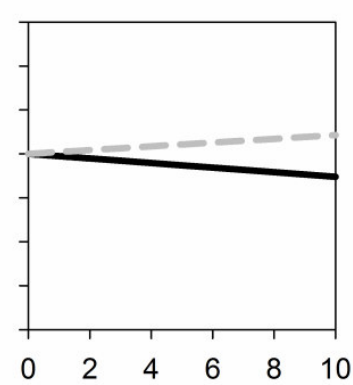

Daily bag limit

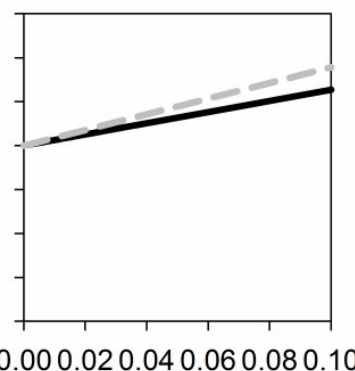

Daily trophy catch
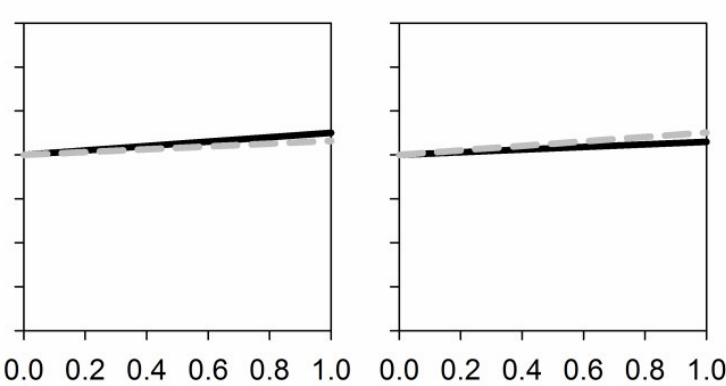

Stocking probability $\left(\mathrm{y}^{-1}\right)$ Wild fish in catch (\%)

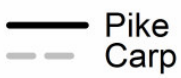

Figure S3. Part-worth utility functions describing the preferences of angler from Lower Saxony for catch related and non-catch related attributes when fishing for pike and carp, obtained from a choice experiment carried out by (Arlinghaus et al. 2014) and using the equations 9a-9i in Table 1 and the parameter set given in Table A1. 
Length Distribution of Pike Cohorts - Start of Year

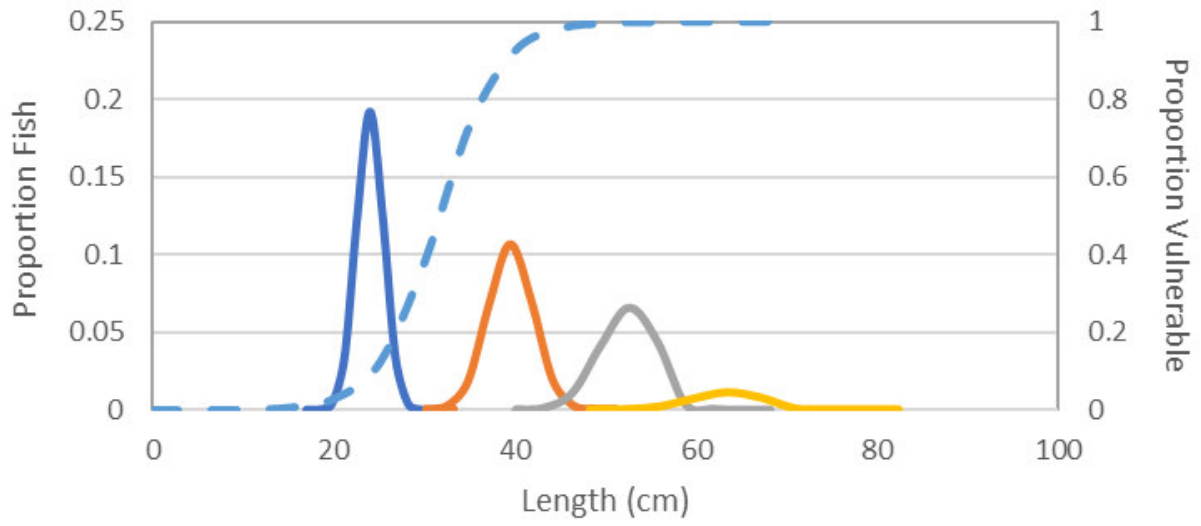

$\longrightarrow$ age-1 age-2 age-3 age-4 - vulnerability

Figure S4. Relative length distribution of pike age-1 to age-4 cohorts in an unstocked population with a minimumlength limit of $42 \mathrm{~cm}$ and a latent fishing pressure of 5 anglers ha ${ }^{-1}$. Values are for the beginning of the year. Other cohorts are not depicted. 


\section{Derivation of unpacked stock-recruitment}

Survival of age-0 fish during the pre-stocking phase $s_{1}$ and the post-stocking phase $s_{2}$ were described by two Ricker stock-recruitment relationships. The method used by Lorenzen (2005) was modified to follow a Ricker model rather than a Beverton-Holt model to be more representative of early survival for pike (Johnston et al. 2013) and carp (Brown and Walker 2004). Overcompensation can result from cannibalism (Hilborn and Stokes 2010), a factor that is common in pike (Wright and Giles 1987, Skov et al. 2003). Cannibalism also occurs in carp populations (Tonn et al. 1994), but reduced age-0 survival at higher adult densities could also be the result of starvation, due to the overlap in diet with larger carp which have an exploitative advantage (Tonn et al. 1994). Larger reproductive investment of larger individuals at lower adult densities could also be a factor contributing to a Ricker-type stock-recruitment relationship (Weber and Brown 2013). The $\alpha_{1}$ and $\alpha_{2}$ parameters, describing the maximum survival rate of fish, and $\beta_{1}$ and $\beta_{2}$ parameters, describing the strength of the density-dependence during preand post-stocking, respectively, were derived in a manner similar to that used by Lorenzen (2005). Length-survival relationships and parameters from the original stock-recruitment relationship were used as follows:

Assuming under zero density the survival rate of larvae to recruitment at age- $1 s^{*}$ was equal to the maximum survival rate $\alpha$ from a Ricker stock-recruitment relationship.

$$
s^{*}=\alpha=\left(\frac{L_{0}}{L_{\mathrm{rec}}}\right)^{\frac{M_{1}^{*}}{h_{\max }}}
$$

where, $L_{0}$ is the larval length at hatch, $L_{\mathrm{rec}}$ is the average length at recruitment, $M_{1}^{*}$ is the natural mortality rate at $1 \mathrm{~cm}$, and $h_{\max }$ is the maximum somatic growth rate. The previous equation can be used to solve for $M_{1}^{*}$,

$$
M_{1}^{*}=h_{\max } \frac{\ln s^{*}}{\ln \frac{L_{0}}{L_{\mathrm{rec}}}} .
$$

Note that $M_{1}$ for unrecruited fish (age-0) is much higher than for recruited fish (Lorenzen 2005). The maximum survival rates during the two phases, pre-stocking $\alpha_{1}$ and post-stocking $\alpha_{2}$, can then be determined,

$$
\alpha_{1}=\left(\frac{L_{0}}{L_{s}}\right)^{\frac{M_{1}^{*}}{h_{\max }}} \text { and } \alpha_{2}=\left(\frac{L_{s}}{L_{\mathrm{rec}}}\right)^{\frac{M_{1}^{*}}{h_{\max }}} \text { such that } \alpha=\alpha_{1} \alpha_{2},
$$


where $L_{s}$ is the length of fish at the time of stocking. One can also solve for $\beta_{1}$ and $\beta_{2}$, if

$$
M_{1}^{*}=h_{\max } \frac{\ln s^{*}}{\ln \frac{L_{0}}{L_{\mathrm{rec}}}}=h_{\max } \frac{\ln s_{2}}{\ln \frac{L_{s}}{L_{\mathrm{rec}}}}
$$

Then by substituting in the Ricker relationships it can be simplified to

$$
\beta_{1}=\frac{\ln \frac{L_{0}}{L_{s}}}{\ln \frac{L_{0}}{L_{\mathrm{rec}}}} \beta
$$

Assuming

$S_{1} S_{2}=\alpha_{1} e^{-\beta_{1} N_{0}} a_{2} e^{-b_{2} \alpha_{1} N_{0} e^{-\beta_{1} N_{0}}}=\alpha e^{-\beta N_{0}}$

$\beta_{2}$ can be determined, using $\alpha_{1}$ and $\beta_{1}$,

$\beta_{2}=\frac{\beta-\beta_{1}}{\alpha_{1} e^{-\beta_{1} N_{0}}}$ 


\section{Derivation of density-dependent allometric mortality}

It is now generally accepted that mortality in fish is related to size in the post-recruited stage (Mangel 2017). Thus, like age-0 fish, survival of age- 1 and older fish was also assumed to be size-dependent and density-dependent using a relationship described by Lorenzen (1996a, 2000).

$$
M_{L}=M_{r}\left(\frac{L}{L_{r}}\right)^{c}
$$

where $M_{L}$ was the instantaneous natural mortality rate of a fish of length $L, M_{r}$ was the instantaneous natural mortality rate of a fish of reference length $L_{r}$, and $c$ was the allometric exponent of size-dependent mortality relationship. Lorenzen (2000) determined $c=-1$ to be the best fit model to describe the allometry of mortality, and values for $c$ reported by Lorenzen (1996a) for unexploited lakes were in this range. Thus, in unexploited systems natural mortality is inversely proportional to length (Lorenzen 2005).

$$
M_{L}=M_{1}\left(\frac{1}{L}\right),
$$

where $M_{1}$ is defined as the natural mortality per unit length (i.e., $L_{r}=1 \mathrm{~cm}$ ) and is usually around 15 for recruited wild fish (Lorenzen 2005). Note that $M_{1}$ for unrecruited fish (age-0) is much higher than for recruited fish (Lorenzen 2005). Based on mortality estimates from the literature when size/age was known, we found that $M_{1} \cong h_{\max }$ across a number of species (Figure S5). While we did not do an exhaustive literature review, this finding is supported by other studies. In his seminal paper, (Pauly 1980) found that natural mortality was dependent on growth parameters estimated from the von Bertalanffy growth model, and more recent investigations found that size-dependent mortality was also dependent on asymptotic size and the von Bertalanffy growth rate parameter (Lorenzen 2000, Gislason et al. 2010, Charnov et al. 2013); parameters that when combined represent the growth rate near $t_{0}$ (Gallucci and Quinn 1979). Thus, we assumed that $M_{1}=h_{\max }$ when deriving our density-dependent allometric mortality relationship. 


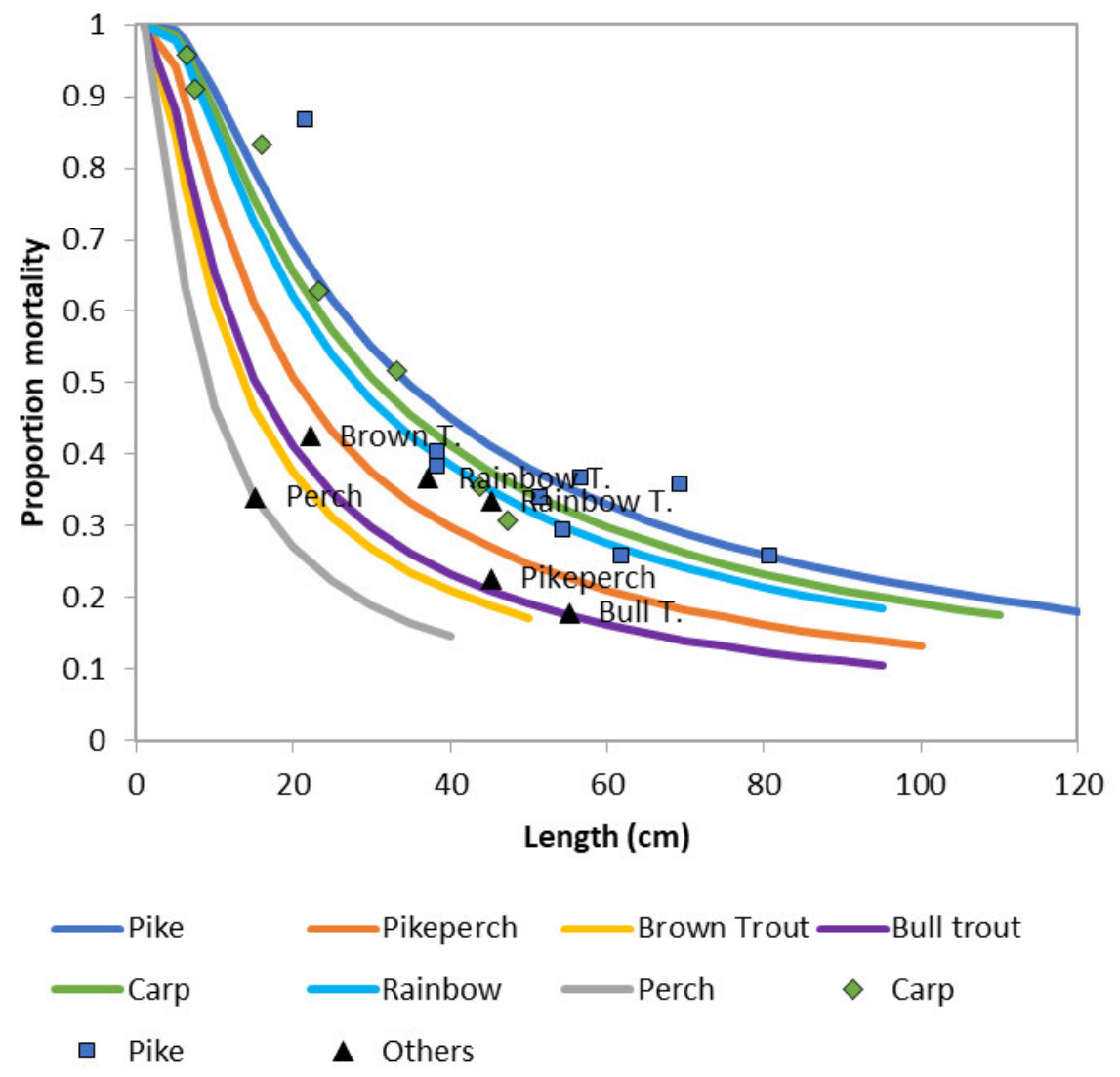

Figure S5. Comparison of some data to predictions from the size-dependent mortality function based on the assumption that $M_{1}=h_{\max }$. Sources: pike (Kipling and Frost 1970, Treasurer et al. 1992), carp (Koehn et al. 2000, Brown et al. 2005, Vilizzi et al. 2015), others (Le Cren et al. 1977, Lind 1977, Crisp 1994, Cox 2000, Post et al. 2003)

Size-dependent mortality is often assumed to be the result of how susceptible fish are to gapelimited predators (e.g., Askey et al. 2013), but might also result from larger fish having an exploitative advantage over a common resource (Tonn et al. 1994). Our model assumes that mortality is a function of fish size and the density of fish in the system, which reflects the density of predators as well as competitors, given the cannibalistic nature of the species modelled. Density-dependence in the size-dependent mortality relationship was introduced by making $c$ density-dependent. This assumes that the mortality rate of large fish will likely change very little, if at all, with density, but predator density will affect smaller fish. By having the effect of density on mortality dissipate with size, we assume that there are fewer predators of sufficient size to prey upon larger fish and that larger fish have an exploitative advantage over resources (e.g., they can have riskier foraging behaviour).

Density-dependent mortality is often assumed to be more important in the regulation of the early life stages in fish, while density-dependent growth is thought to be more important in the later life stages (Lorenzen 2008). Our model reflects this finding while avoiding a knife-edge from density-dependent to density-independent survival. However, studies have documented density- 
dependent survival in age-1 fish (e.g, Post et al. 1999), and Johnston et al. (2007) documented density-dependent survival in mature bull trout (Salvelinus confluentus), which was more severe in the younger (smaller) adults spawning for the first time. Thus, density-dependent mortality in later life stages is not unsupported.

To derive the density-dependent relationship for $c$ we first needed to determine a fixed pivot point of the size-mortality curve. We used $M_{r, L_{\max }}$ as the reference mortality rate and $L_{\max }$ as the reference length at this fixed point, because fish at this size are assumed to have densityindependent mortality. $M_{r, L_{\max }}$ was calculated as follows,

$$
M_{r, L_{\max }}=M_{1}\left(\frac{L_{\max }}{L_{r, 1 \mathrm{~cm}}}\right)^{c}=h_{\max }\left(\frac{L_{\max }}{1}\right)^{-1}=\frac{h_{\max }}{L_{\max }}
$$

assuming that $c=-1$ to represent an unexploited system. Thus,

$$
M_{L}=M_{r, L_{\max }}\left(\frac{L}{L_{\max }}\right)^{c}
$$

Assuming that $c=-1$ at the equilibrium effective density when the population is unfished and unstocked, we were able to generalize a relationship for determining $c$ across species by using relative effective density $D_{\text {rel }}$ rather than absolute effective density $D_{L^{2}}$. Relative effective density was calculated as,

$$
D_{\text {rel }}=\frac{D_{L^{2}}-D_{\text {Equilib }}}{D_{\text {Equilib }}},
$$

Where, $D_{\text {Equilib }}$ was the unexploited equilibrium effective density achieved prior to the introduction of fishing or stocking. Relative effective density influenced $c$ as follows,

$$
c=\frac{\ln \left[1+(1-\Upsilon) D_{\mathrm{rel}}\right]}{\ln \left(M_{r, L_{\max }}\right)}-1
$$

where, $\Upsilon$ was a constant derived from combining density-dependent growth and survival relationships from Post et al. (1999). We informed our model using published relationships on density-dependent growth and growth-dependent mortality of rainbow trout (Oncorhynchus mykiss) reported by Post et al. (1999), because of the exceptional quality of the data.

Post et al. (1999) report two relationships in their study, density-dependent growth and growthdependent mortality for three size classes of age-1 rainbow trout. 


$$
\begin{aligned}
& h_{g}=\Upsilon_{1, g}+\Lambda_{1, g} D_{L^{2}} \\
& M_{g}=\Upsilon_{2, g}+\Lambda_{2, g} h_{g}
\end{aligned}
$$

Where, $h_{g}$ and $M_{g}$ were the somatic growth rate and the natural mortality rate of a size-class $g$, respectively, $\Upsilon_{1, g}$ and $\Upsilon_{2, g}$ were the intercept terms, and $\Lambda_{2, g}$ and $\Lambda_{2, g}$ the slope terms, and $D_{L^{2}}$ is the effective density of the population. Combining these two equations rendered,

$$
M_{g}=\Upsilon_{2, g}+\Lambda_{2, g}\left(\Upsilon_{1, g}+\Lambda_{1, g} D_{L^{2}}\right)
$$

As there were no significant differences among slopes or intercepts for three size classes in the growth-mortality relationships presented by Post et al. (1999), for simplicity we averaged all coefficients across the three size classes and modified them from specific rates to annual rates assuming 138 days (average period from stocking to removal). Thus,

$M=\Upsilon+\Lambda D_{L^{2}}$ where $\Upsilon=\Upsilon_{2}+\Lambda_{2} \Upsilon_{1}$ and $\Lambda=\Lambda_{2} \Lambda_{1}$

Assuming $L=h_{\max }$, the average size of the fish at the beginning of the year, and that $L_{r}=L_{\max }$, a length at which mortality is fixed,

$M=\Upsilon+\Lambda D_{L^{2}}=M_{r, L_{\max }}\left(\frac{h_{\max }}{L_{\max }}\right)^{c}=M_{r, L_{\max }}{ }^{(c+1)}$,

because $M_{r, L_{\max }}=\left(\frac{h_{\max }}{L_{\max }}\right)$.

Solving for $c$

$$
c=\frac{\ln \left(\Upsilon+\Lambda D_{L^{2}}\right)}{\ln \left(M_{r, L_{\max }}\right)}-1
$$

To make this equation general across species, one can assume that densities are relative to some reference density $D_{L^{2}, \mathrm{r}}$ and substitute relative effective densities $D_{\text {rel }}$ for $D_{L^{2}}$, where

$$
D_{\text {rel }}=\frac{D_{L^{2}}-D_{L^{2}, \mathrm{r}}}{D_{L^{2}, \mathrm{r}}}
$$

If one assumes that the reference effective density is the density at which $c=-1$, then $M=1$ for a fish of size $h_{\max }$. Thus, 


$$
\begin{aligned}
& M=\Upsilon+\Lambda D_{L^{2}, r}, \text { so } \\
& D_{L^{2}, \mathrm{r}}=\frac{1-\Upsilon}{\Lambda} .
\end{aligned}
$$

One can use this to simplify the calculation of $c$, as follows

If $D_{L^{2}}=D_{\text {rel }} D_{L^{2}, \mathrm{r}}+D_{L^{2}, \mathrm{r}}=D_{\text {rel }}\left(\frac{1-\Upsilon}{\Lambda}\right)+\frac{1-\Upsilon}{\Lambda}$

then $c=\frac{\ln \left(\Upsilon+\Lambda D_{L^{2}}\right)}{\ln \left(M_{r, L_{\max }}\right)}-1=\frac{\ln \left[\Upsilon+\Lambda\left[D_{\text {rel }}\left(\frac{1-\Upsilon}{\Lambda}\right)+\frac{1-\Upsilon}{\Lambda}\right]\right]}{\ln \left(M_{r, L_{\max }}\right)}-1$,

which can be simplified to

$$
c=\frac{\ln \left[1+(1-\Upsilon) D_{\mathrm{rel}}\right]}{\ln \left(M_{r, L_{\max }}\right)}-1 .
$$

Calculating $c$ for the range of effective densities reported in Post et al. (1999) (0 to $4.410^{-5} \mathrm{~cm}^{2}$ $\mathrm{ha}^{-1}$ ), the predicted values for $c$ fell within the range of -0.26 to -1.42 . Given the $95 \%$ CI for $c$ reported by Lorenzen (1996a) for unexploited lakes (adjusted from weight to length by multiplying by 3 ) were around -0.67 to -1.07 , this range for exploited lakes was considered to be reasonable. 


\section{Model sensitivity to density-dependent mortality in age-1 and older fish}

Given the uncertainty associated with the density-dependent mortality relationship for age-1 and older fish, we investigated the model outcomes in the absence of density-dependence in this relationship (i.e., $c$ was held constant at -1). Results were qualitatively similar (Figures S6-S8). Fingerling stocking still resulted in the greatest total density and fry stocking generally the least, at similar stocking expenditures. Stocking adults resulted in the highest density of fish vulnerable to capture and the highest catch rates. Stocking only resulted in greater net WTP than the use of MLLs alone when the population was overexploited or natural reproduction did not occur. The cost of producing fish that survive to age-3 was greatest for fry and least for adults. The net economic benefit of stocking only exceeded the use of MLLs alone when populations were overexploited or would not otherwise exist. In such cases, low stocking rates and high latent fishing pressure resulted in the greatest net benefit.

There were, however, some small qualitative differences and some quantitative differences that are worth highlighting. When stocking carp into lakes with high latent fishing pressure (10 licenses $\mathrm{ha}^{-1}$ ), we did not find that under liberal length limits fingerling stocking resulted in greater vulnerable fish density and catch rates (Figure S7). This occurred because there was no compensatory reduction in fingerling survival in response to the low density of predators in the system caused by heavy exploitation. For similar reasons, we did not find situations where the survivor costs of fingerlings were cheaper than the production of adults when density-dependent mortality in age-1 and older fish was absent (Figure S7).

Some quantitative differences of note relate to fish abundance. Unlike the density-dependent scenarios, when density-dependent mortality in age- 1 and older pike was absent, even low latent fishing pressure was sufficient to threaten the sustainability of pike populations under liberal MLLs, because the population was unable to compensate for fishing mortality through changes in small fish survival (Figure S7). This also resulted in the population being unsustainable under higher MLLs in the unstocked scenario. In comparison to the density-dependent scenarios stocking high densities of pike fingerlings and adults resulted in greater fish densities and similar or greater catch rates, because there was no density-dependent regulation limiting the survival of these stocked fish and overall abundance (Figure S7). By contrast, stocking low densities of pike or not stocking resulted in lower densities than the density-dependent scenarios, because there was no compensatory response. Carp had lower densities and catch rates when densitydependent survival was absent (Figure S7). In terms of socioeconomic outcomes, survivor costs were higher for both pike and carp in the absence of density-dependent survival. For pike, the lack of density-dependent survival resulted in higher net WTP and net benefits, and the MLL at which the net benefit of stocking exceeded the net benefit of only using MLL was higher, in the high latent effort scenarios (Figure S7) The inability for the population to compensate for high fishing mortality through changes in natural mortality resulted in populations being unsustainable at higher MLLs. 


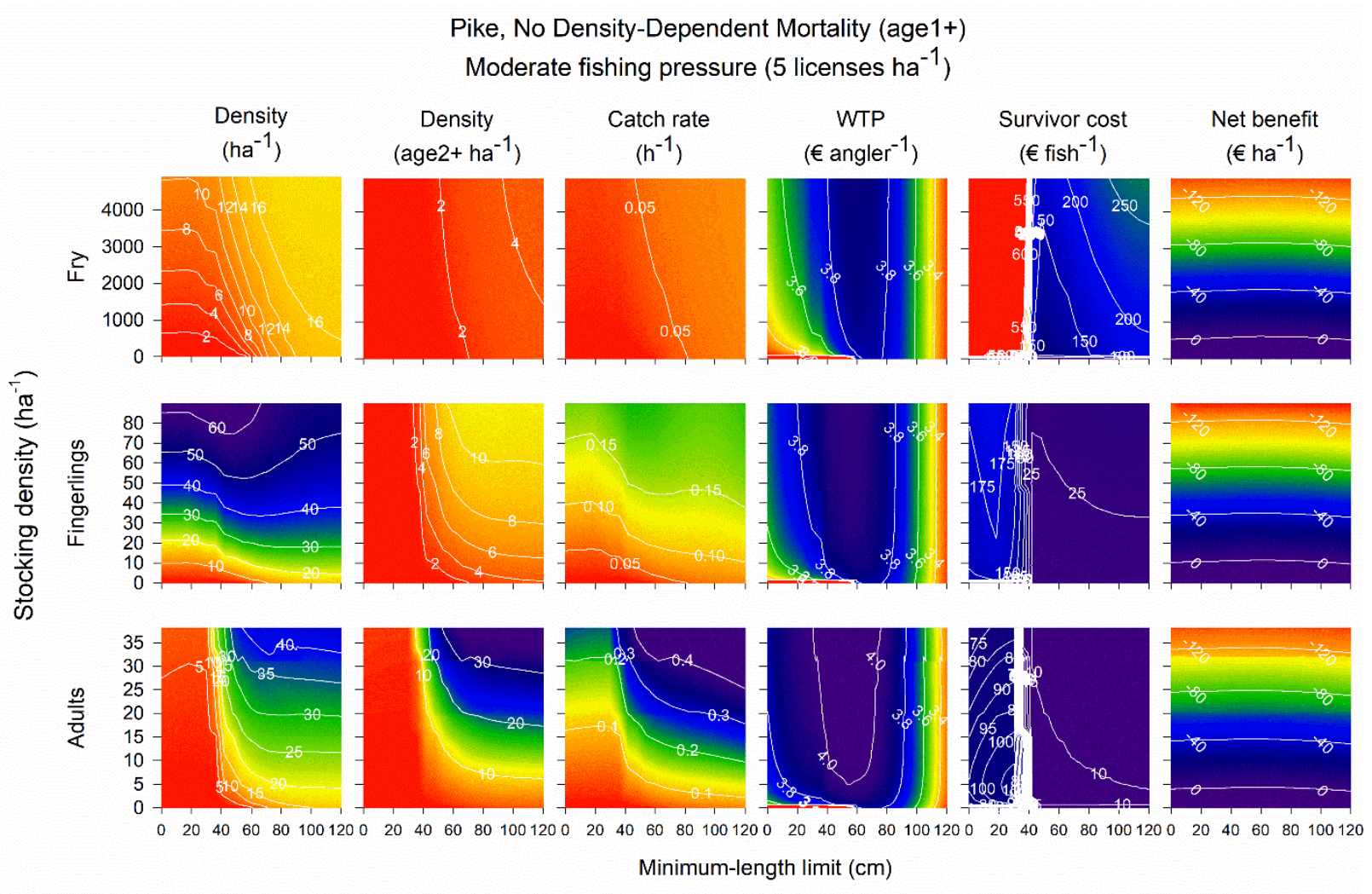

Figure S6. The effects of stocking pike fry $(2 \mathrm{~cm})$, fingerlings $(20 \mathrm{~cm})$ and adults (age-2, 35-40 cm) at a range of densities across a range of minimum-length limits (MLLs) and a range of stocking densities (Table S1) calibrated to reflect the range of annual expenditures $\left(0-154 € \mathrm{ha}^{-1}\right)$ on pike stocking by angling-clubs in Germany (Table 2, scenario 1). Effects of stocking and MLLs on total fish density, density of vulnerable fish (age-2 and older fish at year end), catch rates, change in angler welfare (net willingness-to-pay, WTP) relative to the unregulated and unstocked case, per capita costs of stocked fish surviving to a vulnerable size (their third birthday), and net economic benefit, were evaluated. Latent fishing pressure was moderate ( 5 licenses ha $^{-1}$ ). Very close contour lines indicate rapid changes in the performance measure. Model conditions were identical to those of used to produce Figure 2, with the exception that density-dependent mortality of age- 2 and older fish was absent. 


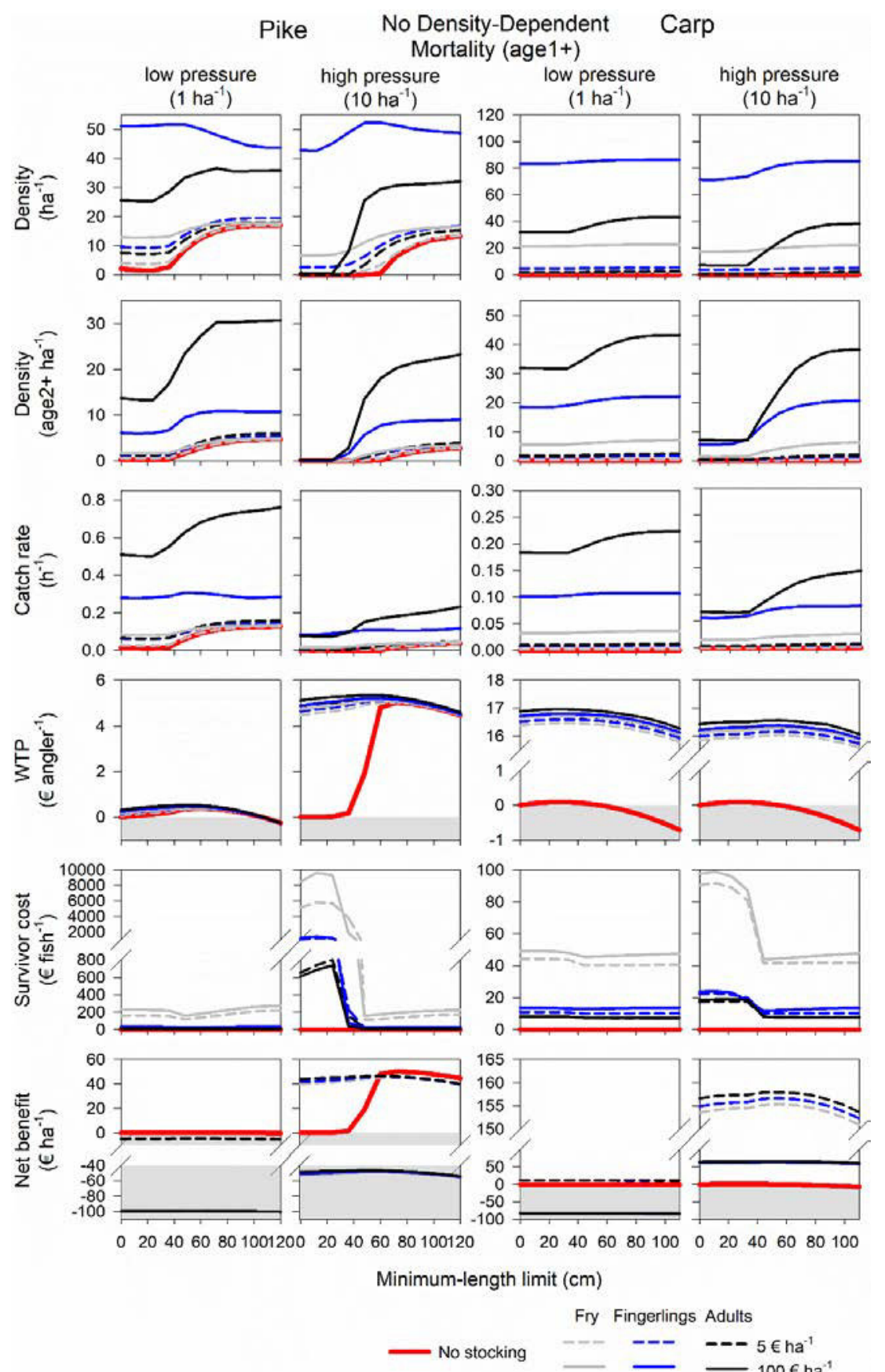

Figure S7. The effect of stocking pike and carp fry, fingerlings and adults at densities that represent annual stocking expenditures of 0,5 , and $100 € \mathrm{ha}^{-1}$ (Table 2, scenario 2). For pike, these expenditures corresponded to densities of 0,159 and 3174 fry ha $^{-1}(2 \mathrm{~cm}), 0,3$ and 58 fingerlings ha ${ }^{-1}(20 \mathrm{~cm})$, and 0,1 and 24 adults ha ${ }^{-1}$ (age-2),

respectively, and for carp to densities of 0,98 and 1967 fry ha $^{-1}(4 \mathrm{~cm}), 0,8$ and 155 fingerlings ha- $(15 \mathrm{~cm})$ and 0 , 1 and 23 adults ha ${ }^{-1}(40 \mathrm{~cm})$, respectively. Effects of stocking and MLLs on total fish density, density of vulnerable fish (age-2 and older fish at year end), catch rates, change in angler welfare (net willingness-to-pay, WTP) relative to the status quo, per capita costs of stocked fish surviving to a fully vulnerable size (their third birthday), and net economic benefit, were evaluated under low and high latent fishing pressure (1 and 10 licenses ha ${ }^{-1}$, respectively). The grey areas indicate situations where the benefit to anglers was not greater than the status quo (no stocking and no MLL), or where there was no positive net economic benefit. Model conditions were identical to those of used to produce Figure 4, with the exception that density-dependent mortality of age- 2 and older fish was absent. 


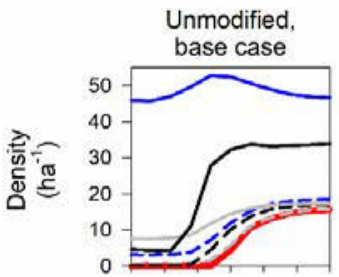

Pike - No Density-Dependent Mortality (age1+)
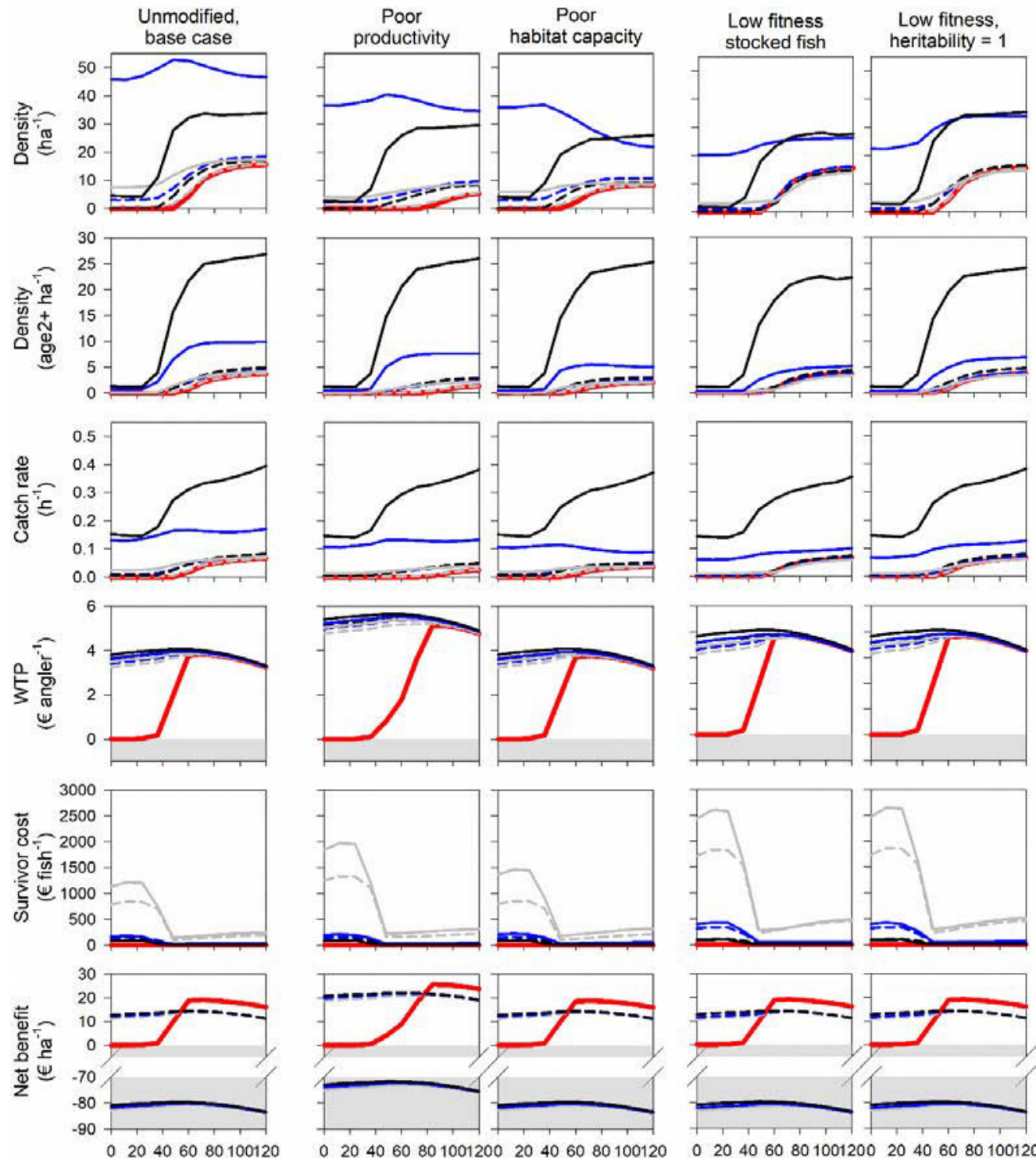

Minimum-length limit $(\mathrm{cm})$

0 $2040608010012002040608010012 \mathrm{C}$

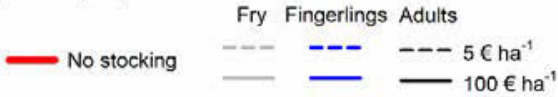

Figure S8. The sensitivity of pike model outcomes to changes in model assumptions, under annual stocking expenditures of 0,5 , and $100 €$ ha $^{-1}$, and moderate latent fishing pressure, 5 licenses ha ${ }^{-1}$ (Table 2, scenarios 3 and 4). For pike, these expenditures corresponded to densities of 0,159 and 3174 fry ha $^{-1}(2 \mathrm{~cm}), 0,3$ and 58 fingerlings ha $^{-1}(20 \mathrm{~cm})$, and 0,1 and 24 adults ha ${ }^{-1}$ (age-2), respectively. The left column represents the unmodified, base model (Table 2, scenario 1). The second and third columns represent lower stock productivity $(\alpha / 2$, Table 2 scenario $3 \mathrm{~A})$ and lower habitat capacity resulting in stronger density-dependence $(2 \cdot \beta$, Table 2 scenario $3 \mathrm{~B})$, respectively. The fourth and fifth columns represent the reduced fitness scenario (relative survival of stocked age- 0 fish was $50 \%$, of stocked adults was $90 \%$, and relative reproductive success was $56 \%$ compared to wild fish), with zero heritability (Table 2 scenario 4A), and 100\% heritability (Table 2 scenario 4B). The grey areas indicate situations where the benefit to anglers was not greater than the status quo (no stocking and no MLL), or where there was no positive net economic benefit. Model conditions were identical to those of used to produce Figure 5, with the exception that density-dependent mortality of age-2 and older fish was absent. 


\section{Appendix S1: Literature Cited}

Arlinghaus, R., B. Beardmore, C. Riepe, J. Meyerhoff, and T. Pagel. 2014. Species-specific preferences of German recreational anglers for freshwater fishing experiences, with emphasis on the intrinsic utilities of fish stocking and wild fishes. Journal of Fish Biology 85:1843-1867.

Arlinghaus, R., E.-M. Cyrus, E. Eschbach, M. Fujitani, D. Hühn, F. Johnston, T. Pagel, C. Riepe, and (eds.). 2015. Hand in Hand für eine nachhaltige Angelfi scherei: Ergebnisse und Empfehlungen aus fünf Jahren praxisorientierter Forschung zu Fischbesatz und seinen Alternativen. Berichte des IGB Vol. 28. Leibniz-Institute of Freshwater Ecology and Inland Fisheries, Berlin, Germany.

Askey, P. J., E. A. Parkinson, and J. R. Post. 2013. Linking fish and angler dynamics to assess stocking strategies for hatchery-dependent, open-access recreational fisheries. North American Journal of Fisheries Management 33:557-568.

Babiak, I., J. Glogowski, E. Brzuska, J. Szumiec, and J. Adamek. 1997. Cryopreservation of sperm of common carp, Cyprinus carpio L. Aquaculture Research 28:567-571.

Barot, S., M. Heino, L. O'Brien, and U. Dieckmann. 2004. Estimating reaction norms of age and size at maturation when age at first reproduction is unknown. Evolutionary Ecology Research 6:659-678.

Brown, P., K. P. Sivakumaran, D. Stoessel, and A. Giles. 2005. Population biology of carp (Cyprinus carpio L.) in the mid-Murray River and Barmah Forest Wetlands, Australia. Marine and Freshwater Research 56:1151-1164.

Brown, P., and T. I. Walker. 2004. CARPSIM: stochastic simulation modelling of wild carp (Cyprinus carpio L.) population dynamics, with applications to pest control. Ecological Modelling 176:83-97.

Charnov, E. L., H. Gislason, and J. G. Pope. 2013. Evolutionary assembly rules for fish life histories. Fish and Fisheries 14:213-224.

Cox, S. P. 2000. Angling quality, effort response, and exploitation in recreational fisheries: field and modeling studies on British Columbia rainbow trout (Oncorhynchus mykiss) lakes. $\mathrm{PhD}$ Thesis. University of British Columbia.

Craig, J. F., and C. Kipling. 1983. Reproduction effort versus the environment; case-histories of Windermere perch, Perca fluviatilis L., and pike, Esox lucius L. Journal of Fish Biology 22:713-727.

Crisp, D. T. 1994. Reproductive investment of female brown trout, Salmo trutta L., in a stream and reservoir system in northern England. Journal of Fish Biology 44:343-349.

Crivelli, A. J. 1981. The biology of the common carp, Cyprinus carpio L. in the Camargue, southern France. Journal of Fish Biology 18:271-290.

Frost, W. E., and C. Kipling. 1967. A study of reproduction, early life, weight-length relationship and growth of pike, Esox lucius L., in Windermere. Journal of Animal Ecology 36:651693. 
Gallucci, V. F., and T. J. Quinn. 1979. Reparameterizing, fitting, and testing a simple growth model. Transactions of the American Fisheries Society 108:14-25.

Gislason, H., N. Daan, J. C. Rice, and J. G. Pope. 2010. Size, growth, temperature and the natural mortality of marine fish. Fish and Fisheries 11:149-158.

Heino, M., U. Dieckmann, and O. R. Godø. 2002. Estimating reaction norms for age and size at maturation with reconstructed immature size distributions: a new technique illustrated by application to Northeast Arctic cod. ICES Journal of Marine Science 59:562-575.

Hilborn, R., and K. Stokes. 2010. Defining overfished stocks: have we lost the plot? Fisheries 35:113-120.

Hühn, D., K. Lübke, C. Skov, and R. Arlinghaus. 2014. Natural recruitment, density-dependent juvenile survival, and the potential for additive effects of stock enhancement: an experimental evaluation of stocking northern pike (Esox lucius) fry. Canadian Journal of Fisheries and Aquatic Sciences 71:1508-1519.

Jelkić, D., A. Opačak, I. Stević, S. Ozimec, J. Jug Dujaković, and R. Safner. 2012. Rearing carp larvae (Cyprinus carpio) in closed recirculatory system (RAS). Ribarstvo 70:9-17.

Johnston, F. D., R. Arlinghaus, and U. Dieckmann. 2013. Fish life history, angler behaviour and optimal management of recreational fisheries. Fish and Fisheries 14:554-579.

Johnston, F. D., J. R. Post, C. J. Mushens, J. D. Stelfox, A. J. Paul, and B. Lajeunesse. 2007. The demography of recovery of an overexploited bull trout, Salvelinus confluentus, population. Canadian Journal of Fisheries and Aquatic Sciences 64:113-126.

Kipling, C., and W. E. Frost. 1969. Variations in the fecundity of pike Esox lucius L. in Windermere. Journal of Fish Biology 1:221-237.

Kipling, C., and W. E. Frost. 1970. A study of mortality, population numbers, year class strengths, production and food consumption of pike, Esox lucius L., in Windermere from 1944 to 1962. Journal of Animal Ecology 39:115-157.

Koehn, J., A. Brumley, and P. Gehrke. 2000. Managing the impacts of carp. Bureau of Rural Sciences, Department of Agriculture, Fisheries and Forestry, Canberra, Australia.

Le Cren, E. D., C. Kipling, and J. C. McCormack. 1977. A study of the numbers, biomass and year-class strengths of perch (Perca fluviatilis L.) in Windermere from 1941 to 1966. Journal of Animal Ecology 46:281-207.

Lind, E. A. 1977. A review of pikeperch (Stizostedion lucioperca), Eurasian perch (Perca fluviatilis), and ruff (Gymnocephalus cernua) in Finland. Journal of the Fisheries Research Board of Canada 34:1684-1695.

Lorenzen, K. 1996a. The relationship between body weight and natural mortality in juvenile and adult fish: a comparison of natural ecosystems and aquaculture. Journal of Fish Biology 49:627-642.

Lorenzen, K. 1996b. A simple von Bertalanffy model for density-dependent growth in extensive aquaculture, with an application to common carp (Cyprinus carpio). Aquaculture 142:191-205. 
Lorenzen, K. 2000. Allometry of natural mortality as a basis for assessing optimal release size in fish-stocking programmes. Canadian Journal of Fisheries and Aquatic Sciences 57:23742381.

Lorenzen, K. 2005. Population dynamics and potential of fisheries stock enhancement: practical theory for assessment and policy analysis. Philosophical Transactions of the Royal Society B: Biological Sciences 360:171-189.

Lorenzen, K. 2008. Fish population regulation beyond stock and recruitment: the role of densitydependent growth in the recruited stock. Bulletin of Marine Science 83:181-196.

Mangel, M. 2017. The inverse life-history problem, size-dependent mortality and two extensions of results of Holt and Beverton. Fish and Fisheries 18:1192-1200.

Pauly, D. 1980. On the interrelationships between natural mortality, growth parameters, and mean environmental temperature in 175 fish stocks. ICES Journal of Marine Science 39:175-192.

Post, J. R., C. Mushens, A. Paul, and M. Sullivan. 2003. Assessment of alternative harvest regulations for sustaining recreational fisheries: model development and application to bull trout. North American Journal of Fisheries Management 23:22-34.

Post, J. R., E. A. Parkinson, and N. T. Johnston. 1999. Density-dependent processes in structured fish populations: interaction strengths in whole-lake experiments. Ecological Monographs 69:155-175.

Skov, C., L. Jacobsen, and S. Berg. 2003. Post-stocking survival of 0+ year pike in ponds as a function of water transparency, habitat complexity, prey availability and size heterogeneity. Journal of Fish Biology 62:311-322.

Tempero, G. W., N. Ling, B. J. Hicks, and M. W. Osborne. 2006. Age composition, growth, and reproduction of koi carp (Cyprinus carpio) in the lower Waikato region, New Zealand. New Zealand Journal of Marine and Freshwater Research 40:571-583.

Tonn, W. M., I. J. Holopainen, and C. A. Paszkowski. 1994. Density-dependent effects and the regulations of crucian carp populations in single-species ponds. Ecology 75:824-834.

Treasurer, J. W., R. Owen, and E. Bowers. 1992. The population dynamics of pike, Esox lucius, and perch, Perca fluviatilis, in a simple predator-prey system. Environmental Biology of Fishes 34:65-78.

Vilizzi, L., F. G. Ekmekçi, A. S. Tarkan, and Z. J. Jackson. 2015. Growth of common carp Cyprinus carpio in Anatolia (Turkey), with a comparison to native and invasive areas worldwide. Ecology of Freshwater Fish 24:165-180.

Vilizzi, L., A. S. Tarkan, and F. G. Ekmekçi. 2013. Stock characteristics and management insights for common carp (Cyprinus carpio) in Anatolia: a review of weight-length relationships and condition factors. Turkish Journal of Fisheries and Aquatic Sciences 13:759-775.

Weber, M. J., and M. L. Brown. 2013. Density-dependence and environmental conditions regulate recruitment and first-year growth of common carp in shallow lakes. Transactions of the American Fisheries Society 142:471-482. 
Weber, M. J., M. J. Hennen, and M. L. Brown. 2011. Simulated population responses of common carp to commercial exploitation. North American Journal of Fisheries Management 31:269-279.

Willis, D. W. 1989. Proposed standard length-weight equation for northern pike. North American Journal of Fisheries Management 9:203-208.

Wright, R. M., and N. Giles. 1987. The survival, growth and diet of pike fry, Esox lucius L., stocked at different densities in experimental ponds. Journal of Fish Biology 30:617-629. 